\title{
EXPANDING TEACHER UNDERSTANDING OF WISCONSIN'S PRAIRIE CHICKENS
}

\author{
By \\ Melinda Stites Brown
}

\author{
A Thesis \\ submitted in partial fulfillment of the \\ requirements for the degree \\ MASTER OF SCIENCE
}

College of Natural Resources

UNIVERSITY OF WISCONSIN

Stevens Point, Wisconsin

August 2003 


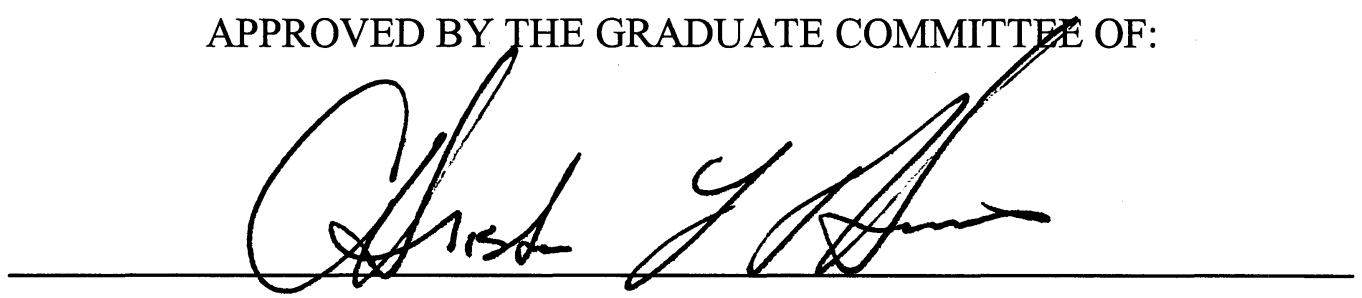

Dr. Christine Thomas, Graduate Advisor

Associate Dean of Academic Affairs and Professor of Resource Management

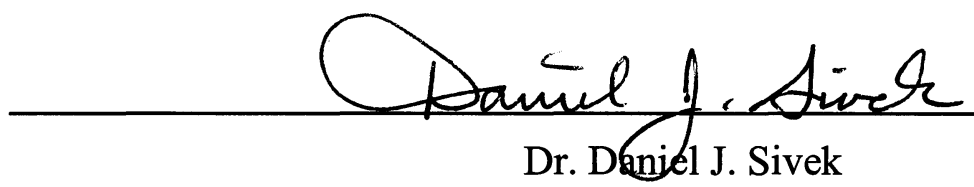

Professor of Environmental Education
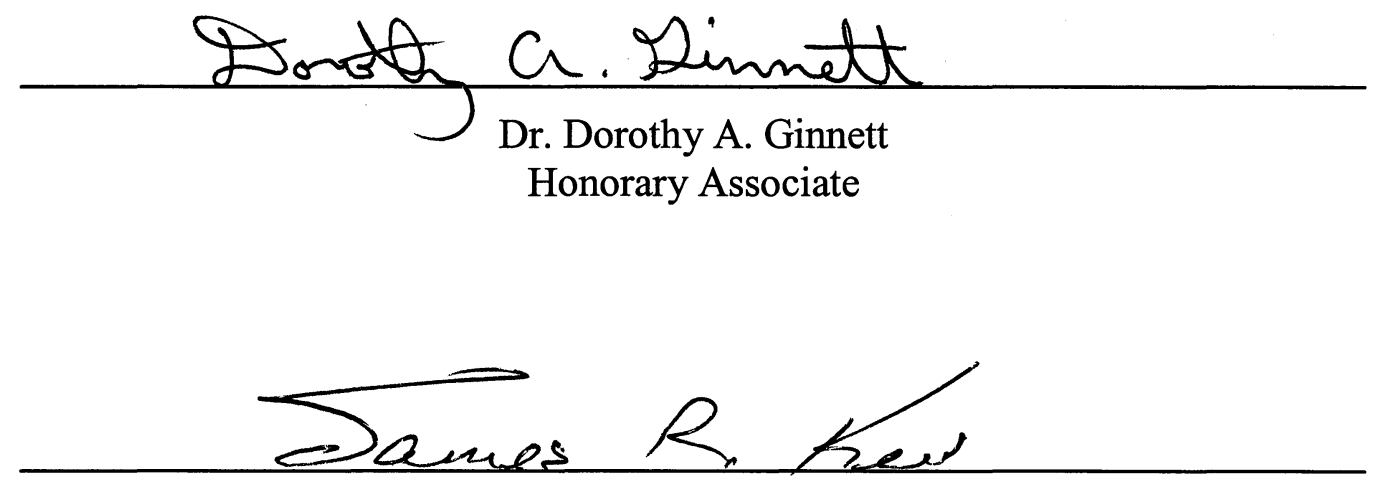

Mr. James R. Keir

Wisconsin Department of Natural Resources Wildlife Biologist 


\begin{abstract}
The purpose of this project was to expand teacher understanding of the greater prairie chicken in central Wisconsin, create resources to facilitate education about the greater prairie chicken in central Wisconsin, and to gain a better understanding of citizens participating in the annual booming ground census on the Buena Vista Marsh, Wisconsin. The project consists of three main parts: development of a prairie chicken workshop track, creation of a prairie chicken educational resource binder, and a survey of booming ground viewers.
\end{abstract}

\title{
Prairie Chicken Workshop
}

Many teachers may currently lack the practical experience, background knowledge and resources needed to infuse environmental education into their curriculum. The Becoming an Outdoors-Woman (BOW) program developed a workshop, specifically based on central Wisconsin's unique prairie chicken population, to present teachers with the knowledge and skills needed to provide quality environmental education. Seventeen high school teachers attended a Beyond BOW workshop that was held April 25-27, 2003 in Rosholt, WI. Attending teachers participated in the following six sessions: prairie chicken ecology, prairie habitat, historical perspectives, environmental education, curriculum development, and viewing prairie chickens at the Buena Vista Marsh in southwest Portage County. Pre- and Post- workshop surveys were used to evaluate the participants' knowledge of prairie chickens and intent to infuse the new information. An overall workshop survey was used to evaluate the effectiveness of the BOW format for teacher specific workshop tracks. Teacher knowledge about prairie chicken ecology, habitat, historical and current populations, and management increased from $48 \%$ correct responses prior to the workshop to $83 \%$ correct responses following the workshop. Following the workshop, $94 \%$ of teacher participants indicated intent to infuse the information gained during this workshop into their curriculum. All participants agreed that the BOW workshop format is effective, that they would be interested in other BOW teacher workshops, and that this workshop would influence their future teaching. This study shows that the BOW workshop format is a useful tool to educate teachers about specific natural resources.

\section{$\underline{\text { Resource Binder }}$}

The constraints to teaching about the environment most often mentioned by teachers include inadequate academic preparation lack of time, and limited environmental materials. A resource binder was created for distribution to workshop participants. The resource binder contained information with the following topic headings: prairie chicken ecology, Buena Vista marsh and prairie habitat, the Hamerstroms, environmental education and sample activities. In addition, the binder contained a 1-hour VHS videotape, seed packets and a CD ROM with images and video clips of prairie chickens. Questions regarding the resource binder and material were included on the overall workshop evaluation. All participants (100\%) indicated that they felt the resource binder would be a helpful resource to them. In addition, all participants indicated that the resource binder would influence their future teaching. 


\section{Booming Ground Viewer Demographics}

Yearly census of prairie chickens plays a vital role in determining the population status of the prairie chickens and can provide a recreational and educational opportunity to public viewers. A survey was used to gather basic demographic information about those viewing prairie chickens on the Buena Vista Marsh in April 2002 and 2003. Information such as sex, age, education level and distance traveled were collected from each viewer. In both years, $88 \%$ of the viewers resided in the state of Wisconsin. More than half of the viewers each year were members of environmental or conservation based clubs or organized groups. Finally, in both years, more than $90 \%$ agreed that their experience viewing the prairie chickens was satisfying. 


\section{ACKNOWLEDGEMENTS}

I would like to thank my graduate advisor Dr. Christine Thomas for providing me a unique graduate project with the BOW program. Also, thanks to my graduate committee members Dr. Dan Sivek, Dr. Dorothy Ginnett and Jim Keir for their continued help and support throughout my stay at UWSP.

Thanks to Wisconsin BOW coordinator Kelly Wisinski and BOW volunteer Michele Miller for their help organizing and hosting the Prairie Chicken Workshop. Thanks to Diane Lueck for her support, editing, and advice. In addition, thanks to the whole BOW staff for their contributions to this project.

This project was funded by a grant from the Wisconsin Environmental Education Board. Additional support was also provided by the Wisconsin Department of Natural Resources. Finally, this project was made possible through support from the Wisconsin Becoming an Outdoors-Woman program and the International Becoming an OutdoorsWoman program.

I would like to thank those teachers who participated in the workshop. Thanks to those who participated in the prairie chicken viewing program, and to Gary Wolf for his help guiding viewers on the Buena Vista Marsh.

A special thanks to my family for their continued support in all that I do and for always encouraging me to be my best. Finally, thanks to Peter Brown, the best husband, friend, and built in project helper that I could ever ask for. 


\section{TABLE OF CONTENTS}

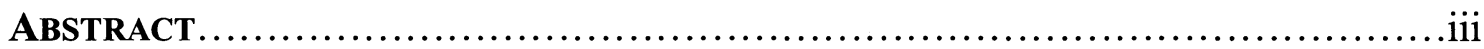

ACKNOWLEDGEMENTS..................................................... v

Table of Contents........................................................ vi

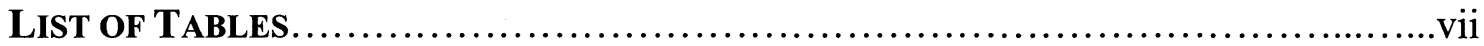

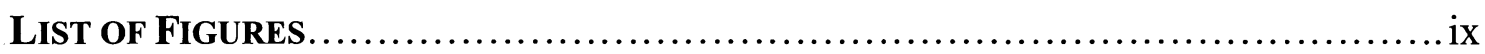

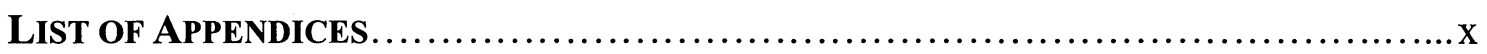

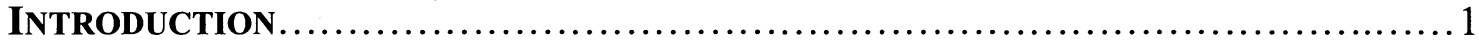

LITERATURE REVIEW.................................................... 6

Becoming an Outdoors-Woman............................................6

Environmental Education................................................... 8

Greater Prairie Chicken.................................................... 15

Booming Ground Viewing.................................................. 26

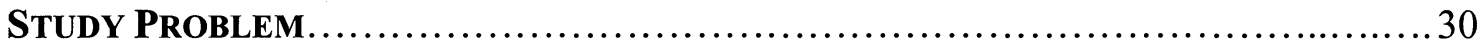

BOW Prairie Chicken Workshop.......................................... 30

Prairie Chicken Resource Binder........................................... 31

Booming Ground Viewer Demographics..................................... 31

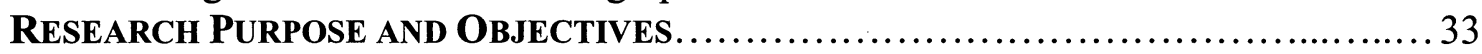

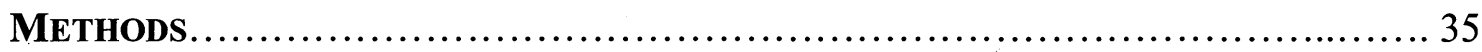

BOW Prairie Chicken Workshop............................................ 35

Prairie Chicken Resource Binder............................................ 47

Booming Ground Viewer Demographics.................................... 48

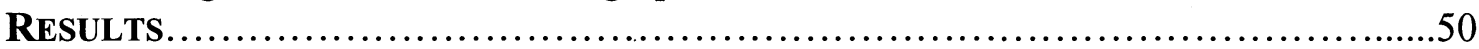

BOW Prairie Chicken Workshop......................................... 50

Prairie Chicken Resource Binder.......................................... 113

Booming Ground Viewer Demographics ................................. 116

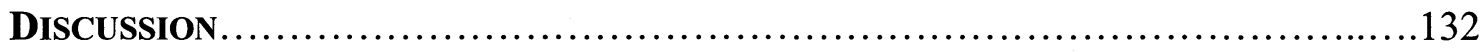

BOW Prairie Chicken Workshop ......................................... 132

Prairie Chicken Resource Binder......................................... 151

Booming Ground Viewer Demographics ................................. 153

IMPLICATIONS AND FUTURE DIRECTIONS...................................... 161

BOW Prairie Chicken Workshop....................................... 161

Prairie Chicken Resource Binder.......................................... 164

Booming Ground Viewer Demographics ..................................... 165

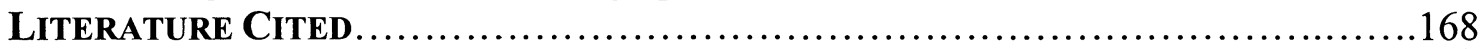

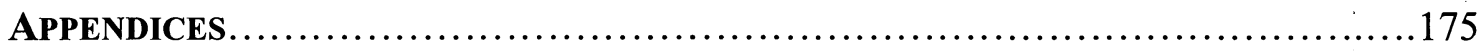




\section{LIST OF TABLES}

Table 1. Demographic characteristics of BOW Prairie Chicken Workshop track participants. .................................................51

Table 2. Size of city in which participants spent most of their lives. .............. 51

Table 3. Education level of participants. ........................................52

Table 4. College courses taken by participants in various subject areas. ........... 52

Table 5. Subjects normally taught by participants. ............................ 53

Table 6 . Grade level(s) currently taught by participants. ....................... 54

Table 7. Participants who cover natural resources management or conservation in their classes. ...................................................5 54

Table 8. School district in which participants are currently teaching. ...............54

Table 9. How participants found out about the BOW program. ...................56

Table 10. Participants who have viewed prairie chickens on the Buena Vista Marsh before ...................................................5 56

Table 11. Types of outdoor recreation in which participants have participated in the past year. ................................................ 57

Table 12. Outdoor or conservation magazines to which participants subscribe. ..... 58

Table 13. Environmental or conservation based clubs or organized groups which participants are presently a member. .......................... 58

Table 14. Natural resource oriented television programs which participants regularly watch.

Table 15. The degree to which participants agree or disagree with the following statements regarding their expectations of the BOW program.

Table 16. Topics and activities included in the BOW program rated according to their value to participants.

Table 17. The degree to which participants agree or disagree with the following statements regarding natural resource management.

Table 18. Participant knowledge scores by major topic area.

Table 19. Questions and participant responses relating to the general ecology of prairie chickens.

Table 20. Questions and participant responses relating to prairie chicken habitat. ... 74

Table 21. Questions and participant responses relating to the status of prairie chickens in Wisconsin.

Table 22. Questions and participant responses relating to the historical status of prairie chickens.

Table 23. Questions and participant responses relating to the management of prairie chickens.

Table 24. Questions and participant responses relating to environmental education... 85

Table 25. The degree to which participants agree or disagree with the following statements regarding the BOW workshop content.

Table 26. The degree to which participants agree or disagree with the following statements regarding the content of the workshop sessions.

Table 27. The degree to which participants agree or disagree with the following statements regarding the resources provided during the workshop. 


\section{LIST OF TABLES (CONTINUED)}

Table 28. The degree to which participants agree or disagree with the following statements regarding the assignment for the one credit option.

Table 29. The degree to which participants agree or disagree with the following statements regarding the workshop structure. ....................... 97

Table 30. The degree to which participants agree or disagree with the following statements regarding the teacher specific workshop track.

Table 31. Participants' comments when asked what they liked most about the workshop.

Table 32. Participants' comments when asked what aspects of the workshop could be improved.

Table 33. Participants' comments when asked if they would you recommend this workshop to a colleague or friend and why or why not.

Table 34. Participants' comments when asked how they will apply information gained during this workshop into their personal or professional life. ... 110

Table 35. Participants' comments when asked if they intend to infuse the information gained in this workshop and how they will do so.

Table 36. Additional comments about the workshop from participants. ........... 112

Table 37. Demographic characteristics of booming ground viewers 2002-2003 .... 117

Table 38. Description of area where viewers live. ..................................118

Table 39. Highest level of formal education completed by viewers. ................ 119

Table 40. Current occupation of viewers. ........................................ 119

Table 41. Distance traveled and State of residence of viewers. ....................121

Table 42. Accommodations and intent of viewers. ................................122

Table 43. Types of outdoor recreation in which viewers have participated. ....... 123

Table 44. Environmental or conservation based clubs or organized groups of which viewers are presently a member.

Table 45. Ways viewers heard about viewing opportunity and previous viewing experience.

Table 46. Part(s) of the information packet viewers found most useful.

Table 47. Part(s) of the information packet viewers found least useful............. 127

Table 48. The degree to which participants agree or disagree with the following statements regarding the information packet.

Table 49. The degree to which participants agree or disagree with the following statements regarding their visit to the booming grounds.

Table 50. Viewer opinion on returning for another visit and encouraging others to visit. 


\section{LIST OF FIGURES}

Figure 1. A ranking of workshop sessions in terms of overall effectiveness

(most helpful/useful) to participants' understanding about

prairie chicken ecology/conservation.

Figure 2. A ranking of workshop sessions in terms of overall value

(most helpful/useful) to participants as an educator.

Figure 3. A ranking of workshop sessions in terms of overall value

(most helpful/useful) to participants personally. 104 


\section{LIST OF APPENDICES}

Appendix A. Participant confirmation letter................................ 175

Appendix B. Instructor confirmation letter.................................. 176

Appendix C. Individual session objectives................................. 177

Appendix D. Workshop schedule ............................................. 180

Appendix E. Cover letter and pre-workshop evaluation.......................... 181

Appendix F. Post-workshop evaluation....................................... 192

Appendix G. Overall workshop evaluation....................................200

Appendix H. Prairie chicken viewer survey................................. 205

Appendix I. Additional comments from overall workshop evaluation.............207

Appendix J. Resource binder contents......................................208

Appendix K. Prairie chicken ecology table of contents and list of resources....... 209

Appendix L. Buena Vista Marsh and prairie habitat table of contents and list of

resources.......................................................213

Appendix M. The Hamerstroms table of contents and list of resources............. 216

Appendix N. Environmental education table of contents and list of resources.......220

Appendix O. Sample activities table of contents and list of resources.............. 223

Appendix P. Complete list of cities in Wisconsin that viewers are from ........... 225

Appendix Q. Complete list of environmental or conservation based clubs .......... 228

Appendix R. Additional comments from the prairie chicken viewer survey.........230 


\section{INTRODUCTION}

The Becoming an Outdoors-Woman (BOW) program offers weekend-long, beginner-level outdoor skills workshops that introduce women to outdoor activities. One of the major factors preventing many women from pursuing outdoor recreation was the lack of educational opportunities to learn outdoor skills (Thomas, 1990). Dr. Christine Thomas developed BOW workshops, the first of their kind in the United States, to offer shooting, fishing, and non-harvest activities, targeted specifically for women, in the hopes of overcoming those barriers. Since the first workshop in 1991, BOW workshops have provided women with the opportunity to learn outdoors skills in a fun, comfortable, non-threatening environment (Thomas \& Peterson, 1993a; 1993b).

The program has grown to the point where each year more than forty states and seven Canadian provinces offer workshops that enroll approximately 20,000 women in North America. While the program has been focused on outdoor skills, program planners often look for ways to reach new audiences. One example of this was a workshop track entitled "Paulette Bunyan" that was offered to assess the need for and effectiveness of forestry workshops for women (Goodman, 2003). For 2003, with strong programming and a track record of successful programs, Wisconsin BOW set its sights on expanding educational opportunities to a new group of participants, namely, high school teachers.

The Becoming an Outdoors-Woman program is working in partnership with the Wisconsin Department of Natural Resources (WDNR) to continue to provide opportunities for the public to view the prairie chicken population on the Buena Vista Marsh. This program began in 1950 as a tool to census the prairie chicken population in Wisconsin. Since 2000, the BOW program has been responsible for managing the 
viewing blind reservations. This task includes advertising the viewing opportunity, providing viewers with the necessary information and materials, and answering any questions about the viewing opportunity and the Wisconsin prairie chicken population that may arise.

Wisconsin is a leader in the field of environmental education (EE) (Ruskey \& Wilke, 1994). Statewide efforts to infuse EE concepts into school systems have included legislative mandates for preservice teacher training as well as the development, implementation, and evaluation of school-district curriculum plans (Lane, Wilke, Champeau, \& Sivek, 1994). Another popular and effective way to promote infusion of EE concepts into classrooms is to offer teachers a variety of in-service learning opportunities. Researchers have found that teachers often do not provide EE instruction because of a perceived lack of adequate background information or training (Lane, et. al., 1994; Lane, Wilke, Champeau, \& Sivek, 1995). This problem is thought to be easily amended through inservice training. Recognizing lack of education as a common thread between women not participating in outdoor activities, and teachers not providing EE, BOW believed there was the potential for using their workshop format to offer teachers an in-service opportunity to learn in a fun, non-threatening, and educational manner.

With teachers recognized as a group that may benefit from the BOW workshop format, we chose to design a workshop for teachers based on central Wisconsin's unique population of prairie chickens. Wisconsin is blessed with one of the few remaining endemic populations of prairie chickens, and has set aside more than 11,000 acres (4453.4 ha) for the management and protection of this threatened species. In 1954, a partnership between the Wisconsin Department of Natural Resources (WDNR) and 
several Wisconsin conservation groups established a prairie chicken management program on the Buena Vista Marsh, in southwestern Portage County, Wisconsin (Wisconsin Department of Natural Resources, 1995). Wisconsin's Prairie Chicken Management Program is recognized throughout the United States as a successful model of habitat management and was viewed as a distinctive and fun topic upon which to base a workshop for teachers. Other reasons for choosing Wisconsin's prairie chicken population as a workshop focus include its threatened status in the state of Wisconsin, prairie chicken's status as an indicator species of the overall health of grassland habitats, as well as the unique opportunities afforded to view the prairie chickens in Wisconsin during the month of April.

Knowing the potential of the BOW program, recognizing teachers as a group that can benefit from in-service opportunities, and being located in proximity of the Buena Vista Marsh prairie chicken population, this project sought to expand the understanding of Wisconsin's prairie chickens in three ways. First, by creating a prairie chicken track in the April 2003 Beyond BOW workshop, this project hoped to help teachers better infuse environmental education (EE) into their classrooms. Second, a prairie chicken resource binder was created to provide the materials needed by teachers to implement what they learn during the workshop into their own classrooms. Third, a demographic survey was taken to gain a better understanding of the prairie chicken booming ground viewer.

\section{PRAIRIE CHICKEN WORKSHOP TRACK}

Becoming an Outdoors-Woman believes that teachers can benefit from both concrete exposure and training in concepts about the wildlife, land and people important 
to conservation in central Wisconsin. The goal of the workshop was threefold: 1) to expand teacher knowledge about prairie chicken ecology, habitat, and the history of early conservationists (whose contributions helped to secure prairie chicken survival), 2) to give teachers the confidence to infuse prairie chicken information into their curriculum, and 3) to increase awareness of teaching opportunities and to create enthusiasm centered on one of our local treasures. A pilot prairie chicken track was held in the April 2002 Beyond BOW workshop. This workshop was used as a trial in developing the Prairie Chicken: Conservation and Courtship track held in the April 2003 Beyond BOW workshop.

\section{$\underline{\text { RESOURCE BINDER }}$}

We recognized that teachers could benefit from materials and example lesson plans in helping them infuse the above concepts into their curriculum. A resource binder was developed to provide additional teaching tools to be used by workshop participants once they have returned to their classroom. The instructional materials provided in the Prairie Chicken Resource Binder were intended for use in teaching grades 9-12. The materials and activities were intended to be easily adapted for a variety of academic disciplines and were designed to support Wisconsin academic standards. Most importantly, this binder was organized such that some or all of the information and activities may be integrated into participating teachers' existing classroom curriculum, but would also stimulate development of new curriculum. 


\section{BOOMING GROUND VIEWER DEMOGRAPHICS}

Each year, a booming ground census plays a vital role in determining the population size of the prairie chickens. In addition, the census provides a recreational and educational opportunity to public viewers. Despite the importance of this census, and the fact that it has been used for approximately 50 years, little is known about the characteristics of viewers and how they come to be involved in the booming ground census. BOW developed a booming ground viewer demographic survey in order to provide a detailed portrait of the characteristics of booming ground viewers. Knowing these characteristics, and how they may change over time, will influence actions that BOW and WDNR take to successfully manage public viewing opportunities such that the critical census data are collected each year. Additionally, information from the demographic survey will help BOW and WDNR target future viewers, initiate additional educational programs, and aid development of viewing programs in other areas.

Wisconsin is recognized nationally as a leader in environmental education (EE) and prairie chicken management. By combining these two strengths with the Becoming an Outdoors-Woman program, we developed new EE initiatives and new learning opportunities for teachers. More importantly, we have established a model program for teachers that can be recreated in a multitude of localities with BOW programs across the country. 


\section{LITERATURE REVIEW}

\section{BECOMING AN OUTDOORS-WOMAN}

The Becoming an Outdoors-Woman (BOW) program is an internationally recognized educational program for women. Dr. Christine Thomas founded BOW in 1991, in order to address the fact that traditionally, men and women have had very different opportunities to learn outdoor skills (Thomas \& Peterson, 1990). In 1990, a workshop entitled "Breaking Down the Barriers to Participation of Women in Angling and Hunting" used focus groups to identify perceived barriers and to recommend suggestions for reducing or eliminating them. Thomas and Peterson $(1990 ; 1993 a ; 1993 b)$ discovered that 14 of the 21 identified barriers were directly or indirectly related to the lack of educational opportunities for women. With this in mind, the first Becoming an Outdoors-Woman clinic was planned and held in Wisconsin in September 1991 (Thomas \& Peterson, 1993a; 1993b). Today, the Becoming an Outdoors-Woman program continues to teach introductory level hunting, fishing and non-harvest skills to women worldwide through BOW workshops. In addition, Beyond BOW workshops were developed to offer more in-depth exposure to one topic. Participants in Beyond BOW workshops choose one track of interest, for example fly fishing, and remain in the same track throughout the weekend. With programs located in 44 states and 7 Canadian provinces, the BOW program served approximately 20,000 women in 2002 alone (Becoming an Outdoors-Woman, 2002).

In addition to offering outdoor skills workshops, BOW has been involved in ongoing research to look at the attitudes, barriers and educational needs of its participants. In 1995, Diane Lueck, now International Director for the BOW program, conducted her 
Master's research on the effects of the Becoming an Outdoors-Woman program on the attitudes of women who attended workshops in Arkansas, Nebraska, Oregon, Texas, and Wisconsin (Lueck, 1995; Lueck \& Thomas, 1997). Her research showed that participants were likely to increase their level of participation in those activities associated with what they had learned in the BOW workshops. In addition, they tended to continue with these activities with almost no dropout rate. Finally, participants who responded to a survey indicated they felt more positive about hunting, fishing, and other outdoor activities as a result of the BOW program and were more likely to hunt or fish in the future than women who did not attend a workshop (Lueck, 1995; Lueck \& Thomas, 1997; Thomas \& Lueck, 1996).

Since Lueck's Master's thesis regarding the Becoming an Outdoors-Woman program, four more additional research projects have been conducted. In 1999, Ensign showed that BOW participants who responded to a survey were significantly more likely to be able to identify the state resource management agency in their state, positively increased the number of hunting and fishing licenses and park permits, and were happy with the structure of BOW workshops (Ensign, 1999; Thomas, Ensign, \& Lueck, 1999). In 2000, Schnell identified barriers for participation of minority women in outdoor-based education. In addition, strategies to overcome those barriers were identified and three workshops were planned to determine the effectiveness of the strategies, one each in Missouri, Texas and Wisconsin (Lueck \& Thomas, 2000; Schnell, 2000). In 2002, Gransee identified barriers for participation of women with physical disabilities in outdoor recreation. A list of strategies for inclusive programming by state agencies, and programs such as BOW, were developed to help increase the participation of under- 
represented populations in outdoor recreation (Gransee, 2002; Gransee, Lueck, \& Thomas, 2002). Finally, in 2003, Goodman assessed the educational needs of women who own non-industrial private forestland in Wisconsin. Two pilot forestry workshops were conducted in Wisconsin in order to assess the need for women-specific forestry education opportunities (Goodman, 2003).

From the first research that showed a widespread and growing enthusiasm among the participants of BOW workshops, to research that continues today, BOW has shown that many women want to be involved in outdoor activities. In addition, participation of these women directly impacts license sales, attitudes and future involvement in outdoor recreation (Lueck, 1995; Ensign, 1999). The BOW program is consistently striving to increase the outreach potential of the program and continues to reach out to all of those interested in "becoming an outdoors woman."

\section{ENVIRONMENTAL EDUCATION}

History and Background

Wisconsin has a rich heritage of conservation leadership including Aldo Leopold, John Muir and Gaylord Nelson. In 1935, another famous conservationist, Wilhelmine LaBudde, wrote Wisconsin's first environmental education (EE) initiative (Ruskey \& Wilke, 1994; Thomas, 1994). The conservation education statute of 1935 was the first to mandate that conservation of natural resources be taught in every common school and that anyone seeking teacher certification in either science or social studies receive adequate instruction in the conservation of natural resources (Ruskey \& Wilke, 1994; 
Wilke, 1985). Since then, environmental education has become part of Wisconsin's legacy. In 1985 the Wisconsin Department of Public Instruction (DPI) promulgated a rule requiring all teachers desiring to teach in the areas of early childhood, elementary education, agriculture, science or social studies achieve EE competencies to receive certification. This initiative strives to provide teachers with the competencies necessary to infuse EE into their classroom curriculum. Since the time of Wilhelmine LaBudde, Wisconsin EE supporters have managed to build a broad-based coalition with a commitment to increasing environmental literacy (Ruskey \& Wilke, 1994).

Lane (1993) summarizes Wisconsin's efforts to assure quality EE in schools. Wisconsin legislature mandated, in 1990, that sequential EE curriculum plans be developed, implemented and evaluated by each school district. Although content and performance standards outline the core components for quality EE, they do not prescribe how EE will be taught at the school level. Wisconsin has developed an EE curriculum planning guide that suggests curricular and instructional strategies, and defines the criteria by which one can judge the quality of education programs.

\section{Goal of EE}

Overall, environmental education is aimed at developing environmental knowledge, awareness and skills. Specifically, it is the goal of environmental education to develop an environmentally literate citizenry and skillful environmental stewards (Hungerford, Peyton, \& Wilke, 1980; Ruskey \& Wilke, 1994). Goals and objectives for EE were first proposed in 1977, when the United Nations sponsored an Intergovernmental Conference on Environmental Education held in Tbilisi, Georgia of the USSR (United Nations Educational, Scientific and Cultural Organization, 1978). 
Recommendations from this conference were revised into a set of four goal levels: ecological foundations, conceptual awareness, investigation and evaluation, and environmental action skills (Hungerford, et al., 1980). It has been suggested that in order to develop environmentally literate citizenry, environmental education needs to be included in school systems (Wilke, 1985). In order for this to occur, teachers need the necessary knowledge, skills and commitment to incorporate EE concepts into their curriculum (Wilke, 1985). Therefore, classroom teachers have a significant role in informing society about our natural resources.

\section{$\underline{\text { EE Infusion in Wisconsin }}$}

Wisconsin employed an infusion model requiring a systematic incorporation of EE into existing curriculum plans. Infusion is defined as the integration of environmental concepts, activities and examples into existing curricular goals without jeopardizing the integrity of the courses themselves (Ramsey, Hungerford, \& Volk, 1992). Infusion is often "thematic" and one advantage is its easy implementation, as schools do not need to construct new classes or hire additional teachers. For example, a mathematics class might have students calculate the amount of recyclable products that 30 students produce in a year. This method does not require that additional environmental educators be hired, however, it does require that teachers be capable of incorporating EE concepts into class curriculum.

The Wisconsin Center for Environmental Education (WCEE) conducted a teacher assessment to determine what the state's teacher population knows, feels, and does relative to teaching about the environment and its associated issues. Of teachers already infusing EE, over $80 \%$ strongly agreed or agreed that $\mathrm{EE}$ should be a priority in the 
schools. In addition, $91 \%$ of these same teachers said that EE mandates are not their reason for infusing EE into class curriculum (Wisconsin Center for Environmental Education, 1997). Findings indicate that teachers believe EE is important enough to be mandated. Conversely, $31 \%$ of respondents indicated that they do not teach about the environment. While there seems no question that $\mathrm{EE}$ is needed and desired in our schools, current programs need improving and quality programs need to be initiated in schools where they are not being provided (Wisconsin Center for Environmental Education, 1997).

\section{Barriers to Infusion of EE}

Ham and Sewing (1988) identified conceptual, educational and logistical barriers that prevent teachers from teaching EE. In this study, lack of time was identified as the primary barrier to providing EE. Another major barrier cited include teachers' perception of not being prepared to teach EE (Ham \& Sewing, 1988).

Other studies have cited similar barriers to teaching EE. More recent research has shown that one of the primary reasons indicated by teachers for not providing EE in their classrooms was the teacher's perception of not having adequate background information or training (Lane, et. al. 1994; Lane, et. al., 1995). The 1997 WCEE study found that reasons for not infusing EE included a perception of $\mathrm{EE}$ as being unrelated to their subject area (25\%), followed by a lack of background in EE (24\%). Strategies that would influence those teachers to teach about the environment included in-service training (33\%), and better access to resources (26\%) (Wisconsin Center for Environmental Education, 1997). 
Another common barrier preventing the infusion of $\mathrm{EE}$ is finding time for $\mathrm{EE}$ instruction without drawing time from other subjects (Monroe \& Cappaert, 1994). Goodlad (1984) found in a 30-hour week, teachers typically spend eight hours on noninstructional routines, behavior management and social activity. The remaining time is spent primarily on core disciplines such as math, language and science. Other constraints to teaching environmental studies most often mentioned are inadequate academic preparation and limited environmental materials.

\section{Teacher Training and Workshops}

Classroom teachers must play an integral role in any school environmental education program as they are heavily relied upon for educating school children about the environment. Huck and Decker (1987) found that teachers with a high regard for the natural environment could contribute significantly to improving the outdoor beliefs of today's youth, and consequently tomorrow's society. Each teacher's capacity to effectively teach about the environment is highly dependent upon his or her interest in the subject, personal teaching abilities, and time and resource availability. Therefore, it is necessary for classroom teachers to be adequately trained in environmental studies themselves. Teacher training is an effective way to educate teachers in order to arm them with the interest, knowledge, and materials to infuse quality EE into their curriculum. Lane, et. al. (1995) discovered that after receiving training in EE, classroom teachers believed that training was effective. In addition, more in-service training in EE for teachers resulted in increased classroom time devoted to EE.

Workshops can be a valuable form of in-service training. A 1983 analysis of the effectiveness of energy education workshops found that teachers who have not attended 
the offered energy workshops were limited in what they teach about energy by what they might already know. In addition, the researchers believed that well-taught workshops probably could contribute both to the background knowledge that teachers possess, as well as to the variety of topics they can teach (Van Koevering \& Sell, 1983).

Westphal and Halverson (1984) conducted a mail survey three years after a workshop in order to determine the long-term effects of a workshop designed to increase awareness, knowledge, and participation in local environmental issues. A five-point Likert scale was used to rate responses regarding the objectives of the workshop. The distribution of responses indicated that, three years after the completion of the workshop, participants generally agreed the workshop was successful in meeting its stated objectives. A 2002 study assessed teachers' priorities for topics, materials, and training on the topic of the Great Lakes. This study found that teachers claim to get most of their Great Lakes information from workshops and classes (Fortner \& Corney, 2002).

Ham and Sewing (1988) recommended suggestions when designing EE workshops based on their research findings of barriers to effective EE. They suggested that workshops be motivational, address EE in all areas of the curriculum, and provide instruction in using both the classroom and the schoolyard for EE. Workshop length is also an important consideration as research has contended that 1-day workshops are not long enough to provide a firm foundation in $\mathrm{EE}$ or its associated teaching strategies (Cooper, Wilke \& Champeau, 1989). Overall, an effective workshop will offer teachers opportunities to participate in hands-on activities, allowing them to develop their knowledge and skills about the topic. In addition, it is important that materials and 
resources, which can be infused directly into classroom curriculum, be disseminated at the workshop.

\section{Field Experiences \& Wildlife}

There can be a propensity to abandon outdoor education as educators attempt to teach more material in a limited time span. Nationwide programs such as Project WILD, Project Learning Tree and Project WET suggest that effective learning can be heightened in natural settings (Project Wild, 2000). These programs are built on the ideal that first hand experiences allow students to more effectively embrace, understand, and remember important concepts. Furthermore, students grounded in outdoor studies are more apt to continue outdoor activities and learning beyond their school years (Project Wild, 2002).

Many researchers support the idea that the classroom is not the only place for genuine learning. A program entitled Windows on the Wild (1994) found that teachers use field trips for enhancement of specific topics covered in class and for general enrichment. Students should be encouraged to engage in field experiences allowing an observation of the natural world on a firsthand basis (Wilke, 1993). Beyer, Dagit and Rinker (1988) state that field experiences provide a vehicle for personal growth and increasing knowledge of scientific methods. Hines, Hungerford and Tomera (1987) found behavior could be altered if an individual's experience seems significant or meaningful to that person. Finally, Cobb (1988) suggests that local resources can enhance science education.

Using EE based on wildlife is one of the most widely used and effective means of achieving high-quality EE in classroom curriculum as wildlife can offer unique opportunities to study many different aspects of the natural world. Wildlife-based EE 
allows students to explore the interrelationships between habitat and wildlife, as well as wildlife and humans. Wildlife-based EE programs can be an enjoyable, memorable experience for students, and when taught in a natural setting can allow students to experience more hands-on activities and first-hand learning situations (Brown, Ermer, Hoffman, \& Heimlich, 2002).

\section{Greater Prairie Chicken}

(Tympanuchus cupido pinnatus)

\section{Historical Distribution}

Before human settlement, the greater prairie chicken (Tympanuchus cupido pinnatus) inhabited the tall grass prairies of North America. Specifically, their range included Nebraska, Kansas, Oklahoma and South Dakota; through the Midwest to Kentucky, Ohio and Tennessee; and northward to Michigan, Wisconsin and Minnesota. As westward settlement expanded grain farming, prairie chickens expanded their range into southern Canada, North Dakota, Montana, Wyoming and Colorado (Prose, 1987). Agricultural practices formed disjointed patches of habitat. Unconnected subpopulations began to characterize the prairie chicken range, a pattern that can still be seen today (Christisen, 1985)

In Wisconsin, a similar pattern was observed. The range and number of greater prairie chickens increased following westward settlement, then dwindled as agricultural development and market hunting intensified (Hamerstrom, Mattson, \& Hamerstrom, 1957; Schorger, 1943). At first the chickens benefited from the landscape created by logging and early farm practices (Schorger, 1943). However, as early as the 1850's a 
decline in prairie chicken abundance was evident. This decline prompted the first Wisconsin game law regarding prairie chickens to be passed in 1851 . This law limited the open season for prairie chickens (Schorger, 1943). Much of the remaining grassland was being converted to farmland. As populations continued to decline, prairie chicken research began in Wisconsin in 1928, under the direction of Alfred O. Gross and the Wisconsin Conservation Department (Hamerstrom \& Hamerstrom, 1973). Prairie chicken populations continued to decline, and in 1955, the hunting of prairie chickens in Wisconsin was banned completely (Wisconsin Department of Natural Resources, 1995). Currently, Wisconsin's greater prairie chicken populations are listed as threatened, and are limited to portions of Portage, Clark, Taylor, Marathon, Wood and Adams counties (Keenlance, 1998).

In Wisconsin today, most prairie chickens are found in grassland reserves, with the majority of the population located in the Buena Vista Marsh (Keenlance, 1998; Niemuth, 2000). Management of the Marsh began in 1949 with a winter food patch program, followed by brush removal in 1954 (Hamerstrom \& Hamerstrom, 1973). The Wisconsin Department of Natural Resources manages portions of the Buena Vista Marsh, now called the Buena Vista Grasslands, totaling more than 12,000 acres (4856.23 ha) of surrogate prairie, composed mainly of introduced grasses and native forbs (Wisconsin Department of Natural Resources, 1995). This grassland preserve consists of established lands dedicated to preserving prairie chickens and thẹir habitat (Hamerstrom, et al., 1957; Hamerstrom \& Hamerstrom, 1973). It is the largest state managed prairie chicken wildlife area in Wisconsin and has created a unique grassland habitat for prairie chickens (Golner, 1997). 


\section{Habitat Requirements}

Habitat is defined as the place where a population finds the necessary resource requirements to carry out all its life activities (Armantrout, 1998). Habitat requirements for prairie chickens are the elements needed to adequately meet the birds' need for food, shelter and reproduction (Jones, 1963). These three requirements are the focus of studies on prairie chicken ecology and the most important parameters guiding modern prairie chicken management.

\section{Food Habits}

Adult greater prairie chickens primarily eat plants. However, they are heavily dependent (up to 97 percent) on insects in the first few weeks of life (Jones, 1963). Before the expansion of agriculture, adult prairie chickens fed on wild seeds, buds, leaves and fruits. Today, cultivated grains make up a substantial part of their diet (Prose, 1987). Diet is largely determined by availability, which can change geographically and seasonally. Variations in seasonal availability can determine which areas are used for foraging (Jones, 1963). For example, Hamerstrom et al. (1957) found that summer foods are generally sufficient in farmland environments. Furthermore, feeding on standing, unpicked yellow dent corn or other small grains is necessary in northern and central Wisconsin during winter. In contrast, Christisen (1985) found no evidence that food was a limiting factor for prairie chickens in Missouri. While many upland game birds seek food in edge habitats, prairie chickens seek their food in open spaces (Hamerstrom, et al., 1957). Water is provided through moist foods and dew, thus standing water is not typically required (Prose, 1987). 


\section{$\underline{\text { Shelter Requirements }}$}

There are three types of grassland needed to support a viable prairie chicken population. Medium density grass is required for nesting and rearing of brood. Short grass cover is used for booming and tall grass is needed for autumn and early winter roosting (Hamerstrom, et al., 1957; Jones, 1963). Therefore, prairie chicken production is dependent on a combination of grass cover types to meet the needs of the birds. Historically, prairie chickens were supported by tallgrass or true prairie grassland. Today, prairie chickens are able to adapt to various types of grasslands, both native and introduced (Prose, 1987).

Grassland is indispensable as nesting and rearing cover and is the most significant habitat type to prairie chicken success (Hamerstrom, et al., 1957; Kirsch, 1974). Lack of nesting cover has been cited as the primary factor limiting successful nesting by prairie chickens (Kirsch, 1974). Well-drained, medium-dense (12-16 inches or 0.30-0.40 meters) stands of grasses are the best nesting cover (Hamerstrom, et al., 1957). Grassy cover from a previous growing season allows hens to conceal themselves and their nests (Prose, 1987). Hamerstrom (1939) observed that prairie chicken nests were made in shallow bowl-shaped depressions in the ground and lined with materials including grasses, leaves or small twigs. Jones (1963) observed nests that were very close either to cultivated pastures or to old fields. After hatching, broods are led to shorter vegetation, such as lightly grazed, mowed or burned areas.

Prairie chickens must have large areas of open grasslands, consisting of short or mowed cover, for booming grounds where courtship and mating occur (Hamerstrom, et al., 1957; Niemuth, 2000). Open space is generally located on elevated grassland sites 
adjacent to areas of taller grasses (Jones, 1963). Open space allows for the possibility for birds to be seen and heard by conspecifics. Visual and auditory cues are of vital importance when attracting a mate (Hamerstrom, et al., 1957).

Roosting cover consists of tall-grass species used both day and night from spring to early winter (Hamerstrom, et al., 1957). Prairie chickens spend over half of their life on a roost, typically on the ground. Roosting sites must provide a measure of protection from climatic factors, but, perhaps more importantly, protection from predators. Roost sites should be accessible to adequate food resources, particularly during the winter, in order to minimize movements that utilize energy and increase exposure to predators (Svedarsky \& Van Amburg, 1996). Overall, the presence of tall-grass species is a good indicator of range suitability for prairie chickens (Evans \& Gilbert, 1969). However, the minimum area of habitat necessary to support prairie chickens is unknown.

\section{$\underline{\text { Reproduction }}$}

Prairie chickens use leks (or booming grounds) as arenas for breeding and territorial display by two or more males (Hamerstrom \& Hamerstrom, 1973). The number and size of booming grounds each year has been shown to vary only roughly with the total annual count of cocks (Hamerstrom \& Hamerstrom, 1973). Hamerstrom et al. (1973) found that booming ground counts can be used as an index to population abundance and can be useful in showing trends over a span of years. They are also useful as an index of habitat quality (Hamerstrom \& Hamerstrom, 1973). Hamerstrom (1939) suggests that the booming of prairie chickens is regulated by the joint action of temperature and light. 
Cocks tend to show strong fidelity to booming grounds year after year and prefer mowed areas (Anderson, 1969; Berger, Hamerstrom, \& Hamerstrom, 1963; Hamerstrom, 1939). Hamerstrom (1939) describes trampled vegetation trails in early spring, over the entire booming ground, made by cocks booming and fighting. He observed that the early season is spent fighting, with each cock trying to establish his own territory. Once territory boundaries are set there is much less fighting, as cocks tend to remain in their respective trails (Hamerstrom, 1939). Once the cocks have organized a booming ground, typically in early April, there is little change in number of cocks present during the rest of the spring (Hamerstrom \& Hamerstrom, 1973). Cocks have been observed using points of higher elevation (blinds and fence posts) for display, particularly when hens are present on the booming grounds (Anderson, 1969; Hamerstrom \& Hamerstrom, 1973). Some juvenile cocks hold territories of their own and reproduce (Hamerstrom \& Hamerstrom, 1973).

Hens do not show the same fidelity to booming grounds as cocks. While cock numbers tend to stay constant throughout spring, hen counts show definite peaks (Hamerstrom \& Hamerstrom, 1973). Hamerstrom and Hamerstrom (1973) observed that numbers on booming grounds progressed from few or no hens in early spring, to a major peak in late April, followed by a second peak in mid-May. In her book, My Double Life, Frances Hamerstrom (1994) describes the love life of the prairie chicken hen. The moment the hens arrive on the booming ground nearby cocks will increase the intensity of their booming. Cocks which are not near the hen will cackle and "flutter jump", which includes repeatedly flying almost straight up into the air and then tumbling back down. At first, hens appear to ignore this behavior and will wander, seemingly randomly, about 
the booming ground. Over the course of a few days, the hen first begins to spread her wings wide in invitation but still runs away from the cocks. Eventually she will hold her invitation until the cock mounts. If the hen "rouses", shakes her feathers violently, and leaves the booming grounds within ten minutes, the copulation was successful (Hamerstrom, 1994). Hens tend to nest within a mile $(1.61 \mathrm{~km})$ of the booming grounds if adequate cover is available (Christisen, 1985).

Although booming grounds occur in open fields, prairie chickens are not as vulnerable to predation as might first appear (Hamerstrom, et al., 1957; Berger, et al., 1963). In fact, their open exposed position is an advantage, allowing more reaction time to predator presence. In addition, by virtue of their group display, they have an advantage of many eyes looking out for predators (Berger, et al., 1963). Berger et al. (1963) noted that in the course of 1,379 encounters between prairie chickens and raptors on booming grounds, only three prairie chickens were killed. Toepfer (1988) believed that kills on booming grounds are uncommon but do still occur. He summarized published reports of booming ground kills as the following: goshawk (10), cooper's hawk (2), red-tailed hawk (1), great horned owl (1), and snowy owl (1). Hamerstrom, Berger and Hamerstrom (1965) indicated that few predators are capable of catching a healthy prairie chicken on booming grounds. Mammalian predators observed include: red fox, coyote, raccoon, striped skunk, and domestic dogs and cats (Svedarsky et. al., 1996). In general, prairie chickens are not easily disturbed while booming, even by mammals, cars or people (Berger, et al., 1963; Hamerstrom, et al., 1965). Although prairie chickens have evolved with a variety of predators, human altered landscapes may 
have affected their vulnerability to certain predators and increased the numbers of other predators (Svedarsky et. al., 1996).

\section{Current Management in Wisconsin}

One must understand the birds' habitat and daily living requirements in order to achieve the best management results (Christisen, 1985). The most limiting habitat factor is a lack of suitable grasslands. This problem has arisen from loss of native prairie, lack of diversity in grasslands, and insufficient amounts of permanent grass (Christisen, 1985). The second major factor affecting grassland suitability for prairie chickens is the presence of agriculture and livestock. Prairie chicken management involves enhancing existing habitat quality and reducing or eliminating detrimental land-use practices (Prose, 1987). Kirsch (1974) believed that under proper management it is possible to maintain a population of 100 male prairie chickens per square mile $\left(2.58 \mathrm{~km}^{2}\right)$.

\section{Grassland Management}

Varied cover type can be maintained by seeding, burning and grazing (Christisen, 1985). These tactics will reduce the amount of idle fields. Without disturbance, idle grasslands in Wisconsin are invaded by woody species, and quickly undergo succession to brush, making the habitat unsuitable for prairie chickens (Niemuth, 2000). Prescribed burning reduces woody cover, produces abundant food for prairie chickens, and is the most successful method for maintaining nest-brood habitat (Kirsch, 1974).

Current management practices in Wisconsin include: 1) prescribed fires, 2) crop rotation, 3) grazing, and 4) resting fields, all conducted throughout the managed grasslands on a five-year rotation (Wisconsin Department of Natural Resources, 1995). 
Controlled fires promote new growth by exposing the soil to sun as a result of removing dormant litter and vegetation. Diversity is also maintained as areas of land are planted in a crop rotation of corn, oats and hay. A portion of corn crop is left standing for winter food. After two years of corn planting, the land in the following two years will be seeded to grass and cut for hay. Finally, the land is left undisturbed for several years. This rotation provides food and shelter, a diversity of weeds and grasses for brooding, and established growth for nesting cover (Wisconsin Department of Natural Resources, 1995).

\section{$\underline{\text { Land-Use conflicts }}$}

Historic levels of prairie chickens declined dramatically, due largely to habitat loss from agricultural development (Schroeder \& Robb, 1993). Suitable habitat for prairie chickens is dependant on the degree of agricultural development. Major losses of grasslands are the result of change from general farming to agribusiness. This change is associated with a shift to a monotypic agricultural environment and a reduction or lower quality cover habitat (Hamerstrom \& Hamerstrom, 1973). In addition, insecticides used on crops can be deadly to prairie chickens, if ingested, and reduce the insect populations on which they are dependent (Prose, 1987). The important relationship between land use and prairie chicken survival indicates the importance of undisturbed grass cover until the nesting and brooding periods are over (Yeatter, 1963). Plowing of fields between April and June can be detrimental to prairie chicken nest survival. Fall plowing and postharvest tillage results in less food for winter survival as well as less cover (Christisen, 1985). Management should include seeding and establishment of suitable grassland though seeding and a postponement of mowing until after the nesting season (Prose, 
1987). In addition, increasing densities of livestock, including cattle, sheep, horses and mules, have also reduced the potential of grasslands to support prairie chickens (Christisen, 1985). Kirsch (1974) concluded that annual grazing is undesirable for prairie chickens, as it reduces residual cover and alters plant succession.

Extensive agriculture can be detrimental to prairie chickens, but limited agriculture can be an important component of prairie chicken habitat (Niemuth, 2000). Managed farming and grazing, however, are current management practices incorporated into prairie chicken management (Wisconsin Department of Natural Resources, 1995). Carefully regulated grazing can stimulate grassland plants while, at the same time, control unwanted woody vegetation. Grazed pastures are also readily used as summer feeding and loafing areas (Niemuth, 2000).

\section{Ecological Patterning}

Early studies of prairie chickens on the Buena Vista Marsh helped determine their range, and were fundamental in establishing the concept of ecological patterning. After 22 years of study, Hamerstrom et al. (1957) published a prairie chicken management plan outlining the fundamental habitat requirements necessary for saving the prairie chickens. They introduced the concept of 'ecological patterning'. This is a scattered distribution of relatively small land parcels, rather than by one large, homogeneous parcel. This plan called for the acquisition of small (40-80 acres [16.2-32.4 ha]), key parcels of land scattered strategically throughout the Buena Vista Marsh. Ultimately, the advantages of scattered habitat include increased distribution of birds throughout the area, interspersion of cover types, increased edge and increased opportunity of new habitats (Hamerstrom, et al., 1957). 
Frederick and Frances Hamerstrom decided that the loss of habitat was such a threat to prairie chickens they began hosting fundraising luncheons in the early 1950's. They were attempting to raise money to purchase scattered parcels of grassland in the Buena Vista Marsh area (Hamerstrom, 1994). In 1954, the Wisconsin Conservation League purchased the first parcel, consisting of 83 acres (32 ha) (Jim Keir, Wisconsin Department of Natural Resources, personal communication, April 2003). Later in 1954 Mr. and Mrs. G. E. Kummer purchased a parcel consisting of 63 acres (26 ha). In 1955 Mrs. C. Jung and The Wisconsin Society of Ornithology each purchased 40 acres (16 ha) (Anderson \& Toepfer, 1999). The amount of land set aside for prairie chickens began to increase rapidly as more individuals became involved and continued purchasing land.

In 1958, Paul Olson and the Dane County Conservation League (DCCL) started the Prairie Chicken Foundation. By 1973, the DCCL had purchased 1,641 acres (665 ha). Following suit, in 1960, Willis Sullivan established the Society of Tympanuchus Cupido Pinnatus (STCP), which had purchased and set aside 7,000 acres (2,835 ha) for prairie chicken habitat (Hamerstrom \& Hamerstrom, 1973). Land purchases by others continued and by 1980 , the total land purchased was 11,800 acres $(4,779$ ha) (Anderson $\&$ Toepfer, 1999). By setting aside land for prairie chicken habitat, the concept of ecological patterning took physical form (Hamerstrom, 1994). By virtue of the Hamerstroms' foresight, and the generosity of the conservation community, the habitat on the Buena Vista Marsh has created a unique grassland habitat for prairie chickens. 


\section{BOOMING GROUND VIEWING}

Observing the courtship display of the greater prairie chicken (Tympanuchus cupido pinnatus) on the Buena Vista Marsh has become a popular springtime activity and is an important tool in the management of prairie chickens in Wisconsin. Approximately 200 persons view the prairie chicken's mating ritual each year, through a program run by The University of Wisconsin-Stevens Point. The viewing is designed to help the Wisconsin Department of Natural Resources (WDNR) survey the number of males on the booming ground. Blinds are strategically placed on the perimeter of booming grounds, allowing viewers to observe the chickens' behavior, while recording valuable census data. Beginning in 1999, the Wisconsin Becoming an Outdoors-Woman (BOW) program has worked in partnership with the Wisconsin Department of Natural Resources to manage the booming ground viewing opportunities for the public. BOW has been responsible for scheduling, facilitating mailings, briefing all viewers on prairie chicken life history, sex determination, behavior, census methods, and guiding viewers to the blinds. Students and educators from universities, colleges and high schools within Wisconsin and neighboring states have been involved in this viewing opportunity.

\section{History}

Anderson and Teopfer (1999) summarize the history of the prairie chicken census in Wisconsin. Using sources that date back to Grange (1930) and Leopold (1931), they describe how A. Leopold and F. J. W. Schmidt conducted the first attempt to census the prairie chicken population in 1929, and estimated the prairie chicken population to be 54,850 . Yet, despite initial high population estimations in 1929, by 1950 the prairie chicken had essentially disappeared from its original range in southern Wisconsin. 
Anderson and Toepfer (1999) is also one of the most comprehensive published accounts of prairie chicken management. Long before the prairie chickens' evident declines, early management practices were implemented in order to help secure the prairie chicken population. In 1928, the first management program, entitled the Van Wormer-Jones Program, was established to provide buckwheat food patches and grain shocks for prairie chickens in central Wisconsin. The following year, A. O. Gross was commissioned by the Wisconsin Conservation Department, now the Wisconsin Department of Natural Resources, to conduct a study of the prairie chicken population (Anderson \& Toepfer, 1999). This project was known as the Wisconsin Prairie Chicken Investigation and was the very first wildlife research project in the state (Keir, 1999).

In 1935, Frederick and Frances Hamerstrom began their research on Wisconsin's prairie chickens under the direction of Aldo Leopold. Together they continued to research the chickens, with a 3-year break from 1944 through 1946, until 1971 (Anderson \& Toepfer, 1999). Their most intensive studies focused on two main areas in central Wisconsin, one of which was the Buena Vista Marsh. They identified the Buena Vista Marsh as being the logical area to concentrate their prairie chicken management efforts for three main reasons: 1) the availability of existing habitat, 2) the lack of conflicting land uses, and 3) the low land prices (Anderson \& Toepfer, 1999). To this day, the Buena Vista Marsh remains as the main area of focus for prairie chicken management.

\section{Booming Ground Census}

In 1950 the Hamerstroms began a yearly census of the prairie chickens in Wisconsin. Hamerstrom and Hamerstrom (1973) outlined census procedures to ensure census continuity and integrity, establishing a significant historical data set that is 
maintained through the viewing program today. Census procedures included finding all booming grounds and counting all cocks on each of the grounds. The Hamerstroms enlisted help from many different people during the booming ground census each spring. They hosted viewers traveling from as far as Finland, England, Germany, France, Australia, China, Norway, Sweden, South Africa, Canada, while most came from the United States (Anderson \& Toepfer, 1999; Hamerstrom, 1994; Hamerstrom \& Hamerstrom, 1973). In her books, Frances Hamerstrom tells many stories of the viewers who came to share their Plainfield home during the prairie chicken booming season (e.g. Hamerstrom, 1994). Ultimately, the Hamerstroms, as wildlife biologists with the Wisconsin Conservation Department, managed the census of the prairie chicken population in the Buena Vista area from 1950 to 1971 (Anderson \& Teopfer, 1999; Hamerstrom \& Hamerstrom, 1973).

Following the Hamerstroms' final census of the Buena Vista in 1971, personnel from the University of Wisconsin-Stevens Point, together with personnel from the Wisconsin Conservation Department, continued to conduct booming ground censuses in succeeding years. Anderson and Toepfer (1999) summarize the history of the census as Ray K. Anderson himself managed the census procedures from 1971 through 1993. Lyle Nauman and Evie Merrill managed the censuses from 1994 through 1998 (Anderson \& Toepfer, 1999). Nauman is still actively involved with other census procedures and continues to help with the program (Lyle Nauman, personal communication, April 2003). In 1999, recognizing that the census procedures were essential to managing the prairie chicken population, Dr. Christine Thomas pledged the help of the Becoming and Outdoors-Woman (BOW) program to manage the booming ground viewers in order to 
maintain this important data set. Today, with the help of BOW, the annual spring census of males on booming grounds continues on the Buena Vista Marsh. The annual census continues to provide a measure of population levels and distribution, as well as a gauge of the effects of habitat management and the changes in land use of surrounding private lands (Keir, 1999). By educating viewers and guiding them to the viewing blinds, the BOW program helps the WDNR to continue to gather essential population counts, as well as ensure the continuing support of the University of Wisconsin-Stevens Point to the Prairie Chicken Project. 


\section{STUDY PROBLEM}

\section{BOW PRAIRIE CHICKEN WORKSHOP}

Throughout the years, Becoming an Outdoors-Woman (BOW) has examined a diverse group of workshop participants and their barriers to outdoor participation. For example, in 2000, BOW focused research on barriers to minority women's participation in BOW workshops (Schnell, 2000). Today, BOW continues to ask and answer critical questions concerning a variety of barriers that prevent women from participating in outdoor recreation.

BOW is also continually trying to reach new audiences. The historically femaledominated teaching profession is a logical place to look for new constituents. Research has shown that there are a variety of barriers that can prevent educators from offering consistent and quality environmental education (EE) in their classrooms. One major barrier is that of education. Teachers feel incompetent or unable to teach EE (Ham \& Sewing, 1987, Lane, et. al, 1994). Teachers will educate their students based on what they personally know and value. This workshop is designed to increase the level of knowledge that teachers have on a specific topic, Wisconsin's Buena Vista prairie chicken population, so that they will feel more comfortable increasing the amount of EE they infuse into their classroom. Ultimately, the goal of this workshop track is to increase the number of teachers and the quality of EE being infused into Wisconsin classrooms. 


\section{PraIRIE CHICKEN RESOURCE BINDER}

Another barrier cited that prevents educators from teaching quality EE is the lack of materials and resources (Ham \& Sewing, 1987, Lane, et. al, 1994). Teachers need easily accessible, quality curriculum resources in order to feel comfortable and to effectively infuse EE. A Prairie Chicken Resource Binder was needed to disseminate factual materials about Wisconsin's prairie chicken population, along with lessons and activities that can be incorporated into their curriculum. The binder provides references and media so that teachers do not need to spend time looking for high quality materials. The binder also provides curriculum to teachers so that they can rapidly infuse the knowledge gained during their recent weekend workshop. By offering high quality tools, along with recent experiences, it is hoped that teachers increase the amount of EE (specifically related to Wisconsin's Buena Vista prairie chicken population) infused into their classroom.

\section{BOOMING GROUND VIEWER DEMOGRAPHICS}

The WDNR is charged with managing the threatened prairie chicken population on the Buena Vista Marsh, Wisconsin. For over 50 years, a census carried out by public observers has been critical in prairie chicken management. The goal of the Wisconsin Department of Natural Resources' annual census is to obtain a $100 \%$ count of all displaying males on the booming grounds of the Buena Vista Marsh. The data gathered during the census lays the groundwork for future prairie chicken population management decisions because it allows WDNR to accurately gauge the population level and distribution of prairie chickens on the Buena Vista Marsh. Currently, the Wisconsin 
BOW program, in a partnership with the WDNR, is managing prairie chicken viewing so that the prairie chicken census can be carried out on a continuing basis. Therefore, BOW and the WDNR recognized the census as critical in the management of a stable prairie chicken population.

Yet, with nearly 200 viewers per year in recent years, little is known about the basic demographics of booming ground viewers who help make this census possible. Recognizing the critical nature of viewer collected census data, and with the intent to maintain the highest level of management of prairie chicken viewers, Becoming an Outdoors-Woman will complete the first survey of prairie chicken viewers.

A survey was needed to determine basic characteristics of booming ground viewers and how they came to participate in the prairie chicken census. This survey was intended to provide a detailed portrait of the characteristics of booming ground viewers. Information gathered in the survey included viewing history, how they heard about this opportunity, a measure of BOW's effectiveness in preparing viewers for their experience, and overall experience viewing the prairie chickens.

Knowing the characteristics of prairie chicken viewers can better help BOW and WDNR promote this unique viewing opportunity. In addition, this important information can help the WDNR know locations from which to actively recruit viewers if there is ever a need to do so. Further, this information will help the scientific community, in that fish and wildlife managers looking to enlist public assistance in management efforts will be able to look to these data as the first description of citizens who are willing to make an active contribution to natural resources management. 


\section{RESEARCH PURPOSE AND OBJECTIVES}

The purpose of this research was to increase knowledge and field opportunities for teachers based on central Wisconsin's unique prairie chicken population, as well as to assist teachers in understanding the integral interactions between wildlife, land and people. Many teachers may currently lack the practical experience, background knowledge and resources needed to infuse environmental education (specifically related to Wisconsin's Buena Vista prairie chicken population, management and history) into their curriculum. A Beyond BOW workshop provided continuing professional development as well as new learning opportunities that empowered teachers with the knowledge and skills needed to provide environmental education (EE) for their students based on central Wisconsin's prairie chicken population.

Specifically, this research strove to fulfill three objectives:

1) Develop a Beyond BOW workshop that increases participating teachers' knowledge of prairie chicken ecology, land conservation, contributions of pioneering female conservationists, and theories of environmental education (EE).

Sub goals for the first objective are to:

- evaluate teachers' knowledge about prairie chickens with both pre- and post-workshop surveys,

- measure participating teachers' perceived intent to infuse the knowledge gained during the workshop into their curriculum, and

- evaluate the effectiveness of the Beyond BOW format for use as a teacher training tool; 
2) Develop a comprehensive educational resource binder on prairie chicken ecology, habitat and management designed for teacher use with grades 9-12; and

3) Develop a demographic survey that will provide a portrait of the characteristics of booming ground viewers; and

Sub goals for the third objective are to:

- describe the characteristics of 2002 and 2003 booming ground viewers, and

- provide the structure for a long-term demographic study on booming ground viewers by serving as a baseline for future studies. 


\section{METHODS}

\section{BOW PRAIRIE ChICKEN WORKSHOP}

\section{$\underline{\text { Study Locations }}$}

The Becoming an Outdoors-Woman (BOW) program hosted a Beyond BOW workshop at the Wisconsin Lions Camp Retreat and Conference Center in Rosholt, Wisconsin. This camp is located on 440 acres (176 ha) with areas of forested land, hiking trails, and a 45 -acre (18 ha) private lake. Sleeping dorms and a dining hall can accommodate up to 220 people. A variety of meeting rooms were also used for the classroom needs of the workshop. Rosholt, Wisconsin, is located 17 miles $(27.2 \mathrm{~km})$ from Stevens Point, Wisconsin.

The Buena Vista Marsh is located approximately 8 miles $(13 \mathrm{~km})$ south of Stevens Point, Wisconsin. This area totals more than 12,000 acres (4856.23 ha) and is managed for prairie chickens by the Wisconsin Department of Natural Resources. It has been described in detail by Hamerstrom et al. (1957) and Hamerstrom and Hamerstrom (1973). The terrain has a mixture of open, level cropland and pasture, sectioned into a checkerboard fashion. Management practices include grazing and mowing, chemical and mechanical brush control, and the planting of food patches consisting of corn (Zea mays) and buckwheat (Fagopyrum esculentum) to provide fall and winter food (Toepfer, 1988). Hamerstrom and Hamerstrom present a 1971 cover type map of this study area.

Pilot Workshop Track

A pilot Prairie Chicken Workshop track was held April 19-21, 2002 at Wisconsin Lion's Camp in Rosholt, Wisconsin. The pilot workshop attempted to 
1) introduce participants to the history, ecology and habitat associated with central Wisconsin's prairie chicken population,

2) introduce a new track to the Beyond BOW program; and

3) utilize this workshop as a "trial run" for the Prairie Chicken Workshop for teachers to be held April 25-27, 2003.

Participants, all non-teachers, took part in four 3.5-hour sessions. The first session, taught by Mindy Brown, Wisconsin BOW graduate assistant, included an introduction to the history of Central Wisconsin's prairie chicken population. Participants learned about the population census that was started in 1950 under the direction of Frances and Frederic Hamerstrom. In addition, they learned about the history of the Buena Vista Marsh and the continued efforts of Wisconsin Department of Natural Resources to manage the Marsh for prairie chickens. In preparation for their own visit to the booming grounds the following day, they learned about prairie chicken courtship behavior and what they could expect to see while on a prairie chicken lek.

The second session consisted of a trip to the prairie chicken booming grounds, located on the Buena Vista Marsh, in southwest Portage County, Wisconsin. Meeting before dawn, BOW participants observed the courtship habits of prairie chickens on their lek. They actively participated in the prairie chicken census and were able to observe prairie chicken behavior first hand.

The third session included instruction about prairie chicken ecology and habitat. Gary Wolf, Wildlife Technician with the Wisconsin Department of Natural Resources, discussed grassland prairie habitat, the life history of prairie chickens, other prairie species that exist on the Buena Vista Marsh, and the management program for prairie 
chickens. In addition, participants learned about, and were able to gain hands-on experience with, the radio telemetry that is used for tracking colored prairie chickens, and the research methods used to observe and count prairie chicken nests and eggs.

The final session included a trip to the Wisconsin Conservation Hall of Fame, located in Schmeeckle Reserve in Stevens Point, Wisconsin. Participants were taught about two Hall of Fame inductees, Frances and Frederic Hamerstrom. Kelly Bleich, friend of the late Frances Hamerstrom, told stories of the Hamerstroms and their involvement in protecting the prairie chicken population in Central Wisconsin.

Upon conclusion of the workshop, participants completed an overall BOW workshop evaluation. The evaluations were reviewed and utilized to revise and plan the 2003 prairie chicken workshop.

\section{$\underline{\text { WEEB Grant }}$}

In anticipation of the 2003 BOW prairie chicken workshop track for teachers, a grant was submitted to the Wisconsin Environmental Education Board in February 2002. The grant was completed by the researcher according to the grant protocol and was submitted to the "General Environmental Education" category.

The submitted grant was successfully funded. Grant funds supported the workshop registration fee and optional one graduate credit fee for all teachers attending the 2003 prairie chicken workshop track. In addition, workshop instructors were covered in this funding, as well as all materials created specifically for this workshop track. 


\section{Workshop Advertising and Promotion}

The workshop was publicized in a number of different media. Two brochures were created to advertise the 2003 workshop. The first brochure, the prairie chicken workshop track brochure, was created to specifically target teachers. This brochure contained information regarding only the prairie chicken workshop track. Information contained in this brochure included a workshop schedule, workshop goals and objectives, and a registration form. Five hundred copies of this first brochure were printed. Two hundred fifty copies were bulk mailed to high school science and biology teachers in the six counties (Wood, Marathon, Waupaca, Portage, Waushara, and Adams) surrounding Stevens Point, Wisconsin. In addition, this brochure was mailed to 30 teachers in the University of Wisconsin - Stevens Point, Extended Master's in Environmental Education program.

A second brochure, the overall workshop brochure, was created to advertise the April 2003 Beyond Becoming an Outdoors-Woman workshop. This brochure included the Prairie Chicken: Conservation and Courtship track amongst the other three tracks to be offered that weekend. Three thousand five hundred copies of the second brochure were printed and bulk mailed to the Wisconsin BOW mailing list.

BOW exhibited at two teacher-related conferences in order to advertise the prairie chicken workshop track. The first exhibit was at the Wisconsin Association for Environmental Education in Rosholt, Wisconsin on October 4 - 5, 2002. A second exhibit was at the Wisconsin Education Association Council in Madison, Wisconsin on October $23-24,2002$. A booth was created and displayed at both of these locations and 
the researcher was present to offer more information about the program. In addition, copies of the prairie chicken workshop track brochure were made available.

Finally, informational releases were included in the Wisconsin DNR publication "EE News" and on the Wisconsin BOW website. In addition, two press releases were created and sent out to media contacts statewide.

\section{$\underline{\text { Participant Selection }}$}

Participants, all teachers, were selected on a first come, first serve basis and were accepted into the workshop in the order in which the registrations were received. Once a registration was received, participants were sent a confirmation letter (Appendix A) and packet that contained a list of suggested clothing, map to the workshop location, basic background information about the Becoming and Outdoors-Woman program, and the syllabus and requirements for the one-credit assignment. The participants were all selfselected and were all teachers currently teaching grades 9-12.

\section{$\underline{\text { Instructor Selection }}$}

Instructors were selected based on their experience with the session content, as well as their overall teaching experience. BOW is founded on the principle of learning new things in a fun, safe, hands-on environment and instructors were selected with this in mind. These professionals represented various agencies from Wisconsin, including UW - Stevens Point, the Wisconsin DNR, the Society of Tympanuchus Cupido Pinnatus, and other individuals involved with the population of prairie chickens in Wisconsin.

Instructors were personally asked by the researcher to share their skills in the workshop. Following their acceptance, a confirmation letter (Appendix B) and packet that contained 
a map to the Lions Camp, a copy of the class syllabus and assignment, and a brief outline of session topics was included in order to give them an overview of the weekend. In addition, an instructor needs form was included to insure that the instructor's area was set up with everything they needed to effectively teach their session.

\section{$\underline{\text { Session Content }}$}

Specific session topics were determined in order to ensure that there was minimal overlap between sessions and to guide instructors in topic areas to cover in their individual sessions. The list of topics to cover was driven by the literature review of prairie chicken ecology, prairie/grassland habitat and environmental education. In addition, specific instructors were asked for their advice and input on what they thought were important topics to include in each session. Finally, concrete session objectives were written (Appendix C) to help drive and organize this process.

\section{Workshop Logistics}

The Prairie Chicken: Conservation and Courtship track was conducted as one of three concurrent tracks included in the weekend-long April Beyond BOW workshop. As such, the workshop location was chosen for its ability to accommodate a total of 4 workshop tracks including housing and dining areas. In addition, adequate classroom space was a requirement.

The workshop schedule (Appendix D) shows the timeline for the weekend events. The schedule for the prairie chicken track deviated from the other three tracks only slightly. In the prairie chicken track, participants traveled to the Buena Vista Marsh before dawn, while all other workshop participants began classes at the regular scheduled 
hour. In addition, two workshop sessions in the prairie chicken track were split into two one-hour and forty-five minute sessions while the three remaining workshop tracks stayed in the same session for three and one-half hours each. Aside from these two differences, all other activities were similar between tracks. All participants slept in the same dormitories, and all participants dined together in the dining hall. Finally, everyone participated together in the social hour, evening program, and BOW raffle and silent auction.

Registration for the workshop was held on Friday, April 25, from 4:30 to 5:30p.m. in the main meeting area. Dinner followed the registration period. This built in extra time for late arrivals, as most teachers were working a full school day on Friday. Following dinner, there was a general welcome session to all of the workshop participants. The welcome served to introduce participants to the history of BOW, explain what they can expect during the weekend, introduce the participants to all of the workshop instructors, and to go over the rules of the facility. Following the welcome, groups were divided up into their individual workshop tracks.

\section{$\underline{\text { Historical Perspectives (Session 1) }}$}

In the historical perspective session, participants learned about the history of prairie chicken populations. Instructors Jim Keir, Wildlife Biologist for the Wisconsin DNR and Lyle Nauman, coordinator for the yearly prairie chicken census in Wisconsin, related the management history of prairie chickens in both Wisconsin and other states. Both instructors discussed the history of land acquisition made on the Buena Vista Marsh for prairie chicken management. In addition, they discussed other areas that maintain prairie chicken populations in Wisconsin. Finally, they discussed different key 
individuals and organizations that helped to preserve the prairie chicken population in Wisconsin. Instruction was given using slides, audio recordings, reference materials and various archive materials, such as a map created by the Hamerstroms.

Kelly Bleich, friend of the late Frances Hamerstrom, told stories of Frederick and Frances Hamerstrom and of their involvement with preserving the prairie chicken population. Participants also learned about Aldo Leopold's conservation ethic and his involvement with the Hamerstroms as their advisor for their Master's degrees. Instruction was given using lecture, story telling, group interaction, song, publications and materials, and artifacts from the Hamerstroms house.

\section{Prairie Chicken Viewing (Session 2)}

Participants traveled to the Buena Vista Marsh, in southwest Portage County, to view the prairie chickens booming on their lek. In order to observe the prairie chickens, participants sat in blinds maintained by the Wisconsin DNR. While in the blinds, participants recorded counts of male and female prairie chickens as part of a census that is conducted by the Wisconsin DNR.

\section{Tour of the Buena Vista Marsh (Session 3)}

Participants took a driving tour of the Buena Vista Marsh, lead by Gary Wolf, Wildlife Technician for the Wisconsin DNR. Participants observed first-hand the effects of various management practices on the Marsh. Participants stopped to view and walk around areas of the Marsh in order to see the various effects of management practices including grazing, prescribed burning, sharecropping, and mowing. 


\section{Prairie Chicken Ecology (Session 4)}

Instructor David Halfmann, field researcher with the Society of Tympanuchus Cupido Pinnatus, instructed on greater prairie chicken ecology. Participants learned about the habitat and food requirements, as well as the reproduction habits of the prairie chicken. In addition, participants were instructed in past and current research that is conducted on the Wisconsin prairie chicken population. Instruction was given using slides, mounts, feathers, bones, nests and egg shells. Finally, participants learned about the uses of radio telemetry and were able to personally try the devices using portable equipment.

\section{$\underline{\text { Prairie Habitat (Session 5) }}$}

Instructor Robert Rosenfield, Professor of Biology, UW - Stevens Point, taught the prairie habitat session. Participants learned about the basic geology and hydrologic regimes of prairies and grasslands. They were instructed on the three different types of prairies: tallgrass, mixed grass and short grass. They learned about various problems that affect these ecosystems, such as fire suppression and proliferation of woody habitat, and finally they learned about key prairie grass species. Instruction was given using lecture, overheads, reference books, museum specimens and grass specimens.

\section{Environmental Education (Session 6)}

Dan Sivek, Professor of Environmental Education at UW - Stevens Point, taught the environmental education (EE) session. Participants discussed Wisconsin's own EE history. They learned the various goals of EE (as per the Tbilisi Declaration), how the EE goals are geared for various grade levels, and how they can help guide classroom 
instruction. Finally, they were introduced to resources of the Wisconsin Center for Environmental Education and various activity guides. Instruction was given using slides, group work, group activities, EE activity resources and reference materials.

\section{Curriculum Development (Session 7)}

Instructor Dorothy Ginnett, Wildlife Ecologist and UW - Stevens Point Instructor, taught the curriculum development session. This session taught about ways to incorporate participants' newly gained knowledge into a lesson plan. Participants discussed the one-credit course requirements and brainstormed ideas to use in their own classroom setting. Topics covered include field trip opportunities, alternative assessment strategies, Wisconsin Model Academic Standards, and student diversity. Instruction was given using lecture, slides, peer work groups, music and video.

\section{$\underline{\text { Survey Development }}$}

Pre- and post-workshop evaluation instruments to collect data for this study were based on surveys previously developed (Peri, 1996; Roberson, 1992). The overall workshop evaluation instrument was based on the BOW workshop evaluation and a survey developed for an on-line EE course (Environmental Education and Training Partnership, 2002). Example surveys were presented to a panel of two college professors and one university extension employee, all with knowledge of educational testing and research. Each member was asked to review the surveys for content, relevance and form. Questions were then altered, deleted or added according to the advice given by the panel. Finally, all surveys were sent to the UW - Stevens Point Institutional Review Board for the Protection of Human Subjects for approval. 
The majority of questions required that the respondent check a box, fill in the appropriate information, or choose the correct answer. A 5-point Likert scale, ranging from Strongly Disagree to Strongly Agree, was used for several questions such that results can be quantified (Weisberg, Krosnick \& Bowen, 1989). Multiple choice style questions were used for the content knowledge portion of the surveys. The remainder of the questions was open ended to allow for personal input from the viewers. All surveys were marked so that workshop participants can be identified allowing pre- and postworkshop surveys to be correlated.

\section{Workshop Evaluation Implementation}

The pre-workshop evaluation was sent to all registered participants (Appendix E). Dillman (1978) suggests that a cover letter telling respondents they are contributing to an important social issue will increase responses, therefore a cover letter was sent with each survey. The pre-workshop evaluation consisted of three parts. The first part served to gather basic demographic information from the participants. The second part sought to determine participants' expectations, beliefs and opinions on a variety of subjects related to the workshop. Finally, the third part of the evaluation was designed to assess participants' current knowledge of Wisconsin's prairie chicken population and other associated knowledge.

The post-workshop evaluation (Appendix F) was given to all participants upon workshop completion. This evaluation was identical to the pre-workshop evaluation, except the demographic portion of the first evaluation was not included.

The overall workshop evaluation (Appendix G) served to evaluate the effectiveness of the workshop. This evaluation consisted of three parts. The first served 
to evaluate the workshop content. The second part was designed to evaluate the workshop structure. Finally, the third portion was designed to evaluate the overall effectiveness of the workshop sessions.

\section{University Credit Option}

All participants were offered the option of receiving one graduate credit through the UW - Extension program. In order to receive the credit, participants had to complete a course assignment that was developed and implemented by Dr. Dorothy Ginnett, main instructor of record for the credit assignment. Those wishing to receive the credit were registered through UW - Extension directly after the completion of the workshop. The main instructor handled credit assignments and final grades.

\section{Limitations of the Study}

All participants were self-selected and thus the study was not completely random. Potential sources of variation exist in the differences in participants. Examples include previous teaching skill levels, educational background and training, and years of experience teaching. Workshop participants may not have reflected the opinions and experiences of other teachers in similar teaching situations. Bias might also occur through forgetfulness or misrepresenting one's activities (Doby, 1967). Finally, an individual's enthusiasm or disinterest in infusing EE into their curriculum might give a ranking higher or lower than another person rating the same level of infusion. Finally, due to timing, there was not an opportunity to follow-up with this study to determine how many teachers actually taught about the information gained in this workshop and how 
many used the resources that were disseminated. Further studies can overcome this last limitation.

\section{$\underline{\text { Analysis }}$}

The data collected were analyzed for frequency of response and recorded in total percentages. Paired T-tests were used to detect differences of opinion statements between the distributions of pre- and post-workshop evaluations and to detect significance of differences between knowledge statement distributions of pre- and postworkshop evaluations. A $P$-value of 0.05 was used to determine the level of significance for all tests.

\section{Prairie Chicken ResourCe BINDER}

\section{$\underline{\text { Resource Binder Development }}$}

The first step in creating the Prairie Chicken Resource Binder was to determine what materials should be included. Interviews with several University professors, all having experience in environmental education and in-service teacher training, garnered suggestions for materials and resources that should be included in the binder. Using these suggestions, a final list of materials and resources was created and once again reviewed by each professor for their approval.

Steps employed to develop the Prairie Chicken Resource binder included reviewing prairie chicken related literature, reviewing EE activities and curriculum, reviewing videos and reviewing photographs related to the prairie chicken population in Wisconsin. 
Background information, projects, and activities were collected from a variety of sources including the Wisconsin Department of Natural Resources (WDNR), the University of Wisconsin-Stevens Point Center for Environmental Education, the UWSP library, and the Internet. Materials were selected based on their age appropriateness for grades 9-12, accuracy of information, effectiveness of activities over time, and overall quality of the resources. Other considerations included suitability to match one of the Wisconsin Environmental Education Standards, and their ability to be integrated, with an activity, into the curriculum. Any resources that did not meet this specified criteria were eliminated.

\section{$\underline{\text { Analysis }}$}

A panel of three university professors and a representative from the WDNR was selected to review the resource binder. An initial copy of the resource binder was presented to the panel. Each member was asked to review the binder for material content, relevancy, age appropriateness and overall content. On the advice received from the panel, changes were made to produce the final product.

\section{BOOMING GROUND VIEWER DEMOGRAPHICS}

\section{$\underline{\text { Survey Development }}$}

This survey was designed to collect the following information; 1) demographic characteristics, 2) how far viewers traveled to observe the prairie chickens, 3) history of viewing the prairie chickens, including any previous year's experience in taking the census the prairie chickens on the Buena Vista Marsh, 4) how well the information 
packet, sent out to all viewers prior to their trip, prepared them for their visit, and 5) attitudes about their visit to the booming ground (Appendix $\mathrm{H}$ ). The development of the questionnaire was aided by input from the Wisconsin Department of Natural Resources, two professors who had experience with surveys, and through personal communication with booming ground viewers from previous years.

All questions required that the respondent either check a box or fill in the appropriate information. The remainder of the questions was open ended to allow for personal input from the viewers. Finally, the survey was sent to the UW - Stevens Point Institutional Review Board for the Protection of Human Subjects for approval.

\section{$\underline{\text { Survey Implementation }}$}

In April 2002 and 2003, surveys were given to all public viewers participating in the Buena Vista Marsh prairie chicken census, run by the Becoming an Outdoors-Woman program. Trained guides distributed the surveys, on letter size paper, to each viewer just before they were guided to their viewing blind. The viewers were asked to complete the survey following the completion of the booming ground activity, just before they left the blinds. Viewers returned surveys, along with the prairie chicken census, in a cache that was picked up later in the morning.

\section{$\underline{\text { Analysis }}$}

Results were compiled by frequency and percentage of respondents. All results were tabulated and summarized. 


\section{RESULTS}

\section{BOW PRAIRIE ChICKEN WORKSHOP}

\section{Pilot Workshop}

A pilot Prairie Chicken Workshop track was held April 19-21, 2002 at Wisconsin Lion's Camp in Rosholt, Wisconsin. Five females, all non-teachers, participated in this track. Upon conclusion of the workshop, participants completed a workshop evaluation. All participants ranked the value of their experience in the Prairie Chicken Workshop track as either "I got more than I paid for" or "Priceless." In addition, they felt all of the instructors were very well informed and presented the materials in an exciting and educational manner. Comments included "Thank you for a great weekend, I will take this knowledge and teach it to others!" and "This gave me an experience I couldn't have on my own."

\section{Prairie Chicken: Conservation and Courtship Workshop Track}

\section{Pre-Workshop Evaluation}

The pre-workshop evaluation was completed by participants before the beginning of the workshop and turned in during the registration period. Thirty pre-workshop evaluations were sent out to registered teacher participants, however, only 17 participants, all teachers, participated in the workshop. All 17 teachers had completed the pre-workshop evaluation and only those evaluations $(n=17)$ were used for data analysis.

\section{Descriptive Demographics}

The first part of this survey served to gather general descriptive characteristics of the workshop track participants such as sex, age, education and residential setting in 
which they spent most of their life. Table 1 shows a fairly even sex ratio with 8 female and 9 male participants. Among the participants, $35 \%$ were in their $20^{\prime}$ and 30 's, while most (65\%) were in their 40's and 50's (Table 1). The mean age of participants was 43 with a range of 27 to 57 years of age. The largest percentage of participants (35\%) spent most of their life in a rural setting. One participant lived in a city with over 100, 000 people, while the remaining $59 \%$ percent lived in an area with fewer than 100,000 people (Table 2).

Table 1. Demographic characteristics of BOW Prairie Chicken Workshop track participants ( $\mathrm{n}=17)$.

\begin{tabular}{|c|c|c|}
\hline Characteristic & Frequency & Percent \\
\hline \multicolumn{3}{|l|}{ Sex } \\
\hline Female & 8 & 47.06 \\
\hline Male & 9 & 52.94 \\
\hline \multicolumn{3}{|l|}{ Age } \\
\hline $20-29$ & 1 & 5.88 \\
\hline $30-39$ & 5 & 29.41 \\
\hline $40-49$ & 8 & 47.06 \\
\hline $50-59$ & 3 & 17.65 \\
\hline
\end{tabular}

Table 2. Size of city in which participants spent most of their lives (n=17).

\begin{tabular}{lcc}
\hline \multicolumn{1}{c}{ City Size } & Frequency & Percent \\
\hline Rural & 6 & 35.29 \\
Community with fewer than 5,000 & 2 & 11.76 \\
Community with 5,000 to 24,999 & 4 & 23.53 \\
City of 25,000 to 99,999 & 4 & 23.53 \\
Major city of over 100,000 & 1 & 5.88 \\
Suburb of major city & 0 & - \\
\hline
\end{tabular}




\section{Educational Background}

The majority of participants (71\%) had earned a Master's degree while the remaining (29\%) had earned a Bachelor's degree (Table 3). When asked if they have taken college courses in certain subject areas, an overwhelming $100 \%$ indicated that they have taken classes in environmental education. In addition, most participants (76\%) have taken classes in conservation of natural resources, and more than half (53\%) have taken classes in wildlife management (Table 4).

Table 3. Education level of participants $(n=17)$.

\begin{tabular}{lcc}
\hline \multicolumn{1}{c}{ Education Level } & Frequency & Percent \\
\hline GED or high school diploma & 0 & - \\
Some college & 0 & - \\
Bachelor's degree & 5 & 29.41 \\
Master's degree & 12 & 70.59 \\
Doctoral degree or equivalent & 0 & - \\
\hline
\end{tabular}

Table 4. College courses taken by participants in various subject areas $(n=17)$.

\begin{tabular}{lcccc}
\hline \multicolumn{1}{c}{ College Courses } & \multicolumn{2}{c}{ Yes } & \multicolumn{2}{c}{ No } \\
& Frequency & Percent & Frequency & Percent \\
\hline Wildlife Management & 9 & 52.94 & 8 & 47.06 \\
Habitat Management & 8 & 47.06 & 9 & 52.94 \\
Conservation of Natural Res. & 13 & 76.47 & 4 & 23.53 \\
Environmental Education & 17 & 100.00 & 0 & - \\
\hline
\end{tabular}

\section{Teaching Experiences}

Participating teachers were asked to indicate which subjects they normally teach (Table 5). The majority of participants (76\%) indicated that they teach biological and 
environmental science. One (6\%) participant teaches earth science and three participants (18\%) listed other and indicated they were teachers of art, agricultural science and special education.

Most participants taught more than one grade level, thus there were 39 responses to the question asking teachers to indicate which grade level they currently teach (Table 6). As this workshop was specifically designed for teachers grade $9-12$, the majority of teachers taught at that level. One teacher (6\%) indicated that they also taught grade 6 , in addition to their high school teaching. When participants were asked if they covered natural resources or conservation in their classrooms, the majority (82\%) indicated that they did. The remaining $18 \%$ responded that they did not currently cover these topics in their teaching (Table 7).

Participating teachers came from 12 different school districts in Wisconsin (Table 8). The school districts of Green Bay, Stevens Point, and Nekoosa, Wisconsin had more than one teacher from that district. Although brochures were bulk mailed to the five counties surrounding Stevens Point, some of the participants were not located within those counties.

Table 5. Subjects normally taught by participants $(n=17)$.

\begin{tabular}{lcc}
\hline \multicolumn{1}{c}{ Subject } & Frequency & Percent \\
\hline Biological / Environmental & 13 & 76.47 \\
Earth Science & 1 & 5.88 \\
Social Science & 0 & - \\
All Subjects & 0 & - \\
Other & 3 & 17.65 \\
\hline
\end{tabular}


Table 6. Grade level(s) currently taught by participants $(n=17)$.

\begin{tabular}{|c|c|c|}
\hline Grade Level & Frequency & Percent \\
\hline $\mathrm{K}-7$ & 1 & 5.88 \\
\hline 8 & 0 & - \\
\hline 9 & 12 & 70.59 \\
\hline 10 & 12 & 70.59 \\
\hline 11 & 12 & 70.59 \\
\hline 12 & 12 & 70.59 \\
\hline
\end{tabular}

Table 7. Participants who cover natural resources management or conservation in their classes $(n=17)$.

\begin{tabular}{lcc}
\hline & & \\
NR Management or Conservation & Frequency & Percent \\
\hline Yes & 14 & 82.35 \\
No & 3 & 17.65 \\
\hline
\end{tabular}

Table 8. School district in which participants are currently teaching $(n=17)$.

\begin{tabular}{lcc}
\hline \multicolumn{1}{c}{ School District } & Frequency & Percent \\
\hline Appleton & 1 & 5.88 \\
Berlin & 1 & 5.88 \\
Fond du Lac & 1 & 5.88 \\
Green Bay & 3 & 17.67 \\
Kettle Moraine & 1 & 5.88 \\
Nekoosa & 2 & 11.76 \\
New London & 1 & 5.88 \\
Shawano Gresham & 1 & 5.88 \\
Stevens Point & 3 & 17.67 \\
Waupaca & 1 & 5.88 \\
Wausau & 1 & 5.88 \\
Wautoma & 1 & 5.88 \\
\hline
\end{tabular}




\section{Workshop Recruitment and Prairie Chicken Viewing Experience}

When asked how they heard about the BOW prairie chicken workshop track, the highest percentage (29\%) of participants indicated a source other than those listed among the options (Table 9). Some participants (29\%) indicated hearing about the program from our exhibit either at the Wisconsin Association of Environmental Education conference, or the Wisconsin Education Association Council conference. While only $18 \%$ of the participants heard of the program from the traditional BOW mailing list, there were 12 inquires from non teachers who were interested in the track and enjoyed hearing what new opportunities BOW was offering.

Participants were asked if they have ever viewed prairie chickens on the Buena Vista Marsh before and 35\% indicated that they had (Table 10). A few of those who had seen the prairie chickens before indicated that they were undergraduate students at the University of Wisconsin - Stevens Point and had viewed the chickens as part of an undergraduate class. 
Table 9. How participants found out about the BOW program $(n=17)$.

\begin{tabular}{lcc}
\hline \multicolumn{1}{c}{ Message Medium } & Frequency & Percent \\
\hline Exhibit at the WAEE & 4 & 23.53 \\
Exhibit at the WEAC & 1 & 5.88 \\
BOW mailing & 3 & 17.65 \\
Internet & 1 & 5.88 \\
Friend & 3 & 17.65 \\
Other & 5 & 29.41 \\
\hline
\end{tabular}

Table 10. Participants who have viewed prairie chickens on the Buena Vista Marsh before $(n=17)$.

\begin{tabular}{lcc} 
Previous Viewing Experience & Frequency & Percent \\
\hline Yes & 6 & 35.29 \\
No & 11 & 64.71 \\
\hline
\end{tabular}

\section{Outdoor Related Experiences}

Outdoor related recreation activities of the participating teachers over the past year are located in Table 11. Participants were asked to mark all responses that apply which resulted in 90 responses. The three activities with the highest percentage participation rates, $82 \%$ each, were bird watching, camping and gardening. These activities were followed closely with $76 \%$ participating in canoeing. Finally, $71 \%$ participated in both hiking or backpacking and photography. Consumptive activities such as fishing (53\%) and hunting (35\%) were lower.

Participants were asked if they subscribe to any outdoor or conservation magazines (Table 12$)$. The majority $(76 \%)$ indicated that they did subscribe to 
conservation magazines. Of those listed, Wisconsin Natural Resources, a state produced natural resources magazine, had the highest percentage of subscribers (35\%). Other magazines with a nationwide distribution were indicated including Audubon and National Geographic. Many participants (12\%) indicated that they did in fact subscribe to outdoor or conservation magazines, but did not indicate specifically to which they subscribed.

A total of $65 \%$ of participants indicated support for environmental or conservation clubs or organized groups (Table 13). The Nature Conservancy, an international organization, is supported by $18 \%$ of the participants. The Natural Resources Defense Council, another international organization, was supported by $12 \%$ of the participants, as was the Wisconsin Association for Environmental Education, a state organization.

More than half of the participants (53\%) indicated that they do not regularly watch natural resource oriented television programs (Table 14). Of the $47 \%$ that do watch natural resource based programming, National Geographic and Nature Channel were each watched regularly by $18 \%$ of the participants.

Table 11. Types of outdoor recreation in which participants have participated in the past year $(n=17)$.

\begin{tabular}{lcc}
\hline \multicolumn{1}{c}{ Outdoor Recreation } & Frequency & Percent \\
\hline Bird watching & 14 & 82.35 \\
Camping & 14 & 82.35 \\
Fishing & 9 & 52.94 \\
Hunting & 6 & 35.29 \\
Hiking or Backpacking & 12 & 70.59 \\
Canoeing & 13 & 76.47 \\
Gardening & 14 & 82.35 \\
Photography & 12 & 70.59 \\
Boating & 4 & 23.53 \\
Other & 2 & 11.76 \\
\hline
\end{tabular}


Table 12. Outdoor or conservation magazines to which participants subscribe $(n=17)$.

\begin{tabular}{lcc}
\hline \multicolumn{1}{c}{ Conservation Magazines } & Frequency & Percent \\
\hline Yes & 13 & 76.47 \\
No & 4 & 23.53 \\
& & \\
List & 1 & 5.88 \\
Audubon & 1 & 5.88 \\
Deer and Deer Hunting & 1 & 5.88 \\
National Geographic & 1 & 5.88 \\
Ocean Conservancy & 1 & 5.88 \\
Silent Sports & 6 & 35.29 \\
Wisconsin Natural Resources & 2 & 11.76 \\
Did not indicate & & \\
\hline
\end{tabular}

Table 13. Environmental or conservation based clubs or organized groups of which participants are presently a member $(n=17)$.

\begin{tabular}{lcc}
\hline \multicolumn{1}{c}{ Conservation Clubs or Groups } & Frequency & Percent \\
\hline Yes & 11 & 64.71 \\
No & 6 & 35.29 \\
& & \\
List & 1 & 5.88 \\
Audubon & 2 & 11.76 \\
Natural Resources Defense Council & 3 & 17.65 \\
The Nature Conservancy & 1 & 5.88 \\
Timber Wolf Information Network & 1 & 5.88 \\
Safari Club International & 2 & 11.76 \\
Wisconsin Association for EE & 1 & 5.88 \\
Did not indicate & & \\
\hline
\end{tabular}


Table 14. Natural resource oriented television programs which participants regularly watch $(n=17)$.

\begin{tabular}{lcc}
\hline Natural Resource TV Programs & Frequency & Percent \\
\hline Yes & 8 & 47.06 \\
No & 9 & 52.94 \\
& & \\
List & & \\
National Geographic & 3 & 17.65 \\
Nature & 3 & 17.65 \\
PBS & 1 & 5.88 \\
Did not indicate & 1 & 5.88 \\
\hline
\end{tabular}




\section{Post-Workshop Evaluation}

The post-workshop evaluation was completed by participants and turned in following the completion of the final workshop session. All 17 teachers completed the post-workshop evaluation and only those evaluations $(\mathrm{n}=17)$ were used for data analysis.

The symbol * indicates a significant shift in distribution between pre- and post- workshop evaluations (alpha $=0.05)$.

\section{Expectations and Beliefs of the BOW Program}

Seven questions were used on both the pre and post-evaluation to determine what participants know and feel about the BOW program and what they expect from their workshop experience. Table 15 summarizes the percent responses made on a five-point Likert scale where responses ranged from Strongly Disagree to Strongly Agree. Questions were matched on both the pre- and post- evaluation, however, some wording was changed in the post-evaluation to make the statements past tense. Pre-evaluation wording is included here, exact wording for post-evaluation can be found in Appendix F.

Before attending the BOW workshop, $59 \%$ of the participants felt that they knew enough about what would happen at the BOW workshop. Following the BOW workshop, $71 \%$ felt they knew enough about the program prior to attending. However, $26 \%$ disagreed with the post-evaluation statement indicating that they felt they did not know enough about the program prior to attending.

Prior to attending the BOW workshop, participants indicated positively their belief that the BOW program would benefit them both personally and professionally. Before the workshop, $94 \%$ felt they would benefit personally from their experience. 
Similarly, $88 \%$ of the participants believed that the BOW program would benefit their work. Following the workshop, $100 \%$ of the participants indicated that they believe they had benefited both personally and professionally from the workshop.

Participants were asked to rate their level of confidence in their ability to teach environmental/conservation education. Prior to the workshop, $88 \%$ of the participants felt confident in their ability to teach on these topics. This number increased to $94 \%$ following the workshop. Teachers were also asked to rate their level of confidence in their ability to teach about prairie chickens. Only $12 \%$ felt confident in teaching about prairie chickens before the workshop, while $100 \%$ felt confident in teaching about prairie chickens following the workshop. This shows a marked increase.

Teacher participants were asked to indicate if they had high expectations for the BOW program. Prior to attending, $94 \%$ of the participants indicated that they did indeed have high expectations for the program. Following the program, $100 \%$ of the participants indicated that their expectations for the program were met. This is a statistic that the BOW program strives for in every single workshop and represents positive feedback for a successful workshop track.

Finally, participants were asked if they intend to infuse the information gained in this workshop into their curriculum. While $82 \%$ of the participants indicated that they did intend to infuse the information gained into their curriculum prior to the workshop, this number increased to $94 \%$ following the conclusion of the workshop. 
Table 15. The degree to which participants agree or disagree with the following statements regarding their expectations of the BOW program ( $n=17$ expressed in Percent, * indicates a significant shift in distribution alpha $=0.05)$.

\begin{tabular}{|c|c|c|c|c|c|c|c|c|c|c|}
\hline \multirow[b]{2}{*}{ Statement } & \multicolumn{5}{|c|}{ Pre-Workshop Evaluation } & \multicolumn{5}{|c|}{ Post-Workshop Evaluation } \\
\hline & $\begin{array}{l}\text { Strongly } \\
\text { Disagree }\end{array}$ & Disagree & Neutral & Agree & $\begin{array}{c}\text { Strongly } \\
\text { Agree }\end{array}$ & $\begin{array}{l}\text { Strongly } \\
\text { Disagree }\end{array}$ & Disagree & Neutral & Agree & $\begin{array}{c}\text { Strongly } \\
\text { Agree }\end{array}$ \\
\hline $\begin{array}{l}\text { At this time, I feel I know } \\
\text { enough about what will happen } \\
\text { at BOW. }\end{array}$ & - & - & 41.18 & 47.06 & 11.76 & 5.88 & 17.65 & 5.88 & 47.06 & 23.53 \\
\hline $\begin{array}{l}\text { I believe the BOW program will } \\
\text { benefit me personally. * }\end{array}$ & - & - & 5.88 & 64.71 & 29.41 & - & - & - & 29.41 & 70.59 \\
\hline $\begin{array}{l}\text { I believe the BOW program will } \\
\text { benefit my work. * }\end{array}$ & - & - & 11.76 & 52.94 & 35.29 & - & - & - & 41.18 & 59.82 \\
\hline $\begin{array}{l}\text { I feel confident in my ability to } \\
\text { teach } \\
\text { environmental/conservation } \\
\text { education. }\end{array}$ & - & - & 11.76 & 23.53 & 64.71 & - & - & 5.88 & 29.41 & 64.71 \\
\hline $\begin{array}{l}\text { I feel confident in my ability to } \\
\text { teach about prairie chickens. * }\end{array}$ & 29.41 & 35.29 & 23.53 & 5.88 & 5.88 & - & - & - & 41.18 & 58.82 \\
\hline $\begin{array}{l}\text { I have high expectations for the } \\
\text { BOW program. * }\end{array}$ & - & - & 5.88 & 64.71 & 29.41 & - & - & - & 23.53 & 76.47 \\
\hline $\begin{array}{l}\text { I intend to infuse the information } \\
\text { gained in this workshop into my } \\
\text { curriculum. }\end{array}$ & - & - & 17.65 & 29.41 & 52.94 & - & - & 5.88 & 17.65 & 76.47 \\
\hline
\end{tabular}


Topics and Activities Included in the BOW Program

Twelve questions were used on both the pre and post-evaluation to determine the value participants placed on the main topic and activity components scheduled during the prairie chicken workshop track. Table 16 summarizes the percent responses made on a five-point Likert scale where responses ranged from Not Valuable to Extremely Valuable. Questions were matched on both the pre- and post- evaluation.

Prior to attending the workshop there was a distribution across the five response options, with most of the results indicating the sessions to be perceived as Moderately to Extremely Valuable. The top three program components indicated as Very to Extremely Valuable, prior to attending, were Natural Resource Management (100\%), Prairie Habitat Trends (88\%), and Current Environmental Issues (associated with prairie chickens) (88\%). Following closely with $82 \%$ each was Prairie Chicken Management and Prairie Chicken Ecology.

Following the completion of the workshop, again, most of the results were perceived as positive. The top two program components, indicated as very to Extremely Valuable (100\% each), were Historical Issues of Prairie Chickens and Prairie Chicken Management. Ten out of the twelve session components received a score of $90 \%$ or above for Very to Extremely important. Overall, there was an increase in percentages of eleven out of twelve of the session components. The remaining component remained the same $(100 \%)$ before and after the workshop. 
Table 16. Topics and activities included in the BOW program rated according to their value to participants $(\mathrm{n}=17$ expressed in Percent, * indicates a significant shift in distribution alpha $=0.05$ ).

\begin{tabular}{|c|c|c|c|c|c|c|c|c|c|c|}
\hline \multirow[b]{2}{*}{ Statement } & \multicolumn{5}{|c|}{ Pre-Workshop Evaluation } & \multicolumn{5}{|c|}{ Post-Workshop Evaluation } \\
\hline & $\begin{array}{c}\text { Not } \\
\text { Valuable }\end{array}$ & $\begin{array}{c}\text { Slightly } \\
\text { Valuable }\end{array}$ & $\begin{array}{c}\text { Mod. } \\
\text { Valuable }\end{array}$ & $\begin{array}{c}\text { Very } \\
\text { Valuable }\end{array}$ & $\begin{array}{c}\text { Extreme } \\
\text { Valuable } \\
\end{array}$ & $\begin{array}{c}\text { Not } \\
\text { Valuable }\end{array}$ & $\begin{array}{c}\text { Slightly } \\
\text { Valuable }\end{array}$ & $\begin{array}{c}\text { Mod. } \\
\text { Valuable }\end{array}$ & $\begin{array}{c}\text { Very } \\
\text { Valuable }\end{array}$ & $\begin{array}{c}\text { Extreme } \\
\text { Valuable } \\
\end{array}$ \\
\hline $\begin{array}{l}\text { Historical issues of prairie } \\
\text { chickens. * }\end{array}$ & - & 11.76 & 17.65 & 41.18 & 29.41 & - & - & - & 35.29 & 64.71 \\
\hline $\begin{array}{l}\text { History of the Buena Vista } \\
\text { Marsh. * }\end{array}$ & - & 11.76 & 23.53 & 47.06 & 17.65 & - & - & 5.88 & 52.94 & 41.18 \\
\hline $\begin{array}{l}\text { Individuals involved with prairie } \\
\text { chickens. * }\end{array}$ & 5.88 & - & 29.41 & 47.06 & 17.62 & - & - & 5.88 & 23.53 & 70.59 \\
\hline Prairie chicken management. & - & 5.88 & 11.76 & 41.18 & 41.18 & - & - & - & 41.18 & 58.82 \\
\hline Prairie chicken ecology. & - & 5.88 & 11.76 & 23.53 & 58.82 & - & - & 5.88 & 41.18 & 52.94 \\
\hline Prairie habitat trends. & - & - & 11.76 & 58.82 & 29.41 & - & - & 5.88 & 35.29 & 58.82 \\
\hline Natural resource management. & - & - & - & 76.47 & 23.53 & - & - & - & 58.82 & 41.18 \\
\hline $\begin{array}{l}\text { Environmental education in } \\
\text { Wisconsin. }\end{array}$ & - & 5.88 & 23.53 & 23.53 & 47.06 & - & 5.88 & 23.53 & 17.65 & 52.94 \\
\hline $\begin{array}{l}\text { Current environmental issues } \\
\text { (associated with prairie } \\
\text { chickens). }\end{array}$ & - & - & 11.76 & 47.06 & 41.18 & - & - & 5.88 & 29.41 & 64.71 \\
\hline Buena Vista Marsh tour. * & - & 11.76 & 17.65 & 35.29 & 35.29 & - & - & 11.76 & 17.65 & 70.59 \\
\hline $\begin{array}{l}\text { Meeting with natural resource } \\
\text { managers. }\end{array}$ & - & 5.88 & 17.65 & 35.29 & 41.18 & - & - & 5.88 & 58.82 & 35.29 \\
\hline Socializing with colleagues. & - & - & 29.41 & 35.29 & 35.29 & - & - & 11.76 & 41.18 & 47.06 \\
\hline
\end{tabular}




\section{Natural Resource Management Statements}

Eight questions were used on both the pre and post-evaluation to determine participants' opinion of natural resource management. Table 17 summarizes the percent responses made on a five-point Likert scale where responses ranged from Strongly Disagree to Strongly Agree. Questions were matched on both the pre- and postevaluation.

All eight questions showed similar distributions of percentages before and after the workshop. The first four questions dealt directly with humans actively managing natural resources. Both prior to and following the workshop, participants Agreed or Strongly Agreed $100 \%$ to the statement "Humans must manage natural resources in order to ensure the future existence of those resources." Prior to the workshop, $100 \%$ of the participants disagreed with the statement that "Management of wildlife is not needed". While the post-evaluation indicated this number to decrease from $100 \%$ to $94 \%$, the overall support against this statement remained strong. Participants (71\%) indicated disagreement with the statement "Extinction of wildlife is an unavoidable result of human involvement with nature" in the pre-evaluation. This percentage remained similar in the post-evaluation (76\%). There was a slight decrease in the support for the statement, "Humans have the capability to successfully manage natural resources" from preevaluation results of $88 \%$ to post-evaluation results of $82 \%$. Finally, $88 \%$ of the participants disagreed to the statement, "There are already enough effective laws to protect the environment" both before and after the workshop.

The next three questions dealt with the participants' beliefs in the role of natural resource management and their involvement with environmental problems. Participants 
indicated before the workshop a disagreement (94\%) with the statement, "I think most of the concern about environmental problems has been exaggerated." Following the workshop, this percentage increased to a $100 \%$ disagreement. Both before and after the workshop participants indicated a solid agreement $(100 \%)$ to the statement, "I want to help solve environmental problems." Finally, there was an increase in the disagreement to the statement, "There is not much that I can do that will help solve environmental problems", from $94 \%$ before the workshop to $100 \%$ following the workshop.

Overall, it is important to note the following statements in the post-evaluation that received $100 \%$ accord from the participants. First, there was $100 \%$ agreement to the following statements, "Humans must manage natural resources in order to ensure the future existence of those resources" and "I want to help solve environmental problems." In addition, there was $100 \%$ disagreement with the following two statements, "I think most of the concern about environmental problems has been exaggerated" and "There is not much that I can do that will help solve environmental problems." 
Table 17. The degree to which participants agree or disagree with the following statements regarding natural resource management $(n=17$ expressed in Percent, * indicates a significant shift in distribution alpha $=0.05)$.

\begin{tabular}{|c|c|c|c|c|c|c|c|c|c|c|}
\hline \multirow[b]{2}{*}{ Statement } & \multicolumn{5}{|c|}{ Pre-Workshop Evaluation } & \multicolumn{5}{|c|}{ Post-Workshop Evaluation } \\
\hline & $\begin{array}{l}\text { Strongly } \\
\text { Disagree }\end{array}$ & Disagree & Neutral & Agree & $\begin{array}{l}\text { Strongly } \\
\text { Agree }\end{array}$ & $\begin{array}{l}\text { Strongly } \\
\text { Disagree }\end{array}$ & Disagree & Neutral & Agree & $\begin{array}{l}\text { Strongly } \\
\text { Agree }\end{array}$ \\
\hline $\begin{array}{l}\text { Humans must manage natural } \\
\text { resources in order to ensure the } \\
\text { future existence of those } \\
\text { resources. }\end{array}$ & - & - & - & 23.53 & 76.47 & - & - & - & 35.29 & 64.71 \\
\hline $\begin{array}{l}\text { Management of wildlife is not } \\
\text { needed. }\end{array}$ & 76.47 & 23.53 & - & - & - & 76.47 & 17.65 & - & 5.88 & - \\
\hline $\begin{array}{l}\text { Extinction of wildlife is an } \\
\text { unavoidable result of human } \\
\text { involvement with nature. }\end{array}$ & 47.06 & 23.53 & 17.65 & 11.76 & - & 41.18 & 35.29 & - & 11.76 & 11.76 \\
\hline $\begin{array}{l}\text { Humans have the capability to } \\
\text { successfully manage natural } \\
\text { resources. * }\end{array}$ & - & - & 11.76 & 52.94 & 35.29 & - & - & 17.65 & 70.59 & 11.76 \\
\hline $\begin{array}{l}\text { There are already enough } \\
\text { effective laws to protect the } \\
\text { environment. }\end{array}$ & 47.06 & 41.18 & 11.76 & - & - & 47.06 & 41.18 & 11.76 & - & - \\
\hline $\begin{array}{l}\text { I think most of the concern about } \\
\text { environmental problems has been } \\
\text { exaggerated. }\end{array}$ & 64.71 & 29.41 & 5.88 & - & - & 76.47 & 23.53 & - & - & - \\
\hline $\begin{array}{l}\text { I want to help solve } \\
\text { environmental problems. }\end{array}$ & - & - & - & 23.53 & 76.47 & - & - & - & 17.65 & 82.35 \\
\hline $\begin{array}{l}\text { There is not much that I can do } \\
\text { that will help solve environmental } \\
\text { problems. }\end{array}$ & 64.71 & 29.41 & - & 5.88 & - & 82.35 & 17.65 & - & - & - \\
\hline
\end{tabular}




\section{$\underline{\text { Knowledge Questions }}$}

A total of thirty-three multiple-choice questions were developed in order to test participants' knowledge before and after the workshop. One question was not used in analysis due to confounding answer options. The questions have been divided by major

topic area. Average scores for both pre- and post-workshop evaluation and overall scores can be found in Table 18. There was an increase in percent correct in all 6 major topic areas and thus an overall increase in scores from pre- to post-evaluation.

In the pre-evaluation, the lowest percent of correct responses was found in the questions regarding the status of prairie chickens in Wisconsin (25\%). The highest percent of correct responses was found in the questions regarding the historical status of prairie chickens (74\%). In the post-evaluation, the lowest percent of correct responses was again found in the questions regarding the status of prairie chickens in Wisconsin (60\%). The highest percent of correct responses was again found in the questions regarding the historical status of prairie chickens $(100 \%)$. Overall, the smallest percent change of correct answers from pre- to post-evaluation was found in questions regarding environmental education (24\%). The highest percent change of correct answers from pre-to post-evaluation was found in questions regarding general ecology of prairie chickens (50\%). Finally, there was a $35 \%$ increase in correct answers from pre- to postevaluation. 
Table 18. Participant knowledge scores by major topic area $(n=17)$

\begin{tabular}{lccc}
\hline \multicolumn{1}{c}{ Major Topic Area } & $\begin{array}{c}\text { Pre- } \\
\text { Workshop }\end{array}$ & $\begin{array}{c}\text { Post- } \\
\text { Workshop }\end{array}$ & Change \\
Percent & Percent & Percent \\
\hline General ecology of prairie chickens & 43.38 & 93.38 & 50.00 \\
Prairie chicken habitat & 48.53 & 76.47 & 27.94 \\
Status of prairie chickens in Wisconsin & 25.00 & 60.30 & 35.30 \\
Historical status of prairie chickens & 73.53 & 100.00 & 26.47 \\
Management of prairie chickens & 35.29 & 83.09 & 47.80 \\
Environmental education & 60.77 & 84.32 & 23.55 \\
Overall & 47.75 & 82.93 & 35.18 \\
\hline
\end{tabular}

\section{Questions Relating to the General Ecology of Prairie Chickens}

Average scores for the eight questions relating to the general ecology of prairie chickens increased from $43 \%$ in the pre-evaluation to $93 \%$ in the post-evaluation. Results of individual questions in this category can be found in Table 19.

The correct answer identifying the scientific name of the greater prairie chicken was recognized by less than half of the participants $(47 \%)$ prior to the workshop. Following the workshop, this number increased to a perfect score of $100 \%$. When participants were asked to identify other states that have a prairie chicken population, little more than half (53\%) identified the correct answer in the pre-evaluation. Again, $100 \%$ were able to identify the correct response in the post-evaluation. When asked to identify the diet of both juvenile and adult prairie chickens, the participants answered in an identical fashion to the previous question with $53 \%$ identifying the correct answer on the pre-evaluation and $100 \%$ identifying the correct question following the workshop. This similar trend was seen when $58 \%$ of the participants correctly identified the answers 
to "“"Lek" is defined as..." and "Cocks (male prairie chickens) do not show strong fidelity to booming grounds year after year" in the pre-evaluation while that number increased, again to $100 \%$ in the post-evaluation.

The final three questions showed increases in correct answers from pre- to postevaluation as well. In these questions, less than half of the participants were able to identify the correct answers regarding hen fidelity to booming grounds (18\%), clutch and brood size (35\%), and signs of successful copulation (43\%). However, following the workshop, the percent of correct answers increased in all three questions to $59 \%, 88 \%$ and $100 \%$ respectively. 
Table 19. Questions and participant responses relating to the general ecology of prairie chickens * $(n=17)$.

Pre-Workshop Post-Workshop

Question

What is the scientific name for the greater prairie chicken?
a. Tympanuchus phasianellus
b. Bonasa umbellus
c. Tympanuchus cupido $\checkmark$
d. don't know

Other states that have a greater prairie chicken population include:
a. Minnesota, North Dakota, Colorado
b. Ohio, Connecticut, Delaware
c. Washington, Montana, Texas
d. don't know
a. insects, cultivated grains
b. plants, meat
c. berries, corn
d. don't know for food, and make up a substantial par of the diet in the adult stage.

\section{Juvenile prairie chickens are heavily dependant on}

"Lek" is defined as...
a. the berries that many animals are dependent upon as a food source.
b. an area where animals carry on display and courtship behavior.
c. a small prairie rodent.
d. don't know

\section{Percent}

11.76

$47.06 \checkmark$

41.18

52.94

5.88

41.18
$52.94 \checkmark$
$-$
47.06

58.82

100.00

41.18
100.00

Percent

100.00

-

(

$\checkmark=$ correct response 
Table 19 (Continued). Questions and participant responses relating to the general ecology of prairie chickens (n=17).

Cocks (male prairie chickens) do not show strong fidelity to booming grounds year after year.

Hens (female prairie chickens) do not show strong fidelity to booming grounds year after year.

11.76

58.82

29.41

c. don't know
a. true
b. false
c. don't know

Prairie chickens tend to have per year with an average of

clutch. broods(s) eggs per

eggs per
a. $1,2-3$
b. $2,2-3$
c. $1,10-15 \checkmark$
d. $2,10-15$
e. don't know

A sign that copulation is successful can be seen by... a. a cock that ceases to boom for the remainder of the morning.

b. a hen who "rouses", or shakes her feather violently, and leaves the booming grounds within ten minutes.

c. a cock and hen pair that leave the booming ground together.

d. don't know
88.24 11.76
5.88

5.88

35.29

58.82

3

(1000

$\checkmark$




\section{Questions Relating to Prairie Chicken Habitat}

Average scores for the 4 questions relating to prairie chicken habitat increased from $49 \%$ in the pre-evaluation to $76 \%$ in the post-evaluation. Results of individual questions in this category can be found in Table 20.

In the pre-evaluation, less than half (47\%) of the participants were able to identify the grass cover types necessary to meet the needs of prairie chickens. Following the workshop, this number increased to $76 \%$. Similarly, only $35 \%$ of the participants identified the correct answer when asked if both native and introduced grasslands were able to support prairie chicken populations. This percentage increased to $82 \%$ following the workshop. More than half of the participants $(71 \%)$ were able to identify that prairie chickens use short grass cover for booming. This percentage increased to a perfect score of $100 \%$ following the workshop. Finally, only $41 \%$ of the participants were able to identify the most significant habitat type necessary to prairie chicken success prior to the workshop. This number did not increase significantly (47\%) in the post-workshop evaluation. 
Table 20. Questions and participant responses relating to prairie chicken habitat (n=17).

Pre-Workshop Post-Workshop

Question

Prairie chicken production is dependent on of grass cover type(s) to meet the needs of the birds.

Historically, prairie chickens were supported by Tallgrass or true prairie grassland. Toady, they are able to adapt to various types of grasslands, both native and introduced.

Short grass cover is used for...

is/are identified as the most significant habitat type to prairie chicken success.

\section{Answer Options}
a. one kind
b. two kinds
c. a combination $\checkmark$
d. none, they are not dependent on grass cover
e. don't know
a. true
b. false
c. don't know

Percent

11.76

$47.06 \checkmark$

11.76

29.41
Percent

5.88

17.65

76.47

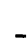

$82.35 \checkmark$

17.65

23.53

41.18
a. booming.
b. roosting.
c. Nesting and brood rearing.
d. don't know
a. Booming grounds
b. Roosting Cover
c. Nesting and brood rearing cover $\checkmark$
d. don't know

70.59
-
-
29.41

17.65

35.29

41.18

41.18 


\section{Questions Relating to the Status of Prairie Chickens in Wisconsin}

Average scores for the four questions relating to the status of prairie chickens in Wisconsin increased from $25 \%$ in the pre-evaluation to $60 \%$ in the post-evaluation. Results of individual questions in this category can be found in Table 21.

When asked the number of species of grouse native to Wisconsin, $29 \%$ were able to identify four as the correct answer in the pre-workshop evaluation. This number increased to $64 \%$ in the post-workshop evaluation. When asked to identify the status of prairie chickens in Wisconsin, 53\% correctly identified them as a threatened species prior to the workshop. This number increased to $88 \%$ following the workshop. Only $6 \%$ of the participants were able to identify the correct number of male prairie chickens on the Buena Vista Marsh prior to the workshop. This number remained unchanged in the postworkshop evaluation. This is due to the fact that this answer was never directly discussed. The participants were told the total number of prairie chickens in Wisconsin, and that there is a 50:50 sex ratio. However, they were never told the specific number of prairie chickens on the Buena Vista Marsh versus other areas. Finally, participants were asked to identify which areas had significant counts of male prairie chickens in Wisconsin. Prior to the workshop, $12 \%$ of the participants were able to identify the correct answer. This percentage of correct answers increased to $82 \%$ following the completion of the workshop. 
Table 21. Questions and participant responses relating to the status of prairie chickens in Wisconsin (n=17).

Pre-Workshop Post-Workshop

\begin{tabular}{|c|c|c|c|}
\hline Question & Answer Options & Percent & Percent \\
\hline There are $\quad$ species of grouse native to & a. 3 & 29.41 & 35.29 \\
\hline \multirow[t]{3}{*}{ Wisconsin. } & b. $4 \checkmark$ & $29.41 \checkmark$ & $64.71 \checkmark$ \\
\hline & c. 5 & - & - \\
\hline & d. don't know & 41.18 & - \\
\hline \multirow{4}{*}{$\begin{array}{l}\text { The status of the greater prairie chicken population } \\
\text { in Wisconsin is... }\end{array}$} & a. endangered & 17.65 & 11.76 \\
\hline & b. threatened $\checkmark$ & $52.94 \checkmark$ & $88.24 \checkmark$ \\
\hline & c. extinct & - & - \\
\hline & d. don't know & 29.41 & - \\
\hline \multirow{4}{*}{$\begin{array}{l}\text { In } 2002 \text {, the population of male prairie chickens on } \\
\text { the Buena Vista Marsh was estimated to be around }\end{array}$} & a. $220 \checkmark$ & $5.88 \checkmark$ & $5.88 \checkmark$ \\
\hline & b. 540 & 5.88 & 64.71 \\
\hline & c. 1,100 & 17.65 & 23.53 \\
\hline & d. don't know & 70.59 & 5.88 \\
\hline \multicolumn{4}{|l|}{ Significant counts of male prairie chickens in } \\
\hline \multirow[t]{5}{*}{ Wisconsin were reported in... } & a. Leola Grasslands & 5.88 & - \\
\hline & b. Meadow Valley Wildlife Area & - & - \\
\hline & c. Paul Olson Area & - & - \\
\hline & d. both a and c $\checkmark$ & $11.76 \checkmark$ & $82.35 \checkmark$ \\
\hline & e. don't know & 82.35 & 17.65 \\
\hline
\end{tabular}




\section{Questions Relating to the Historical Status of Prairie Chickens}

Average scores for the three questions relating to the historical status of prairie chickens increased from $74 \%$ in the pre-evaluation to $100 \%$ in the post-evaluation. Results of individual questions in this category can be found in Table 22.

Prior to the workshop, $53 \%$ of the participants were able to identify the correct answer concerning the historic range and number of prairie chickens. Following the workshop, this number increased to a perfect score of $100 \%$. The majority of participants (94\%) identified habitat loss from agricultural development as the main reason for the decline in historic levels of prairie chickens. This number also increased to $100 \%$ as all participants identified the correct answer on the post-workshop evaluation.

The final question, asking participants to identify which year a decline in the prairie chicken population was first evident was discarded as it was deemed, following the workshop, to have confounding answer options. 
Table 22. Questions and participant responses relating to the historical status of prairie chickens $(n=17)$.

Pre-Workshop Post-Workshop

a. remained fairly stable through time.

b. Increased following westward settlement then dwindled.

c. Increased and continues to increase with management

d. don't know

a. habitat loss from agricultural development.

b. parasitic diseases.

c. use of insecticides on farms.

d. global warming.

e. don't know
Question

Through time, the range and number of greater prairie chickens has...
Historic levels of prairie chickens declined dramatically due largely to...
a. 1850
b. 1900
c. 1910
d. 1950
e. don't know

A decline in prairie chicken abundance in Wisconsin was first evident as early as...

* Question was not included in analyses due to confounding answer options.

Percent

47.06

Percent

$\begin{array}{cc}94.12 \checkmark & 100.00 \checkmark \\ - & - \\ - & - \\ - & - \\ 5.88 & -\end{array}$

$\begin{array}{cc}17.65 & 17.65 \\ - & 11.76 \\ 29.41 & 41.18 \\ - & 29.41 \\ 52.94 & -\end{array}$




\section{Questions Relating to the Management of Prairie Chickens}

Average scores for the eight questions relating to the management of prairie chickens increased from $35 \%$ in the pre-evaluation to $83 \%$ in the post-evaluation. Results of individual questions in this category can be found in Table 23.

Prior to the workshop, none of the participants $(0 \%)$ were able to identify zoo specimens as the one prairie chicken management practice that is not used in states other than in Wisconsin. Following the workshop, $65 \%$ of the participants were able to identify the correct answer. Less than one fourth of the participants (24\%) were able to identify translocations as the correct answer for the one prairie chicken management practice that is not used in Wisconsin. Following the workshop, $88 \%$ of the participants identified the correct answer. Again, none of the participants ( $0 \%)$ were able to identify the correct answer on the pre-workshop evaluation when they were asked to identify the gentlemen under whom prairie chicken research began in 1928 in Wisconsin. Following the workshop only $24 \%$ of the participants were able to identify Alfred O. Gross as the correct answer.

The final four questions in this section saw higher percentages of correct answers in the post-workshop evaluation. When asked, prior to the workshop, to describe "ecological patterning" as the Hamerstroms had described, $35 \%$ of the participants were able to identify the correct answer. Following the workshop, this number increased to $100 \%$. In addition, $47 \%$ of the participants were able to identify the Wisconsin Department of Natural Resources as the organization in charge of prairie chicken management in Wisconsin on the pre-workshop evaluation. This number increased to $94 \%$ on the post-workshop evaluation. Prior to the workshop, when asked to identify the 
major threats to prairie chickens, $59 \%$ of participants were able to correctly do so. This percentage increased to $94 \%$ following the workshop. When asked to identify which research method was not used to study prairie chickens in the state of Wisconsin, the percentage of correct answers increased from $41 \%$ prior to the workshop to $100 \%$ following the workshop. Finally, when asked if booming ground counts can be used as an index to population abundance, $76 \%$ of participants indicated true as the correct answer before the workshop. This percentage increased to a perfect score of $100 \%$ following the workshop. 
Table 23. Questions and participant responses relating to the management of prairie chickens $(n=17)$.

Pre-Workshop Post-Workshop

\begin{tabular}{|c|c|c|c|}
\hline Question & Answer Options & Percent & Percent \\
\hline $\begin{array}{l}\text { Prairie chicken population management practices } \\
\text { used in states other than Wisconsin include all but } \\
\text { which one: }\end{array}$ & $\begin{array}{ll}\text { a. } & \text { hunting } \\
\text { b. zoo specimens } \checkmark \\
\text { c. grazing } \\
\text { d. translocations } \\
\text { e. don't know }\end{array}$ & $\begin{array}{c}23.53 \\
-\checkmark \\
11.76 \\
- \\
64.71\end{array}$ & $\begin{array}{c}23.53 \\
64.71 \checkmark \\
- \\
- \\
11.76\end{array}$ \\
\hline $\begin{array}{l}\text { Habitat management practices used in Wisconsin } \\
\text { include all but which one: }\end{array}$ & $\begin{array}{l}\text { a. predator control } \\
\text { b. prescribed burning } \\
\text { c. crop rotation } \\
\text { d. translocations } \checkmark \\
\text { e. don't know }\end{array}$ & $\begin{array}{l}11.76 \\
- \\
17.65 \\
23.53 \checkmark \\
47.06\end{array}$ & $\begin{array}{c}11.76 \\
- \\
- \\
88.24 \checkmark \\
-\end{array}$ \\
\hline $\begin{array}{l}\text { Prairie chicken research began in Wisconsin in } 1928 \text {, } \\
\text { under the direction of... }\end{array}$ & $\begin{array}{l}\text { a. Lyle Nauman } \\
\text { b. Alfred O. Gross } \checkmark \\
\text { c. Frederick and Frances } \\
\text { Hamerstrom } \\
\text { d. Willis Sullivan } \\
\text { e. don't know }\end{array}$ & $\begin{array}{c}- \\
-\checkmark \\
76.47 \\
23.53\end{array}$ & $\begin{array}{l}- \\
23.53 \checkmark \\
41.18 \\
23.53 \\
11.76\end{array}$ \\
\hline
\end{tabular}


Table 23 (Continued) Questions and participant responses relating to the management of prairie chickens (n=17).

\begin{tabular}{|c|c|c|c|}
\hline $\begin{array}{l}\text { "Ecological patterning", as described by the } \\
\text { Hamerstroms is... }\end{array}$ & $\begin{array}{l}\text { a. the natural practice of landscape } \\
\text { management that patterns one } \\
\text { area after another. } \\
\text { b. a method to apply pesticides and } \\
\text { herbicides at minimal doses in } \\
\text { spot treatments. } \\
\text { c. a scattered distribution of } \\
\text { relatively small land parcels, } \\
\text { rather than one large, } \\
\text { homogenous parcel. } \\
\text { d. don't know }\end{array}$ & $\begin{array}{l}35.29 \checkmark \\
47.06\end{array}$ & $100.00 \checkmark$ \\
\hline $\begin{array}{l}\text { Today, what is the organization in charge of prairie } \\
\text { chicken management in Wisconsin? }\end{array}$ & $\begin{array}{l}\text { a. Dane County Conservation } \\
\text { League } \\
\text { b. Wisconsin Society of } \\
\text { Ornithology } \\
\text { c. Fish and Wildlife Service } \\
\text { d. Wisconsin Department of } \\
\text { Natural Resources } \checkmark \\
\text { e. don't know }\end{array}$ & $\begin{array}{c}11.76 \\
- \\
5.88 \\
47.06 \checkmark \\
35.29\end{array}$ & $\begin{array}{c}5.88 \\
- \\
- \\
94.12 \checkmark \\
-\end{array}$ \\
\hline $\begin{array}{l}\text { Today, the major threats to prairie chicken } \\
\text { conservation in Wisconsin include all but one: }\end{array}$ & $\begin{array}{l}\text { a. loss of genetic diversity } \\
\text { b. habitat loss / fragmentation } \\
\text { c. unconnected subpopulations } \\
\text { d. uncontrolled fire } \checkmark \\
\text { e. don't know }\end{array}$ & $\begin{array}{c}5.88 \\
- \\
5.88 \\
58.82 \checkmark \\
29.41\end{array}$ & $\begin{array}{c}- \\
- \\
5.88 \\
94.12 \checkmark \\
-\end{array}$ \\
\hline
\end{tabular}


Table 23 (Continued). Questions and participant responses relating to the management of prairie chickens (n=17).

\begin{tabular}{llc}
\hline $\begin{array}{l}\text { In Wisconsin, researchers learn more about prairie } \\
\text { chickens behavior and habitat use by all of the }\end{array}$ & a. annual census and blind & - \\
following methods except: & observation & - \\
& b. captive breeding $\checkmark$ & $51.18 \checkmark$ \\
& c. monitoring radio marked birds & 5.88 \\
& d. study populations in other states & - \\
& e. don't know & - \\
Booming ground counts can be used as an index to & a. true $\checkmark$ & $76.47 \checkmark$ \\
$\begin{array}{l}\text { population abundance and can be useful in showing } \\
\text { trends over a span of years. }\end{array}$ & b. false & - \\
\hline
\end{tabular}




\section{Questions Relating to Environmental Education}

Average scores for the six questions relating to environmental education increased from $61 \%$ in the pre-evaluation to $84 \%$ in the post-evaluation. Results of individual questions in this category can be found in Table 24.

When asked in the pre-workshop evaluation in which year Wilhelmine LaBudde wrote Wisconsin's first environmental education (EE) initiative, only $12 \%$ of the participants identified 1935 as the correct answer. This percentage increased to $71 \%$ in the post-workshop evaluation. The second question regarding the 1977 conference on environmental education maintained similar percentages with $71 \%$ responding correctly on the pre-workshop evaluation and $76 \%$ responding correctly on the post-workshop evaluation. When asked on the pre-workshop evaluation to identify the office responsible for environmental education in Wisconsin, $41 \%$ of the participants identified the correct answer as the Wisconsin Department of Public Instruction. This percentage increased to $71 \%$ following the workshop.

Prior to the workshop, $82 \%$ correctly identified the goal of environmental education. This number increased to $94 \%$ following the workshop. Similarly, $76 \%$ of the participants correctly identified infusion as the model that Wisconsin employed to incorporate environmental education into existing curriculum plans. Following the workshop, $94 \%$ identified the correct answer. Finally, following the workshop, $100 \%$ of the participants identified citizen action experience as another subgoal of environmental education, beside environmental ethic, that focuses on grades 9-12. This was an increase from the $82 \%$ that answered the question correctly on the pre-workshop evaluation. 
Table 24. Questions and participant responses relating to environmental education (n=17).

Pre-Workshop Post-Workshop

\section{Question}

Wilhelmine LaBudde wrote Wisconsin's first environmental education (EE) initiative in...

marked...

\begin{tabular}{lcc} 
& Answer Options & Percent \\
\hline a. $1935 \checkmark$ & $11.76 \checkmark$ \\
b. 1955 & 11.76 \\
c. 1975 & 5.88 \\
d. 1995 & - \\
e. don't know & 70.59
\end{tabular}

Percent

70.59

11.76

17.65

a. the celebration of environmental education reform in the United States.

b. the acceptance of environmental education in the school systems.

c. the first intergovernmental conference on environmental education.

d. don't know

29.41

a. Wisconsin Department of

11.76

The office responsible
in Wisconsin is the...

b. Wisconsin Department of Public Instruction.

c. Wisconsin Association for

d. don't know 
Table 24 (Continued). Questions and participant responses relating to environmental education. (n=17).

\begin{tabular}{|c|c|c|c|}
\hline The goal of environmental education is to... & $\begin{array}{l}\text { a. produce environmentally } \\
\text { responsible citizens who can } \\
\text { work for a balance between } \\
\text { quality of life and quality of the } \\
\text { environment. } \checkmark \\
\text { b. create active citizens with } \\
\text { increased participation in } \\
\text { outdoor activities who show a } \\
\text { genuine concern for the } \\
\text { environment. } \\
\text { c. practice education in an outdoors } \\
\text { setting in order to show first } \\
\text { hand the hazards that humans } \\
\text { can inflict on the surrounding } \\
\text { environment. } \\
\text { d. don't know }\end{array}$ & $82.24 \checkmark$ & $94.12 \checkmark$ \\
\hline $\begin{array}{l}\text { Wisconsin employed an } \\
\text { a systematic incorporation of EE into existing } \\
\text { curriculum plans. }\end{array}$ & $\begin{array}{l}\text { a. implementation } \\
\text { b. infusion } \checkmark \\
\text { c. induction } \\
\text { d. don't know }\end{array}$ & $\begin{array}{c}- \\
76.47 \checkmark \\
- \\
23.53\end{array}$ & $\begin{array}{c}5.88 \\
94.12 \checkmark \\
- \\
-\end{array}$ \\
\hline $\begin{array}{l}\text { Beside environmental ethic, the other EE subgoal } \\
\text { that focuses on grades } 9-12 \text { is... }\end{array}$ & $\begin{array}{l}\text { a. perceptual awareness. } \\
\text { b. knowledge. } \\
\text { c. citizen action experience. } \checkmark \\
\text { d. don't know }\end{array}$ & $\begin{array}{l}- \\
11.76 \\
82.35 \checkmark \\
5.88\end{array}$ & $\begin{array}{c}- \\
- \\
100.00 \checkmark \\
-\end{array}$ \\
\hline
\end{tabular}




\section{Overall Workshop Evaluation}

The overall workshop evaluation was completed by participants following the completion of the workshop. The evaluation served to gather participants' feedback regarding workshop content, structure and organization in addition to gathering additional comments and suggestions.

\section{BOW Workshop Content}

Nine questions were used to determine how participants felt regarding the BOW workshop content. Table 25 summarizes the percent responses made on a five-point Likert scale where responses ranged from Strongly Disagree to Strongly Agree. All questions showed results perceived as positive, as all responses fell in the range of Neutral to Strongly Agree, with no responses indicating Strongly Disagree or Disagree.

When asked if the participants believed that the workshop provided them with factual information, $100 \%$ agreed. In addition, $100 \%$ indicated that the workshop helped them understand the information gained during the workshop. Participants were asked if the workshop challenged them intellectually and $94 \%$ responded positively. All of the participants (100\%) indicated that they felt the workshop was applicable to their current or future career.

All participants (100\%) agreed to the statement indicating that this workshop presented them with resources they will be able to use in the future. In addition, all participants $(100 \%)$ indicated that they were comfortable using those resources that were presented. 
When asked if they gained hands-on skills associated with prairie chicken ecology/conservation, $94 \%$ of the participants indicted that they agree with that statement. Finally, all participants (100\%) indicated that they became familiar with general prairie chicken ecology/conservation concepts, and that they consider themselves more knowledgeable about prairie chicken ecology/conservation after taking this course. 
Table 25. The degree to which participants agree or disagree with the following statements regarding the BOW workshop content ( $n=17$ expressed in Percent).

\begin{tabular}{|c|c|c|c|c|c|}
\hline Statement & $\begin{array}{l}\text { Strongly } \\
\text { Disagree }\end{array}$ & Disagree & Neutral & Agree & $\begin{array}{c}\text { Strongly } \\
\text { Agree }\end{array}$ \\
\hline $\begin{array}{l}\text { The workshop provided me with } \\
\text { factual information. }\end{array}$ & - & - & - & 5.88 & 94.12 \\
\hline $\begin{array}{l}\text { The workshop helped me understand } \\
\text { the information. }\end{array}$ & - & - & - & 23.53 & 76.47 \\
\hline $\begin{array}{l}\text { The workshop challenged me } \\
\text { intellectually. }\end{array}$ & - & - & 5.88 & 29.41 & 64.71 \\
\hline $\begin{array}{l}\text { The workshop was applicable to my } \\
\text { current or future career. }\end{array}$ & - & - & - & 23.53 & 76.47 \\
\hline $\begin{array}{l}\text { This workshop presented me with } \\
\text { resources I will be able to use in the } \\
\text { future. }\end{array}$ & - & - & - & 5.88 & 94.12 \\
\hline $\begin{array}{l}\text { I am comfortable using the resources } \\
\text { presented to me during the workshop. }\end{array}$ & - & - & - & 17.65 & 82.35 \\
\hline $\begin{array}{l}\text { I feel I gained hands-on skills } \\
\text { associated with prairie chicken } \\
\text { ecology/conservation. }\end{array}$ & - & - & 5.88 & 29.41 & 64.71 \\
\hline $\begin{array}{l}\text { I became familiar with general prairie } \\
\text { chicken ecology/conservation } \\
\text { concepts. }\end{array}$ & - & - & - & 29.41 & 70.59 \\
\hline $\begin{array}{l}\text { I consider myself more } \\
\text { knowledgeable about prairie chicken } \\
\text { ecology/conservation after taking this } \\
\text { course. }\end{array}$ & - & - & - & 11.76 & 88.24 \\
\hline
\end{tabular}




\section{$\underline{\text { Workshop Session Content }}$}

Nine questions were used to determine how participants felt regarding the workshop session content. Table 26 summarizes the percent responses made on a fivepoint Likert scale where responses ranged from Strongly Disagree to Strongly Agree.

Most responses to workshop session content questions were favorable with participants indicating that they Agreed or Strongly Agreed to the statements.

Participants were asked to rate the statements of each session in order to indicate how it helped to expand their understanding of what they learned in that session. All participants (100\%) indicated that the "Historical Perspective" session helped them expand their knowledge about the past and present prairie chicken population in Wisconsin, expand their knowledge of the Buena Vista Marsh, and expand their knowledge of pioneering conservationists involved with prairie chickens.

The next statement related to the participants' experience viewing prairie chickens on their booming grounds. All participants (100\%) indicated that the prairie chicken viewing session helped them expand their understanding of prairie chicken courtship and behavior.

The majority of participants (82\%) indicated that the "Buena Vista Marsh Tour" session helped them expand their knowledge of management practices on the Marsh. Six percent of the participants disagreed with this statement. Similarly, $88 \%$ of the participants indicated that the "Prairie Chicken Ecology" session helped them to expand their understandings of prairie chicken ecology. Twelve percent of the participants disagreed with this statement. 
Finally, participants were asked to rate the "Environmental Education" and "Curriculum Development" sessions in terms of helping them to expand their understanding about the topics. More than half (59\%) of the participants agreed that the "Environmental Education" session helped them to expand their understanding of environmental education. Six percent of the participants disagreed with this statement. When participants were asked to rate the statement regarding the "Curriculum Development" session, $41 \%$ agreed that this session helped them understand how to develop curriculum using the knowledge gained in this workshop. Twenty nine percent disagreed with that statement. 
Table 26. The degree to which participants agree or disagree with the following statements regarding the content of the workshop sessions ( $n=17$ expressed in Percent).

\begin{tabular}{|c|c|c|c|c|c|}
\hline Statement & $\begin{array}{l}\text { Strongly } \\
\text { Disagree }\end{array}$ & Disagree & Neutral & Agree & $\begin{array}{c}\text { Strongly } \\
\text { Agree }\end{array}$ \\
\hline $\begin{array}{l}\text { The "Historical Perspective" session } \\
\text { helped me expand my knowledge } \\
\text { about the past and present prairie } \\
\text { chicken population in Wisconsin. }\end{array}$ & - & - & - & 29.41 & 70.59 \\
\hline $\begin{array}{l}\text { The "Historical Perspective" session } \\
\text { helped me expand my knowledge of } \\
\text { the Buena Vista Marsh. }\end{array}$ & - & - & - & 47.06 & 52.94 \\
\hline $\begin{array}{l}\text { The "Historical Perspective" session } \\
\text { helped me expand my knowledge of } \\
\text { pioneering conservationist involved } \\
\text { with prairie chickens. }\end{array}$ & - & - & - & 35.29 & 64.71 \\
\hline $\begin{array}{l}\text { The "Prairie Chicken Viewing" } \\
\text { session helped me expand my } \\
\text { understanding of prairie chicken } \\
\text { courtship and behavior. }\end{array}$ & - & - & - & 11.76 & 88.24 \\
\hline $\begin{array}{l}\text { The "Buena Vista Marsh Tour" } \\
\text { session helped me expand my } \\
\text { knowledge of management practices } \\
\text { on the Marsh. }\end{array}$ & - & 5.88 & 11.76 & 23.53 & 58.82 \\
\hline
\end{tabular}


Table 26 (Continued). The degree to which participants agree or disagree with the following statements regarding the content of the workshop sessions ( $n=17$ expressed in Percent).

\begin{tabular}{|c|c|c|c|c|c|}
\hline Statement & $\begin{array}{l}\text { Strongly } \\
\text { Disagree }\end{array}$ & Disagree & Neutral & Agree & $\begin{array}{c}\text { Strongly } \\
\text { Agree }\end{array}$ \\
\hline $\begin{array}{l}\text { The "Prairie Chicken Ecology" } \\
\text { session helped me to expand my } \\
\text { understandings of prairie chicken } \\
\text { ecology. }\end{array}$ & - & 11.76 & - & 52.94 & 35.29 \\
\hline $\begin{array}{l}\text { The "Prairie Habitat" session helped } \\
\text { me to expand my understanding of } \\
\text { prairie habitat. }\end{array}$ & - & - & - & 29.41 & 70.59 \\
\hline $\begin{array}{l}\text { The "Environmental Education" } \\
\text { session helped me to expand my } \\
\text { understanding of environmental } \\
\text { education. }\end{array}$ & - & 5.88 & 35.29 & 23.53 & 35.29 \\
\hline $\begin{array}{l}\text { The 'Curriculum Development' } \\
\text { session helped me to understand how } \\
\text { to develop curriculum using the } \\
\text { knowledge gained in this workshop. }\end{array}$ & 11.76 & 17.65 & 29.41 & 29.41 & 11.76 \\
\hline
\end{tabular}




\section{$\underline{\text { Resource Binder }}$}

Two questions were used to determine how participants felt regarding the resource binder. Table 27 summarizes the percent responses made on a five-point Likert scale where responses ranged from Strongly Disagree to Strongly Agree.

The response to the resource binder was perceived as extremely positive. All participants (100\%) indicated that they felt the resource binder is a helpful resource to them. In addition, all participants $(100 \%)$ indicated that the resource binder would influence their future teaching.

\section{$\underline{\text { One-credit Assignment }}$}

Two questions were used to determine how participants felt regarding one-credit assignment. Table 28 summarizes the percent responses made on a five-point Likert scale where responses ranged from Strongly Disagree to Strongly Agree.

Overall, participants did not show strong support for either statement regarding the assignment to receive one University credit. When asked if the assignment seems appropriate $6 \%$ of the participants agreed while $53 \%$ disagreed. The remaining $41 \%$ indicated feeling neutral to this statement. When asked if the assignment will be useful to them as an educator, $53 \%$ indicated agreement to that statement while $18 \%$ disagreed. 
Table 27. The degree to which participants agree or disagree with the following statements regarding the resource binder provided during the workshop (n=17 expressed in Percent).

\begin{tabular}{|c|c|c|c|c|c|}
\hline Statement & $\begin{array}{l}\text { Strongly } \\
\text { Disagree } \\
\end{array}$ & Disagree & Neutral & Agree & $\begin{array}{c}\text { Strongly } \\
\text { Agree }\end{array}$ \\
\hline $\begin{array}{l}\text { The resource binder is a helpful } \\
\text { resource to me. }\end{array}$ & - & - & - & 23.53 & 76.47 \\
\hline $\begin{array}{l}\text { The resource binder will influence } \\
\text { my future teaching. }\end{array}$ & - & - & - & 35.29 & 64.71 \\
\hline
\end{tabular}

Table 28. The degree to which participants agree or disagree with the following statements regarding the assignment for the one-credit option ( $n=17$ expressed in Percent).

\begin{tabular}{lcccc}
\hline \multicolumn{1}{c}{ Statement } & $\begin{array}{l}\text { Strongly } \\
\text { Disagree }\end{array}$ & Disagree & Neutral & $\begin{array}{c}\text { Strongly } \\
\text { Agree }\end{array}$ \\
\hline The assignment seems appropriate. & 35.29 & 17.65 & 41.18 & - \\
$\begin{array}{l}\text { The assignment will be useful to me } \\
\text { as an educator. }\end{array}$ & - & 17.65 & 29.41 & 29.88 \\
\hline
\end{tabular}




\section{Workshop Structure}

Seven questions were used to determine how participants felt regarding the workshop structure. Table 29 summarizes the percent responses made on a five-point Likert scale where responses ranged from Strongly Disagree to Strongly Agree.

All participants (100\%) agreed that the workshop seemed well organized, that the workshop sessions seemed to flow logically, that the registration process was easy to understand, and that the BOW staff members were helpful and courteous. Many additional comments were given stating the great organization and flow of the workshop. When asked if there was sufficient interaction between participants $94 \%$ of the participants agreed with this statement while $6 \%$ strongly disagreed. When asked if there seemed to be sufficient interaction between students and the instructors, $94 \%$ of the participants agreed. Finally, when asked if the sessions seemed appropriate in length, $88 \%$ of the participants agreed with this statement, while $6 \%$ disagreed. 
Table 29. The degree to which participants agree or disagree with the following statements regarding the workshop structure ( $n=17$ expressed in Percent).

\begin{tabular}{|c|c|c|c|c|c|}
\hline Statement & $\begin{array}{l}\text { Strongly } \\
\text { Disagree }\end{array}$ & Disagree & Neutral & Agree & $\begin{array}{l}\text { Strongly } \\
\text { Agree }\end{array}$ \\
\hline The workshop was well organized & - & - & - & 11.76 & 88.24 \\
\hline $\begin{array}{l}\text { The workshop sessions seemed to } \\
\text { flow logically. }\end{array}$ & - & - & - & 29.41 & 70.59 \\
\hline $\begin{array}{l}\text { There seemed to be sufficient } \\
\text { interaction between participants. }\end{array}$ & 5.88 & - & - & 23.53 & 70.59 \\
\hline $\begin{array}{l}\text { There seemed to be sufficient } \\
\text { interaction between students and the } \\
\text { instructor. }\end{array}$ & - & - & 5.88 & 47.06 & 47.06 \\
\hline $\begin{array}{l}\text { The sessions were appropriate in } \\
\text { length. }\end{array}$ & - & 5.88 & 5.88 & 41.18 & 47.06 \\
\hline $\begin{array}{l}\text { The registration process was easy to } \\
\text { understand. }\end{array}$ & - & - & - & 11.76 & 88.24 \\
\hline $\begin{array}{l}\text { The BOW staff members were } \\
\text { helpful and courteous. }\end{array}$ & - & - & - & 11.76 & 88.24 \\
\hline
\end{tabular}




\section{Teacher Specific Workshop Track}

Four questions were used to determine how participants felt regarding the workshop structure. Table 30 summarizes the percent responses made on a five-point Likert scale where responses ranged from Strongly Disagree to Strongly Agree.

The responses to this series of questions were perceived as exceedingly positive. All participants (100\%) agreed to these four statements. Participants (100\%) indicated that the BOW workshop format is effective for 'teacher specific' workshop tracks. Participants (100\%) indicated that they would be interested in other BOW teacher specific workshop tracks and that they would consider attending other BOW workshops that focused on another species. Finally, all participants (100\%) indicated that this workshop would influence their future teaching.

Additional room was left for teachers to expand on their answer to the question "I would be interested in other BOW teacher specific workshop tracks" by asking "why or why not?" Written comments to this portion of the question can be found in Appendix I. 
Table 30. The degree to which participants agree or disagree with the following statements regarding the teacher specific workshop track (n=17 expressed in Percent).

\begin{tabular}{|c|c|c|c|c|c|}
\hline Statement & $\begin{array}{l}\text { Strongly } \\
\text { Disagree }\end{array}$ & Disagree & Neutral & Agree & $\begin{array}{c}\text { Strongly } \\
\text { Agree }\end{array}$ \\
\hline $\begin{array}{l}\text { The BOW workshop format is } \\
\text { effective for 'teacher specific' } \\
\text { workshop tracks. }\end{array}$ & - & - & - & 52.94 & 47.06 \\
\hline $\begin{array}{l}\text { I would be interested in other BOW } \\
\text { teacher specific workshop tracks. }\end{array}$ & - & - & - & 47.06 & 52.94 \\
\hline $\begin{array}{l}\text { I would consider attending other } \\
\text { BOW workshops that focused on } \\
\text { another species. }\end{array}$ & - & - & - & 29.41 & 70.59 \\
\hline $\begin{array}{l}\text { This workshop will influence my } \\
\text { future teaching. }\end{array}$ & - & - & - & 23.53 & 76.47 \\
\hline
\end{tabular}




\section{$\underline{\text { Session Effectiveness }}$}

We wanted to be able to rank the workshop sessions in terms of overall effectiveness (most helpful or useful) to the teacher participants. The teachers were asked to rank the sessions on a scale of 1 to 7 , with 7 being the most helpful/useful and 1 being the least helpful/useful. Each session's scores were added up individually and then divided by the total possible points that each session could receive. The results are displayed in Figures 1-3. Workshop sessions are located on the $\mathrm{x}$-axis. Percent response is located on the y-axis. Fourteen participants successfully filled out this portion of the overall workshop evaluation, therefore $n=14$.

Teachers were asked to indicate which workshop sessions were most helpful or useful in understanding about prairie chicken ecology and conservation (Figure 1). Participants indicated that "Prairie Chicken Viewing" (95\%), "Prairie Habitat" (78\%), and "Historical Perspectives" (74\%) were the most helpful sessions in terms of understanding prairie chicken ecology and conservation. Participants indicated that "Environmental Education" (31\%) and "Curriculum Development" (22\%) were the least helpful or useful in understanding about prairie chicken ecology and conservation.

Teacher participants were then asked to indicate which workshop sessions were most helpful or useful to them as an educator (Figure 2). Again, participants indicated those same three sessions, "Prairie Chicken Viewing" (92\%), "Prairie Habitat" (73\%), and "Historical Perspectives" (72\%) as the most helpful sessions to them as an educator. Similarly, "Environmental Education" (34\%) and "Curriculum Development” (23\%) were the least helpful or useful to them as an educator. 
Finally, participants were asked to rank the workshop sessions in terms of most helpful or useful to them personally (Figure 3). As seen with the previous two questions, the top three sessions indicated as the most helpful or useful to participants personally was "Prairie Chicken Viewing" (95\%), "Prairie Habitat" (73\%), and "Historical Perspectives" (71\%). Again, the two classes indicated as the least helpful to them personally were "Environmental Education" (33\%) and "Curriculum Development" $(22 \%)$. 
Figure 1. A ranking of workshop sessions in terms of overall effectiveness (most helpful/useful) to participants' understanding about prairie chicken ecology/conservation $(n=14)$.

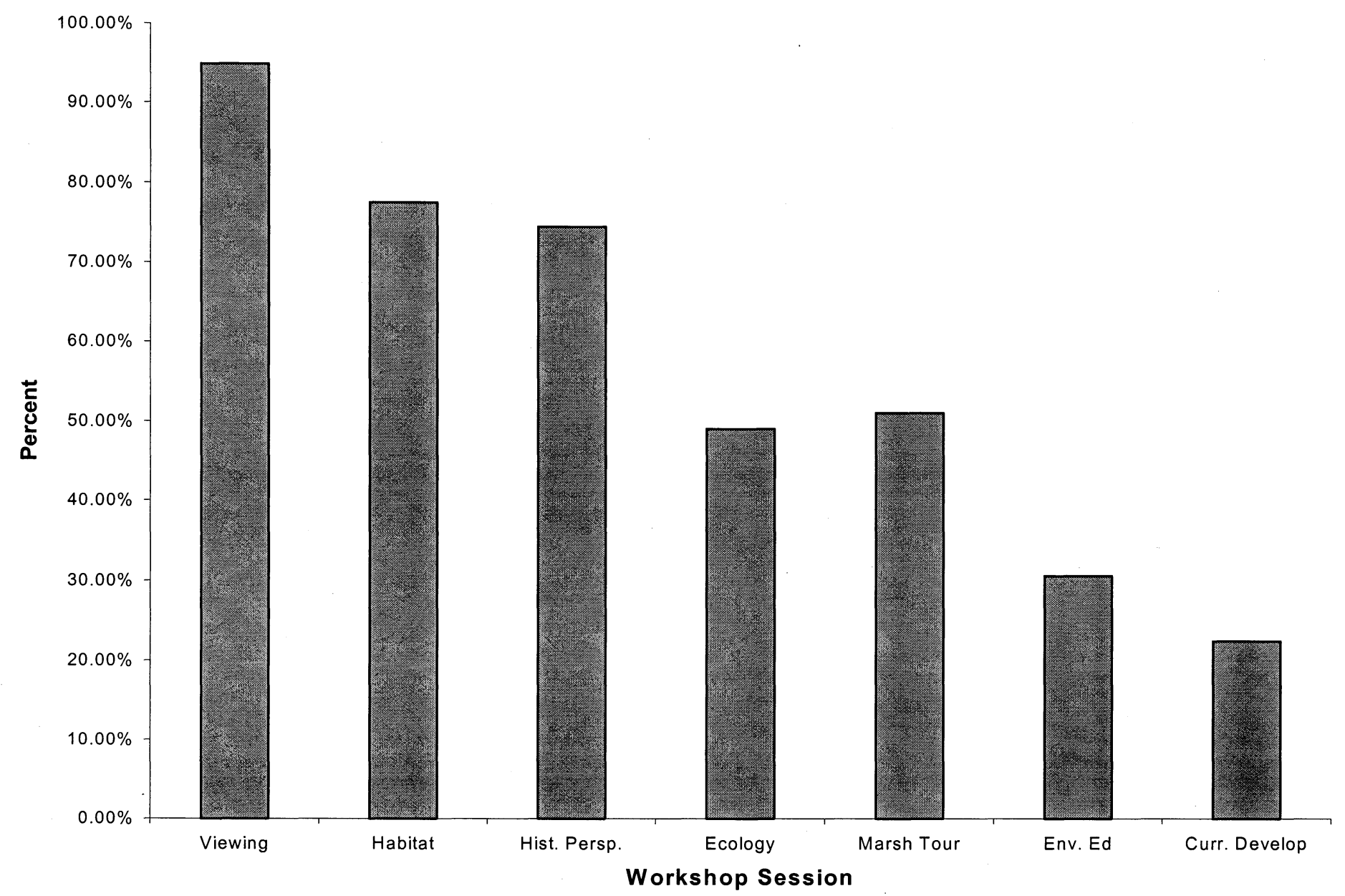


Figure 2. A ranking of workshop sessions in terms of overall value (most helpful/useful) to participants as an educator $(\mathrm{n}=14)$.

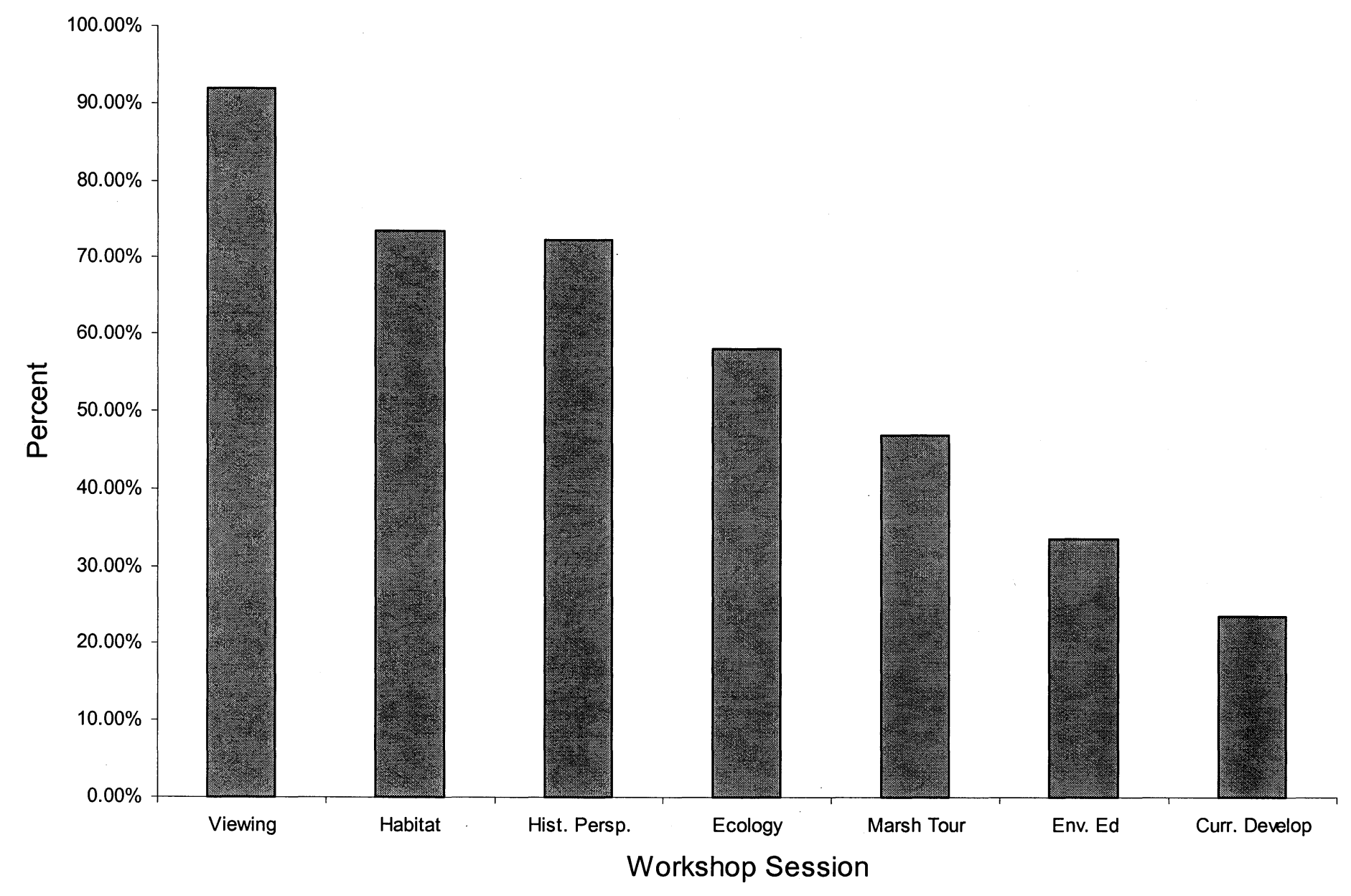


Figure 3. A ranking of workshop sessions in terms of overall value (most helpful/useful) to participants personally ( $n=14)$.

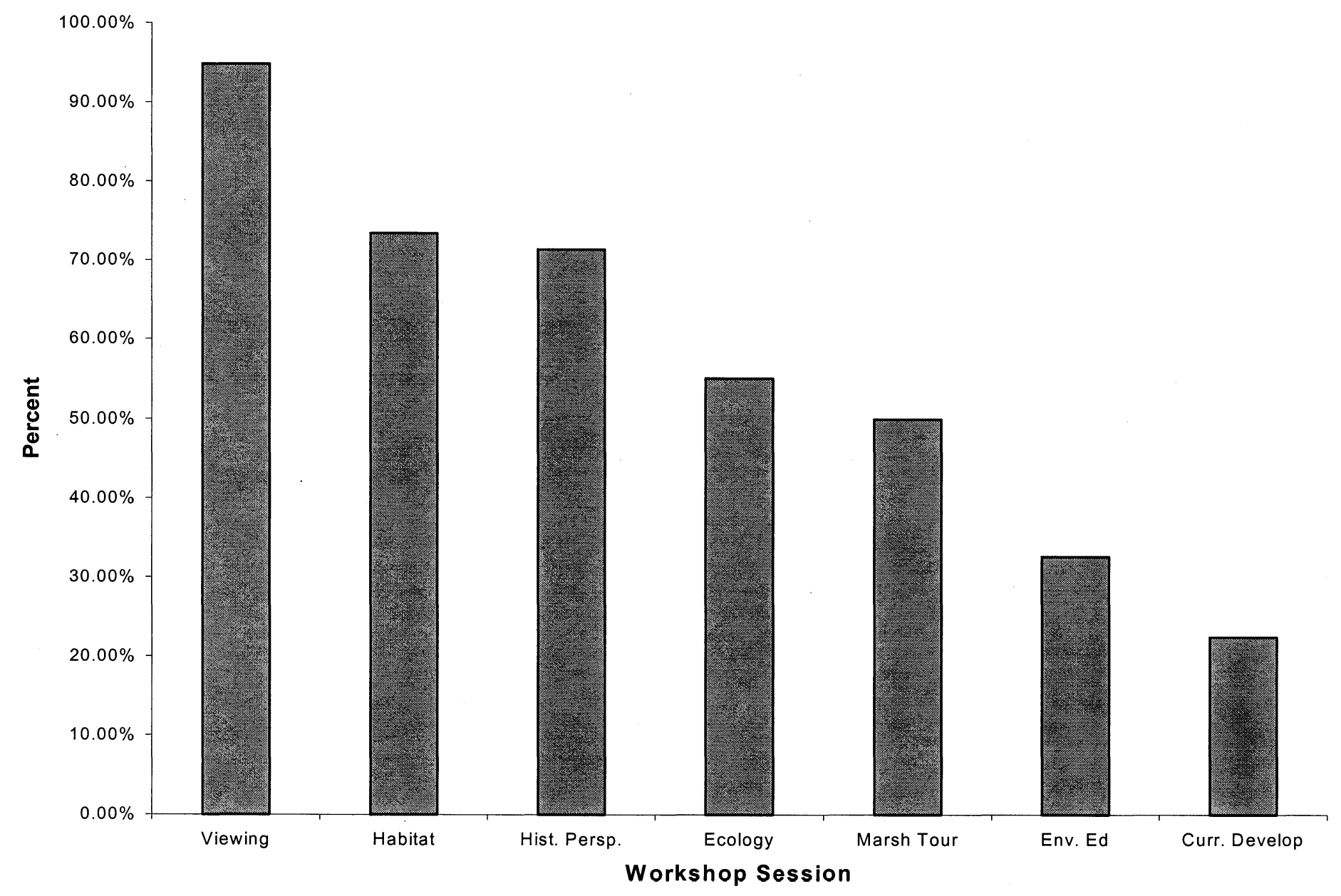




\section{$\underline{\text { Additional Comments }}$}

Six open ended questions regarding the workshop overall were asked in order to determine what participants liked most about the workshop, what aspects of the workshop could be improved, how they will apply the information gained into their professional and personal lives, how they will infuse the information gained into their curriculum, and if they would recommend this workshop to a colleague or friend. Responses to these questions were generally positive and included some suggestions to help improve the workshop for consecutive years.

Participants were asked to comment on what they liked most about the workshop (Table 31). Many participants indicated they enjoyed viewing the prairie chickens and the prairie habitat session taught by Bob Rosenfield. In addition, many participants commented on the organization of the workshop as something they liked most.

Participants were asked to comment on what aspects of the workshop could be improved (Table 32). Multiple participants made comments about the assignment requirement in order to receive one-credit. In addition, it was suggested that more free time be allotted after returning from viewing the prairie chickens.

When asked if they would recommend this workshop to a colleague or friend, all responding participants indicated that they would (Table 33). Table 34 represents comments teacher participants made when asked how they would use the information gained during the workshop in their personal or professional life. Participants mentioned sharing the information with family and students. In addition, many indicated a desire to view the prairie chickens again. 
Participants were asked if they intend to infuse the information gained in this workshop into their classrooms and how they will do so (Table 35). Participants commented on different ways they would use various parts of the workshop information into their classroom. Finally, Table 36 displays overall comments made by participants. Most comments were very positive regarding the workshop and resources. The only comment that was not very positive indicated that the instructors needed more time (i.e. longer sessions) and that the one-credit assignment is intimidating. 
Table 31. Participants' comments when asked what they liked most about the workshop $(\mathrm{n}=16)$.

\section{Response}

- Organization and ability to apply what we learned. An outstanding opportunity to go in more depth about the topic.

- Prairie chicken viewing.

- Its thoroughness.

- I liked the prairie chicken viewing and tour of the Hamerstroms' home.

- Information, organization, sharing, location.

- Viewing prairie chickens!! Grasslands section with Rosenfield.

- Well organized but flexible. The viewing of the booming.

- Time in the blinds. Discussions with peers.

- Chicken observations, tour, interaction with staff and participants.

- Viewing the booming grounds.

- Watching chickens.

- Viewing the chickens. Tour of Hamerstrom home.

- Viewing the birds.

- I enjoyed observing the chickens.

- Bob's talk.

- Viewing prairie chickens and discussion with Bob Rosenfield. Hands-on experience and discussion with experts. 
Table 32. Participants' comments when asked what aspects of the workshop could be improved $(n=13)$.

\section{Response}

- Curriculum development. Make the requirements realistic.

- Longer morning break to rest after prairie chicken viewing.

- Possibly the tour of the marsh, possibly extend into a hike.

- The assignment is too detailed for this amount of credit and time to finish it.

- Assignment length, credits.

- Assignment!! Length and nature of sessions - get away from lecture style, more hands on.

- More "teacher ready" materials - not the binder, in classes - overheads, worksheets, etc.

- More time for interactions. Hands-on telemetry. Hamerstrom home visit was too long.

- More time needed to cover the portfolio project.

- The assignment is inappropriate for the amount of time given. The session by Dr. Ginnett was very teacher centered and content driven. It was too fast paced and lacked necessary participant participation.

- Alternate schedule for those who are not staying on site.

- A little more free time after viewing prairie chickens and coffee (very minor suggestion).

- Shorter assignment for 1 credit. 
Table 33. Participants' comments when asked if they would you recommend this workshop to a colleague or friend and why or why not $(n=15)$.

\section{Response}

- Yes, incredibly practical, fun and well organized.

- Yes, it was one of the best wildlife courses I have ever had in 15 years.

- Yes, the interconnections to all subject matter.

- Yes. Interesting content and well managed.

- Yes with a word about the assignment - find out more information before hand.

- Yes, if assignment is changed.

- Yes, excellent look at GPC.

- Yes. Prairie chickens may not be around in 10 years. Some of my friends like this stuff more than I do.

- Yes - unique wildlife experience.

- Yes, definitely.

- To some, the performance task...its depth and extent might give many pause.

- Yes, I thought the information that I gained and attitudes that I acquired were very valuable and rewarding.

- Yes, fun and useful. I hope I can work it into my course.

- Yes, important to stay up to date.

- Yes! I learned a lot. 
Table 34. Participants' comments when asked how they will apply information gained during this workshop into their personal or professional life $(n=14)$.

\section{Response}

- Personal - I will share with friends, colleagues, and I want my daughter to watch prairie chickens booming one day.

- Passing knowledge, deeper appreciation.

- I'll go view chickens again. I will teach or use info in curriculum

- It definitely applies. It provided necessary information for personal and professional use. It gave me needed resources for what I'm teaching.

- Improved my own land ethic and understanding of conservation. Professionally I will use this info in my class.

- Infuse in wildlife class plus I interact quite a bit with our environmental instructor.

- I know more about prairie chickens. I'd like to come back to count chickens again and bring other groups of students.

- Teaching, farming/grazing practices, family experiences.

- Will introduce to family members, will infuse info into course work

- I will try to integrate it into teaching. Personally, I will be particularly attuned to grassland/prairie issues and info.

- Yes.

- In my personal life I will use the inspiration and information to support my environmental science.

- I would like to bring family to a chicken count. I will share my experience with students and would like to integrate more EE into my class.

- I will definitely infuse the material into my classroom activates and have with students!! 
Table 35. Participants' comments when asked if they intend to infuse the information gained in this workshop and how they will do so $(n=15)$.

\section{Response}

- I'll be using this in my program to develop a mini track.

- Lesson plan on wildlife success stories with field trip to help with research.

- I'll infuse it into science or WI history curriculum.

- Sharing information with other teachers.

- Ecology class material, environmental club field trip!

- Better look at WI threatened and endangered plants/animals. Look at DNR's role in habitat management.

- Population studies, exercises in graphing. Action for environmental club.

- Summer school, Outdoor Ed activities. Spring visit to booming grounds.

- Will use prairie habitat as end of year authentic assignment for Biology. Murals, virtual tours, native species, vertebrate comparative anatomy. Will use info for discussion of ethical conservation and biodiversity.

- I will use the lesson plans written for the performance assessment.

- Background info taught beforehand. Field trip to the Hamerstrom house, on location sketching and painting. Historical aspects of the personalities.

- I may use the prairie chicken as a model organism for various purposes in class.

- I'm hoping to rework some of classification to infuse more appreciation of biodiversity.

- In ecosystem units and biodiversity.

- Use with population studies unit, genetics unit and habitat restoration. 


\section{Response}

- Thank you, it was excellent.

- It was awesome!

- Thank you. Yet, unrealistic course assignment expectations. Also, Dr. Ginnett underestimates her veteran audience. She provided some good source material, yet most of her lecture was much more oriented to a high school student/preenvironmentally educated audience. She may benefit from being an audience member of her audience.

- Well done - it was a big project to organize. Your efforts are really appreciated!

- Thanks!

- Excellent! Very good workshop!

- Well done, just supply some extra WD40 for the bed springs. Curriculum session very long winded and condescending.

- Great Job!

- Great experience - Thanks!

- All instructors needed more time...Portfolio project is intimidating.

- Great resources and hands on stuff!!! It really helps as a busy educator.

- Excellent.

- Absolutely great! - Well organized. 


\section{Prairie Chicken ResourCe BINDER}

The resource binder consisted of four main parts: printed materials, video, $\mathrm{CD}$ Rom, and prairie seed packets. The resource binder table of contents can be found in Appendix J.

\section{$\underline{\text { Printed Materials }}$}

The printed materials were divided into five main sections using three ring binder dividers. The sections were as follows: Prairie Chicken Ecology, Prairie Habitat, The Hamerstroms, Environmental Education, and Sample Activities. Each section includes relevant literature such as professional journal articles, newspaper articles, book chapters, maps, and other various materials. Each section contained its own table of contents. The table of contents for each section briefly described what references could be found in that section and in what order. In addition, the table of contents page included relevant citations indicating where each source was found. Finally, a resources page was created for each of the five sections. The table of contents and resources page can be found in the following Appendices: Prairie Chicken Ecology (Appendix K), Buena Vista Marsh \& Prairie Habitat (Appendix L), The Hamerstroms (Appendix M), Environmental Education (Appendix N), and Sample Activities (Appendix O).

$\underline{\text { Video }}$

The VHS video that was created for this workshop contains two 30-minute videos, totaling 1 hour of footage. The first segment, entitled "Wisconsin Prairie Chicken: A Cause for Preservation" was produced by the Wisconsin Department of 
Natural Resources in 1988. This film depicts greater prairie chicken ecology, prairie/grassland habitat, and the conservation efforts to save this unique species. This film also contains interviews with many individuals who dedicated their lives to researching the prairie chickens, including Frances and Frederick Hamerstrom.

The American Museum of Natural History Library produced the second 30minute clip, entitled "Sunrise Serenade" in 1950. This film contains footage of greater prairie chickens booming, as well as the booming activities of two other grouse species. Finally, there is a unique footage of a traditional Native American prairie chicken dance.

\section{$\underline{\text { CD Rom }}$}

The researcher created the compact disk exclusively for this resource binder. This disk contains audio files, video files, still photos, and census data of greater prairie chickens. All still photos and digital video clips were taken and arranged by the researcher. The spreadsheet containing the census data was created by the researcher using the 2002 census counts published by the Wisconsin Department of Natural Resources. Census data is located in a Microsoft Excel spreadsheet, still photos are JPEG files, audio files are Mp3 files, and video files are MPEG files. Both audio and video files can be accessed using Microsoft Media Player. Several versions of Microsoft Media Player were included on the CD Rom for downloading to the user's computer.

\section{Prairie Seed Packets}

Prairie seeds were collected by the researcher in the fall of 2002 in Central Wisconsin. Six seed packets were included in the resource binder, so that each 
participant received a seed packet of the following seeds: Big blue-stem (Andropogon gerardii), Little blue-stem (Schizachyrium scoparium), Blazing-star (Liatris aspera), Yellow coneflower (Ratibida pinnata), Lead plant (Amorpha canescens), and Whorled milkweed (Asclepias verticillata) 


\section{BOOMING GROUND VIEWER DEMOGRAPHICS}

The viewer demographic survey was completed by prairie chicken viewers directly after their viewing session and was turned in before they left the Buena Vista Marsh. In 2002, 219 viewers participated in the viewing program and 136 returned surveys for a return rate of $62 \%$. Only those evaluations $(\mathrm{n}=136)$ were used for data analysis in 2002. In 2003, 230 viewers participated in the viewing program and 217 participants returned surveys for a return rate of $94 \%$. Only those evaluations $(n=217)$ were used for data analysis in 2003.

\section{Descriptive Demographics}

The first part of this survey served to gather general descriptive characteristics of the prairie chicken viewers such as sex, age, and residential setting in which they live. Table 37 shows fairly even sex ratios for both years. In $2002,52 \%$ of the viewers were females and $48 \%$ were males. In 2003 there were more male viewers (53\%) versus female viewers $(47 \%)$.

Among the 2002 participants, $12 \%$ were under the age of $20,24 \%$ were in their 20's and 30's (Table 37). Viewers in their 40's to 50's made up the largest percentage at $46 \%$. Finally, $19 \%$ of the 2002 viewers were in their 60 's to 70 's. The mean age of 2002 viewers was 45.4 with a range of 9 to 79 years of age. The 2003 survey showed $15 \%$ of the viewers under the age of 20 . The largest percentage (46\%) was made up of viewers in their 20's and 30's. Those viewers between in their 40's and 50's comprised $31 \%$ of the group, while the remainder ( $8 \%$ ) were between the ages of 60 to 70 . The mean age of 2003 viewers was 35.9 with a range of 8 to 75 years of age. 
In 2002 , the largest percentage of participants (25\%) lived in a city with 25,000 to 99,999 people followed by $22 \%$ living in a community with 5,000 to 24,999 people (Table 38). The smallest percentage (6\%) lived in a suburb of a major city. In 2003, the largest percentage of participants (29\%) lived in a community with 5,000 to 24,999 people followed by $22 \%$ living in a city with 25,000 to 99,999 people. The smallest percentage lived in either a major city with over 100,000 people or a suburb of a major city (10\% each).

Table 37. Demographic characteristics of booming ground viewers 2002-2003 (2002 $\mathrm{n}=136,2003 \mathrm{n}=\mathbf{2 1 7})$.

\begin{tabular}{|c|c|c|c|c|}
\hline ' & \multicolumn{2}{|c|}{2002} & \multicolumn{2}{|c|}{2003} \\
\hline Characteristic & Frequency & Percent & Frequency & Percent \\
\hline \multicolumn{5}{|l|}{ Sex } \\
\hline Female & 71 & 52.21 & 101 & 46.54 \\
\hline Male & 65 & 47.79 & 116 & 53.46 \\
\hline \multicolumn{5}{|l|}{ Age } \\
\hline $1-9$ & 1 & 0.74 & 7 & 2.76 \\
\hline $10-19$ & 15 & 11.03 & 26 & 11.98 \\
\hline $20-29$ & 11 & 8.09 & 71 & 32.72 \\
\hline $30-39$ & 21 & 15.44 & 28 & 13.36 \\
\hline $40-49$ & 23 & 16.91 & 33 & 15.21 \\
\hline $50-59$ & 39 & 28.68 & 34 & 15.67 \\
\hline $60-69$ & 12 & 8.82 & 13 & 5.99 \\
\hline $70-79$ & 14 & 10.29 & 5 & 2.30 \\
\hline
\end{tabular}


Table 38. Description of area where viewers live $(2002 n=136,2003 n=217)$.

\begin{tabular}{lcc|cc}
\hline \multicolumn{1}{c}{ City Size } & 2002 & \multicolumn{2}{c}{2003} \\
& Frequency & Percent & Frequency & Percent \\
\hline Rural & 43 & 19.82 & 20 & 14.71 \\
Community with under 5,000 & 29 & 13.36 & 18 & 13.24 \\
Community with 5,000 to 24,999 & 47 & 21.66 & 40 & 29.41 \\
City of 25,000 to 99,999 & 55 & 25.35 & 30 & 22.06 \\
Major city of over 100,000 & 31 & 14.29 & 14 & 10.29 \\
Suburb of major city & 12 & 5.53 & 14 & 10.29 \\
\hline
\end{tabular}

\section{Education and Occupation}

Table 39 indicates the highest percentage of viewers in 2002 had either attended graduate or professional school (38\%) or had received an undergraduate college degree (38\%). This was followed by $12 \%$ of the viewers who were currently attending school and $11 \%$ of viewers who had received a GED or high school diploma. The lowest percentage of viewers had either marked completion of apprenticeship, trade school or similar program $(0.7 \%)$ or other $(0.7 \%)$. In 2003 the results were similar to the previous year's distribution. The highest percentage of viewers had received either an undergraduate college degree (29\%), followed closely by those who had received a graduate or professional degree (28\%), or a GED or high school degree $(27 \%)$. The remaining viewers were currently attending school (14\%), had completed an apprenticeship, trade school or similar program $(2 \%)$ or marked other $(0.5 \%)$.

In 2002, when asked to describe their current occupation, the largest group of responses (21\%) indicated that they were retired (Table 40$)$. This was followed by students (14\%) and by those involved with technical services (13\%). No viewers ( $0 \%)$ indicated that they were unemployed. In 2003, there was a shift as the largest group of 
viewers was students (44\%), followed by those in the educational field (15\%). No viewers $(0 \%)$ indicated clerical services as their means of employment.

Table 39. Highest level of formal education completed by viewers $(2002 \mathrm{n}=136$, $2003 \mathrm{n}=217$ ).

\begin{tabular}{lcc|cc}
\hline & \multicolumn{2}{c|}{2002} & \multicolumn{2}{c}{2003} \\
\multicolumn{1}{c}{ Education Level } & Frequency & Percent & Frequency & Percent \\
\hline Apprenticeship, trade school or & 1 & 0.74 & 4 & 1.84 \\
similar program & & & & \\
Currently attending (grade) & 16 & 11.76 & 31 & 14.29 \\
GED or high school diploma & 15 & 11.03 & 59 & 27.19 \\
Graduate or Professional school & 52 & 38.24 & 60 & 27.65 \\
Undergraduate college degree & 51 & 37.50 & 62 & 28.57 \\
Other & 1 & 0.74 & 1 & 0.46 \\
\hline
\end{tabular}

Table 40. Current occupation of viewers $(2002 n=136,2003 n=217)$.

\begin{tabular}{lcc|cc} 
& \multicolumn{2}{c|}{2002} & \multicolumn{2}{c}{2003} \\
\multicolumn{1}{c}{ Occupation } & Frequency & Percent & Frequency & Percent \\
\hline Clerical & 8 & 5.88 & 0 & - \\
Homemaker & 1 & 0.74 & 3 & 1.38 \\
Sales & 7 & 5.15 & 3 & 1.38 \\
Service & 11 & 8.09 & 21 & 9.68 \\
Technical & 18 & 13.24 & 13 & 5.99 \\
Professional & 10 & 7.35 & 13 & 5.99 \\
Educational & 14 & 10.29 & 33 & 15.21 \\
Retired & 29 & 21.32 & 12 & 5.53 \\
Student & 19 & 13.97 & 96 & 44.24 \\
Unemployed & 0 & - & 7 & 3.23 \\
Other & 16 & 11.76 & 11 & 5.07 \\
no response & 3 & 2.21 & 5 & 2.30 \\
\hline
\end{tabular}




\section{Travel and Accommodations}

Questions were asked of the viewers to determine how far they have traveled to view the prairie chickens and if they had stayed in a local area hotel the evening before their viewing experience. We also wanted to determine if prairie chicken viewing was the main focus of their trip, or if their viewing was part of a larger trip.

Results found in Table 41 indicate the distance traveled by viewers as well as the state in which they reside. For those viewers from Wisconsin, the city of residence was tabulated and those results can be found in Appendix P. In 2002, the largest percentage (37\%) traveled 1 to 50 miles to view the prairie chickens. This was followed by $101-150$ miles (27\%). The smallest percentage of viewers (3\%) traveled $251-300$ miles and $4 \%$ of the viewers traveled over 301 miles to view the prairie chickens. Similar results were seen in 2003 as $35 \%$ of the viewers traveled $1-50$ miles. This was followed by $23 \%$ of the viewers who traveled 51-100 miles. Approximately 7\% of the viewers traveled over 301 miles to view the prairie chickens.

Table 41 also indicates the state in which viewers reside. In both 2002 and 2003, the majority of viewers $(88 \%)$ reside in Wisconsin. Viewers also lived in neighboring states such as Iowa, Minnesota and Illinois. Finally, some viewers had traveled from as far as California and Canada to view the prairie chickens.

When asked if viewers stayed in a local area hotel the night before viewing the prairie chickens, less than half, $40 \%$ in 2002 and $23 \%$ in 2003 , indicated that they had (Table 42). The majority of viewers, $82 \%$ in 2002 and $76 \%$ in 2003 , indicated that prairie chicken viewing was not part of a larger trip. Finally, for the majority of viewers, $91 \%$ in 2002 and $96 \%$ in 2003, prairie chicken viewing was the main focus of their trip. 
Table 41. Distance traveled and State of residence of viewers $(2002 \mathrm{n}=136,2003$ $\mathbf{n}=\mathbf{2 1 7})$.

\begin{tabular}{lcc|cc}
\hline & \multicolumn{2}{c|}{2002} & \multicolumn{2}{c}{2003} \\
\multicolumn{1}{c}{ Characteristic } & Frequency & Percent & Frequency & Percent \\
\hline Distance & & & & \\
$1-50$ & 50 & 36.76 & 77 & 35.48 \\
$51-100$ & 17 & 12.50 & 50 & 23.04 \\
$101-150$ & 37 & 27.21 & 35 & 16.13 \\
$151-200$ & 16 & 11.76 & 32 & 14.75 \\
$201-250$ & 6 & 4.41 & 4 & 1.84 \\
$251-300$ & 4 & 2.94 & 4 & 1.84 \\
$301+$ & 6 & 4.41 & 15 & 6.91 \\
& & & & \\
State & 1 & 0.74 & - & - \\
California & - & - & 1 & 0.46 \\
Colorado & 5 & 3.68 & 3 & 1.38 \\
Illinois & 2 & 1.47 & - & - \\
Idaho & - & - & 10 & 4.61 \\
Iowa & 4 & 2.94 & - & - \\
Michigan & 4 & 2.94 & 10 & 4.61 \\
Minnesota & - & - & 1 & 0.46 \\
Montana & - & - & 1 & 0.46 \\
Ohio & - & - & 1 & 0.46 \\
Washington & 119 & 87.50 & 190 & 87.56 \\
Wisconsin & 1 & 0.74 & - & - \\
Canada & & & & \\
\hline
\end{tabular}


Table 42. Accommodations and intent of viewers $(2002 \mathrm{n}=136,2003 \mathrm{n}=217)$.

\begin{tabular}{|c|c|c|c|c|}
\hline \multirow[b]{2}{*}{ Characteristic } & \multicolumn{2}{|c|}{2002} & \multicolumn{2}{|c|}{2003} \\
\hline & Frequency & Percent & Frequency & Percent \\
\hline \multicolumn{5}{|c|}{$\begin{array}{l}\text { The night before viewing the prairie } \\
\text { chickens did you stay in a local area } \\
\text { hotel? }\end{array}$} \\
\hline Yes & 54 & 39.71 & 50 & 23.04 \\
\hline No & 82 & 60.29 & 167 & 76.96 \\
\hline \multicolumn{5}{|c|}{$\begin{array}{l}\text { Is this prairie chicken viewing } \\
\text { session part of a larger trip? }\end{array}$} \\
\hline Yes & 25 & 18.38 & 52 & 23.96 \\
\hline No & 111 & 81.62 & 165 & 76.04 \\
\hline \multicolumn{5}{|c|}{$\begin{array}{l}\text { Was prairie chicken viewing the } \\
\text { main focus of your trip? }\end{array}$} \\
\hline Yes & 124 & 91.18 & 208 & 95.85 \\
\hline No & 12 & 8.82 & 9 & 4.15 \\
\hline
\end{tabular}

\section{Outdoor Related Experiences}

Outdoor related recreation activities of the viewers are located in Table 43.

Participants were asked to mark all responses that apply which resulted in 572 responses in 2002 and 1047 responses in 2003.

In 2002, the three activities with the highest percentage participation rates were hiking (74\%), bird watching (70\%), and camping (62\%) (Table 43). Hunting (28\%) and boating (26\%) showed the lowest percentage participation. In 2003, the three activities with the highest percentage participation rates among viewers were the same as those in 2002 , in a slightly different order; hiking (81\%), camping (74\%), and bird watching (69\%). Boating (40\%) and hunting (34\%) again showed the lowest percentage participation rates. 
In 2002 , a total of $55 \%$ of participants indicated membership in environmental or conservation based clubs or organized groups (Table 44). International organizations received the most support from viewers in 2002. For example, The Nature Conservancy was supported by $31 \%$ of the participants. Audubon Society, another international organization was supported by $24 \%$ of the viewers, and the Sierra Club was supported by $21 \%$ of the viewers. In 2003 , slightly more than half $(52 \%)$ of the viewers indicated support for environmental or conservation clubs or organized groups. Again, the same three international organizations received the most support with $26 \%, 18 \%$ and $15 \%$ respectively. Smaller state organizations such as the Wisconsin Society for Ornithologists and various birding clubs received support in both years as well. A complete list of all clubs mentioned by viewers can be found in Appendix Q.

Table 43. Types of outdoor recreation in which viewers have participated (2002 $n=136,2003 n=217)$.

\begin{tabular}{lcc|cc}
\hline & \multicolumn{2}{c|}{2002} & \multicolumn{2}{c}{2003} \\
\multicolumn{1}{c}{ Outdoor Recreation } & Frequency & Percent & Frequency & Percent \\
\hline Hiking & 101 & 74.26 & 175 & 80.65 \\
Bird Watching & 95 & 69.85 & 150 & 69.12 \\
Camping & 84 & 61.76 & 161 & 74.19 \\
Canoeing & 68 & 50.00 & 138 & 63.59 \\
Photography & 66 & 48.53 & 119 & 54.84 \\
Fishing & 59 & 43.38 & 120 & 55.30 \\
Hunting & 38 & 27.94 & 73 & 33.64 \\
Boating & 36 & 26.47 & 87 & 40.09 \\
Other & 25 & 18.38 & 24 & 11.06 \\
\hline
\end{tabular}


Table 44. Environmental or conservation based clubs or organized groups of which viewers are presently a member $(2002 \mathrm{n}=136,2003 \mathrm{n}=217)$.

\begin{tabular}{lcc|cc}
\hline & \multicolumn{2}{c|}{2002} & \multicolumn{2}{c}{2003} \\
Environmental Club or Group & Frequency & Percent & Frequency & Percent \\
\hline Yes & 75 & 55.15 & 112 & 51.61 \\
No & 61 & 44.85 & 105 & 48.39 \\
& & & & \\
List & & & & \\
Audubon Society & 18 & 24.00 & 20 & 17.86 \\
Birding Clubs & 2 & 2.67 & 8 & 7.14 \\
Ducks Unlimited & 3 & 4.00 & 6 & 5.36 \\
International Crane Foundation & 4 & 5.33 & 1 & 0.89 \\
National Wildlife Federation & 8 & 10.67 & 8 & 7.14 \\
Nature Centers & 4 & 5.33 & 15 & 13.38 \\
Sierra Club & 16 & 21.33 & 17 & 15.18 \\
The Nature Conservancy & 23 & 30.67 & 29 & 25.89 \\
The Wilderness Society & 1 & 1.33 & 12 & 10.71 \\
Trout Unlimited & 3 & 4.00 & 8 & 7.14 \\
Wisconsin Society for & 5 & 6.67 & 10 & 8.93 \\
$\quad$ Ornithologists & & & & \\
\hline
\end{tabular}

Viewer Recruitment and Prairie Chicken Viewing Experience

When asked how they heard about the prairie chicken viewing opportunity, the highest percentage in both years, $48 \%$ in 2002 and $51 \%$ in 2003, indicated "other" as the source of information (Table 45). Of those who indicated what the other source was, the most common cited was, "teacher/professor," "spouse," or "undergraduate at UWSP." The second most common source from which viewers indicate hearing about the viewing opportunity was from a friend ( $45 \%$ each year). In 2002, remaining viewers indicated that they heard about the program from a magazine (18\%), newspaper $(12 \%)$ or the Internet (7\%). In 2003, those that did not indicate "other" or "friend" heard about the opportunity from either the newspaper or internet ( $6 \%$ each) or from a magazine $(4 \%)$. 
Participants were asked if they have ever viewed prairie chickens on the Buena Vista Marsh before (Table 45). In 2002, 29\% indicated that they had previously viewed prairie chickens on the Buena Vista Marsh. This percentage increased to 36\% in 2003. Conversely, each year, more than half of the participants had never before viewed the prairie chickens on the Buena Vista Marsh.

Table 45. Ways viewers heard about viewing opportunity and previous viewing experience $(2002 \mathrm{n}=136,2003 \mathrm{n}=\mathbf{2 1 7})$.

\begin{tabular}{lcc|cc}
\hline \multicolumn{1}{c|}{2002} & \multicolumn{2}{c}{2003} \\
\multicolumn{1}{c}{ Characteristic } & Frequency & Percent & Frequency & Percent \\
\hline $\begin{array}{l}\text { How did you hear about the prairie } \\
\text { chicken viewing opportunity? }\end{array}$ & & & & \\
$\quad$ Other & 65 & 47.79 & 110 & 50.69 \\
Friend & 61 & 44.85 & 97 & 44.70 \\
Magazine & 24 & 17.65 & 9 & 4.15 \\
Newspaper & 16 & 11.76 & 12 & 5.53 \\
Internet & 9 & 6.62 & 13 & 5.99 \\
& & & & \\
Have you ever viewed prairie & & & & \\
chickens on the Buena Vista Marsh & & & & \\
before? & & & & \\
$\quad$ Yes & 39 & 28.68 & 79 & 36.41 \\
No & 97 & 71.32 & 138 & 63.59 \\
\hline
\end{tabular}




\section{Information Packet}

We wanted to know if the information packet viewers received, prior to their viewing experience, was adequate in preparing them for their visit and if anything should be included or deleted from this packet. The results of items that viewers found most useful can be found in Table 46. Because viewers were asked to check all that apply, there were 373 responses in 2002 and 415 responses in 2003.

There was consistency between the years 2002 and 2003 in terms of what viewers indicated were the most useful parts of the information packet. In both years, viewers found the background information on prairie chickens to be the most useful as indicated by $61 \%$ in 2002 and by $75 \%$ in 2003 (Table 46 ). The second most useful portion of the information packet was the map and directions ( $57 \%$ in $2002,44 \%$ in 2003). Finally, the third most useful part of the information, as indicated by $35 \%$ of the viewers in 2002 and $30 \%$ of the viewers in 2003 was the list of accommodations \& what to bring.

The results of items that viewers found to be the least useful can be found in Table 47. Because viewers were asked to check all that apply, there were 114 responses in 2002 and 147 responses in 2003. In 2002, more than half of the viewers (54\%) chose "none" among the list as the least useful part of the information. Map and directions were chosen by $9 \%$ of the viewers as the least useful followed by the magazine story and list of accommodations \& what to bring ( $8 \%$ each). Again in 2003, more than half (51\%) of the viewers chose "none" as the choice among the list as the least useful part of the information packet. The magazine story was the next least useful item with $10 \%$ viewers choosing that item, followed by $9 \%$ of the viewers choosing the list of accommodations $\&$ what to bring as the least useful item in the information packet. 
Table 46. Part(s) of the information packet viewers found most useful (2002 $n=136$, $2003 n=169)$.

\begin{tabular}{lcc|cc}
\hline & \multicolumn{2}{c|}{2002} & \multicolumn{2}{c}{2003} \\
\multicolumn{1}{c}{ Information Packet } & Frequency & Percent & Frequency & Percent \\
\hline Background information on & 83 & 61.03 & 127 & 75.15 \\
prairie chickens & & & & \\
Census methods & 44 & 32.35 & 48 & 28.40 \\
Color brochure & 47 & 34.56 & 26 & 15.38 \\
List of accommodations \& What & 48 & 35.29 & 50 & 29.59 \\
$\quad$ to bring & 28 & 20.59 & 21 & 12.43 \\
Magazine story & 78 & 57.35 & 75 & 44.38 \\
Map \& Directions & 39 & 28.68 & 64 & 37.87 \\
Sample census & 6 & 4.41 & 2 & 1.18 \\
None & & & &
\end{tabular}

Table 47. Part(s) of the information packet viewers found least useful. (2002 $n=136$, $2003 \mathrm{n}=170$ ).

\begin{tabular}{lcc|cc}
\hline & \multicolumn{2}{c|}{2002} & \multicolumn{2}{c}{2003} \\
\multicolumn{1}{c}{ Information Packet } & Frequency & Percent & Frequency & Percent \\
\hline $\begin{array}{l}\text { Background information on } \\
\text { prairie chickens }\end{array}$ & 1 & 0.74 & 2 & 1.18 \\
Census methods & 1 & 0.74 & 1 & 0.59 \\
Color brochure & 3 & 2.21 & 10 & 5.88 \\
List of accommodations \& What & 11 & 8.09 & 16 & 9.41 \\
$\quad$ to bring & 11 & 8.09 & 17 & 10.00 \\
Magazine story & 12 & 8.82 & 11 & 6.47 \\
Map \& Directions & 1 & 0.74 & 3 & 1.76 \\
Sample census & 74 & 54.41 & 81 & 51.18 \\
None & & &
\end{tabular}




\section{Learning Experiences}

We wanted to determine if viewers felt they were learning information from both the information packet that is sent out as well as from their experience of viewing the prairie chickens. Four questions were used to determine how participants felt regarding any learning experiences from the information packet and visit to the booming ground. Tables 48 and 49 summarize the percent responses made on a five-point Likert scale where responses ranged from Strongly Disagree to Strongly Agree. The number of useable responses to these questions varied in the year 2003. Many did not respond to the questions regarding what they learned from the information packet. Many had written on the surveys that they were students and their professor did not give them copies of the packet before coming to view the prairie chickens. Thus, only surveys with recorded responses were used in these questions and the sample size for each is indicated.

In Table 48 we asked viewers if the information packets adequately prepared them for their visit to the booming ground. In $2002,89 \%$ of the viewers agreed with this statement. However, $5 \%$ strongly disagreed. In $2003,96 \%$ agreed with this statement while $0.6 \%$ strongly disagreed.

We also asked viewers if the information packet helped them learn about prairie chickens. In 2002, 87\% agreed that the information packet did help them learn about prairie chickens, while $3 \%$ strongly disagreed. In 2003, $93 \%$ agreed with this statement. Overall, the majority of viewers indicated that the information packet adequately prepared them for their visit and that it also helped them learn about prairie chickens. Viewers were also asked to indicate what they learned from the information packet. These written comments can be found in Appendix R. 
Table 49 summarizes the results to two statements regarding what viewers learned from their viewing experience and about their viewing experience overall. In $2002,92 \%$ of the viewers indicated that their visit to the booming ground helped them learn about prairie chickens. Conversely, $6 \%$ indicated that they strongly disagree to this statement. In $2003,98 \%$ agreed to this statement while $0.5 \%$ strongly disagreed.

In $2002,92 \%$ agreed to the statement, "my experience viewing the prairie chickens was satisfying." However, $4 \%$ strongly disagreed. In $2003,96 \%$ of the viewers agreed with the above statement, while $0.5 \%$ strongly disagreed. Overall, the majority of viewers from both years indicated that their viewing experience was satisfying. 
Table 48. The degree to which participants agree or disagree with the following statements regarding the information packet (2002 n=136, 2003 n=170 expressed in Percent).

\begin{tabular}{|c|c|c|c|c|c|c|c|c|c|c|}
\hline \multirow[b]{2}{*}{ Statement } & \multicolumn{5}{|c|}{2002} & \multicolumn{5}{|c|}{2003} \\
\hline & $\begin{array}{l}\text { Strongly } \\
\text { Disagree }\end{array}$ & Disagree & Neutral & Agree & $\begin{array}{c}\text { Strongly } \\
\text { Agree }\end{array}$ & $\begin{array}{l}\text { Strongly } \\
\text { Disagree }\end{array}$ & Disagree & Neutral & Agree & $\begin{array}{c}\text { Strongly } \\
\text { Agree }\end{array}$ \\
\hline $\begin{array}{l}\text { The information packet I } \\
\text { received adequately prepared } \\
\text { me for my visit. }\end{array}$ & 4.69 & - & 6.25 & 10.94 & 78.13 & 0.59 & - & 2.94 & 21.76 & 74.71 \\
\hline $\begin{array}{l}\text { The information packet helped } \\
\text { me learn about prairie chickens. }\end{array}$ & 3.36 & - & 10.08 & 18.49 & 68.07 & - & - & 6.47 & 33.53 & 59.41 \\
\hline
\end{tabular}

Table 49. The degree to which participants agree or disagree with the following statements regarding their visit to the booming grounds (2002 $\mathrm{n}=136,2003 \mathrm{n}=215$ expressed in Percent).

\begin{tabular}{|c|c|c|c|c|c|c|c|c|c|c|}
\hline & \multicolumn{5}{|c|}{2002} & \multicolumn{5}{|c|}{2003} \\
\hline Statement & $\begin{array}{l}\text { Strongly } \\
\text { Disagree }\end{array}$ & Disagree & Neutral & Agree & $\begin{array}{l}\text { Strongly } \\
\text { Agree }\end{array}$ & $\begin{array}{l}\text { Strongly } \\
\text { Disagree }\end{array}$ & Disagree & Neutral & Agree & $\begin{array}{c}\text { Strongly } \\
\text { Agree }\end{array}$ \\
\hline $\begin{array}{l}\text { My visit to the booming } \\
\text { grounds helped me learn about } \\
\text { prairie chickens. }\end{array}$ & 5.51 & - & 2.36 & 11.02 & 81.10 & - & - & 1.86 & 19.07 & 78.60 \\
\hline $\begin{array}{l}\text { My experience viewing the } \\
\text { prairie chickens was satisfying. }\end{array}$ & 3.94 & - & 3.94 & 8.66 & 83.46 & 0.47 & - & 3.26 & 13.49 & 82.33 \\
\hline
\end{tabular}




\section{$\underline{\text { Returning Visits }}$}

We wanted to know if viewers would personally return for another visit, and if they would encourage others to participate in this viewing opportunity. Table 45 summarizes these results. It was felt that these answers serve as a good indication to the overall satisfaction with the viewing experience. Viewers were asked the question "why or why not" to follow their answers to the questions below. These written comments can be found in Appendix R.

In $2002,82 \%$ of the viewers indicated that they would return for another visit (Table 50). This number increased to $92 \%$ in 2003 . When asked if they would encourage others to participate in this opportunity, $94 \%$ of the viewers in 2002 indicated that they would. In 2003 , this number rose to resounding 'yes' with $99 \%$ of the viewers indicating that they would encourage others to participate.

Table 50. Viewer opinion on returning for another visit and encouraging others to visit. (2002 $\mathrm{n}=120,2003 \mathrm{n}=\mathbf{2 1 5})$.

\begin{tabular}{lcc|cc}
\hline \multicolumn{1}{c|}{ Characteristic } & Frequency & Percent & Frequency & Percent \\
\hline Would you return for another visit? & & & & \\
$\quad$ Yes & 112 & 82.35 & 199 & 91.71 \\
No & 8 & 5.88 & 16 & 7.37 \\
no response & 16 & 11.76 & 2 & 0.92 \\
Would you encourage others to & & & & \\
participate in this opportunity? & & & & \\
Yes & 128 & 94.12 & 214 & 98.62 \\
No & 1 & 0.74 & 1 & 0.46 \\
no response & 7 & 5.15 & 2 & 0.91 \\
& & & & \\
\hline
\end{tabular}




\title{
DISCUSSION
}

The goal of this project was to expand teachers' level of knowledge and intent to infuse prairie chicken education into Wisconsin classrooms. Using a prairie chicken education workshop, a resource binder and a viewer demographic survey, this project was able to increase teachers' understanding of prairie chicken ecology and conservation, create materials for teachers to use in the classroom, and develop an understanding of the demographics of prairie chicken viewers on the Buena Vista Marsh.

\section{BOW PRAIRIE CHICKEN WORKSHOP}

\author{
2002 Pilot Workshop
}

In April 2002, a pilot Prairie Chicken Workshop was held at the Wisconsin Lions camp in Rosholt, Wisconsin. This trial run was meant to provide insight into the logistics and needs of participants and instructors during the planned 2003 workshop. This pilot workshop proved extremely valuable in planning the upcoming workshop and is highly recommended to those planning similar programs.

\section{Prairie Chicken: Conservation and Courtship Workshop Track}

\section{Pre-Workshop Evaluation}

The pre-workshop evaluation provided critical information on the participants' prior knowledge of prairie chickens before attending the workshop. In addition, it provided useful descriptive demographics and information on teachers' educational 
background, teaching experiences and outdoor related experiences, all of which can be used for recruitment to similar workshops.

\section{Descriptive Demographics}

In order to better plan for and recruit participants to similar BOW workshops, descriptive demographics were gathered for participants in this workshop. Usually males choose not to participate in BOW workshops, making all participants female. However, males showed a great deal of interest in the prairie chicken workshop. The workshop had 17 participants, nine of whom were male (Table 1). Initially there were some concerns that the presence of males at a typically all female workshop might change the learning environment created during a typical BOW workshop. During the 2003 prairie chicken workshop, coordinators felt that the male participants did not affect the learning environment within the prairie chicken workshop track, nor across workshop tracks, whatsoever.

More than half of the participants (65\%) in the prairie chicken workshop track were over the age of 40 (Table 1). This is a typical age structure for BOW workshop participants. People this age effectively learn and benefit from the BOW workshop format and style. The presence of older teachers may indicate that teachers are looking to continue their learning experiences. The fact that more than half of the participants were over the age of 40 may indicate that teachers are actually looking to come back to an educational environment to gain additional knowledge and resources.

It is interesting to note that $35 \%$ of participants indicated spending most of their life in a rural environment (Table 2). This is likely the result of workshop recruitment 
aimed at the local rural areas. Similarly, the majority of the area surrounding Stevens Point could be considered rural.

\section{Educational Background}

Participants in the Prairie Chicken Workshop were highly educated overall with the majority (71\%) having already completed a Master's degree (Table 3 ). In addition, a high number of teachers $(76 \%)$ had taken college courses in conservation of natural resources, while an overwhelming $100 \%$ had completed courses in environmental education (Table 4). Finally, approximately 13 of the 17 participants had taken an environmental education course from Dr. Daniel Sivek, EE session instructor for the workshop (Daniel J. Sivek, Professor of Environmental Education, personal communication, April 2003). This shows that teachers who are trained in the field of natural resource conservation and environmental education are looking to continue their educational experiences in these fields. It is unclear, however, whether teachers are looking to expand their knowledge in order to receive continuing education credits, or have a personal desire to bring the highest quality education to their students.

\section{Teaching Experiences}

The majority of teachers (76\%) indicated that they teach biological or environmental science (Table 5). This was expected, as brochures were bulk mailed directly to biology and science teachers in the surrounding school districts. However, the inclusion of teachers teaching other subjects $(24 \%)$ was welcomed. While participants who do not normally teach biological or environmental sciences may not have had the 
same background knowledge coming into the workshop, there was no indication that they did not receive the same benefits from the workshop. Further, there was no indication that they felt this workshop was inappropriate for the subjects they teach. Therefore, it is believed that teachers of many different subjects could benefit from future workshops.

We were interested in addressing the gap in curriculum and materials for teaching grades 9-12. This was decided after a preliminary review of available environmental curriculum found substantially more environmentally based curriculum for teaching elementary and middle school students. In addition, we wanted to encourage teachers to bring their students to the booming grounds on the Buena Vista Marsh in subsequent years. It was believed that older students were better suited for this field experience primarily because it requires a bit more maturity on the part of the viewer. Finally, it was believed that the prairie chicken population and its associated environmental issues could be studied and evaluated, in various subjects, at a level appropriate for the $9-12^{\text {th }}$ setting.

Teachers from 12 different school districts participated in the workshop (Table 8). While recruiting participants from the five counties surrounding Stevens Point was a priority, teachers from outside the immediate area were welcome. Recruitment of teachers was conducted by several methods, however, the method indicated most often was 'other' (29\%) and participants most commonly mentioned "a brochure in my box at school" (Table 9). The brochure was made specifically for this workshop track and was bulk mailed to the five counties surrounding Stevens Point. Of the other recruitment methods, the exhibit at the WEAC conference in Madison, Wisconsin did not seem to be a successful recruiting technique, as only one participant indicated this was how they found out about the BOW program. While this conference was large and included 
teachers who taught many subjects at all grade levels, there was considerable cost invested in this exhibit, including travel, lodging and exhibiting fees. It is felt that these expenditures could be better used for other smaller scale exhibits similar to the WAEE

conference. These conferences tended to be smaller, allowing more time to interact with individuals interested in the program, and include a more selective target audience.

\section{Outdoor Related Experiences}

All participants indicated that they participated in at least one outdoor related recreation activity over the past year while most participants indicated more than one activity (Table 11). In addition to outdoor activities, participants showed interest in environmental and conservation activities through reading conservation magazines, involvement in conservation clubs or groups, or watching natural resource oriented television programs.

It is interesting to note that $35 \%$ of participants subscribe to Wisconsin Natural Resources Magazine, published by the Wisconsin DNR (Table 12). This magazine is available at a discounted rate to schools, and is currently distributed to many schools in the state. Therefore, this is identified as a key conduit in reaching both teachers and students with information about both the BOW program and opportunities associated with prairie chickens. This study has shown that teachers most likely to participate in a program such as this already participate in outdoor related activities and consult outdoor related media. 


\section{Post-Workshop Evaluation}

The post-evaluation was used to measure participants' changes in four areas: expectations and beliefs of the BOW program, topics and activities included in the BOW program, natural resource management statements, and prairie chicken knowledge questions.

\section{Expectations and Beliefs about the BOW Program}

Four of the seven questions used to determine what participants know and feel about the BOW program and what they can expect from their workshop experience showed tremendous support for the program. All participants (100\%), on the postworkshop evaluation, agreed with the following four statements, and all four statements showed a significant $($ alpha $=0.05)$ shift in distribution between pre- and post- workshop evaluations. First, all participants believed that the BOW program will benefit them personally. All believed that the BOW program will benefit their work. All felt confident in their ability to teach about prairie chickens, and finally, all felt the BOW program met their expectations (Table 15).

The responses to the above statements not only reflect the positive reception of the prairie chicken workshop track, but also reaffirm the continued successes of the BOW program as an educational program. All teachers agreeing that the program benefited them both personally and professionally shows that this workshop presented an effective educational opportunity for teachers. Perhaps the most positive reinforcement of the workshop was all teachers feeling confident in their ability to teach about prairie chickens. This indicates the workshop effectively taught what it had intended because not only did 
teachers gain knowledge associated with prairie chickens, but they gained the confidence to then feel comfortable bringing that knowledge to their classrooms. Finally, all participants agreed that the BOW program met their expectations, which is a result that is hoped for in every BOW workshop. Because the program strives to do whatever is necessary so that all participants feel that their expectations were met, this statistic shows that the BOW program met one of its key goals.

Topics and Activities Included in the BOW Program

Overall, participants placed a higher value on the topics and activities included in the BOW program after experiencing them during the workshop (Table 16). This indicates that participants greatly appreciated the topics and activities. While all classes showed a higher value after the workshop, four classes in particular were rated by the participants as being the most valuable. Individuals involved with prairie chickens and the Buena Vista Marsh tour rated both as the most valuable topic and activities (71\%) to participants. This was followed closely by historical issues of prairie chickens and current environmental issues associated with prairie chickens (65\%). These statistics show an interesting trend toward sociological themes. While the majority of teachers taught "hard science" subjects, and would be expected to most appreciate the hands on ecological themes of prairie habitat and prairie chicken ecology sessions, teachers placed the most value on the sociologically themed topics.

Again, all classes were seen to increase in the participants' perception of value after the workshop indicating that all sessions were considered useful. Some explanations for the increase in value include the quality of instruction. Some topics may 
have seemed less interesting or valuable to participants before the workshop, yet became increasingly more valuable during the actual instruction due to the resources and materials presented by the instructors. Another explanation may be that participants simply didn't know what to expect of the topics and activities before the workshop. Perhaps the topic or activity was misinterpreted, or the title did not do the actual instruction justice, and the true value was not realized until completion of the activity. Overall, these statistics show the value in all topics and activities included in the workshop and suggest that the same or very similar topics should remain in future workshops.

\section{Natural Resource Management Statements}

Eight questions used to measure the degree to which participants agreed or disagreed with statements regarding natural resources management were not useful in evaluating the workshop. However, they were useful in evaluating the participants' background beliefs. Two statements were interesting to note in this section. First, all participants agreed that they want to help solve environmental problems, with $82 \%$ strongly agreeing (Table 17). This shows that the workshop participants are actively choosing to become involved in solving environmental problems. Agreeing with this statement indicates some level of awareness of environmental problems, willingness to learn how to solve those problems, and the self-confidence to act. In a similar question, all participants disagreed with the statement that there is not much they can do that will help solve environmental problems, with $82 \%$ strongly disagreeing. Again, workshop participants indicated a belief that there is something that they can do to help solve 
environmental problems, which perhaps was one of the reasons they chose to participate in this environmentally based workshop. In all eight statements, there was little change in the responses before and after the workshop. This is probably because of the highly advanced nature of the participants' educational backgrounds. They had already formed many strong beliefs and values before attending the workshop.

\section{$\underline{\text { Knowledge Questions }}$}

Participant knowledge scores increased in all topic areas following the completion of the workshop. Overall, the knowledge scores increased from $48 \%$ correct before the workshop to $83 \%$ correct after the workshop, indicating an overall increase by $35 \%$ (Table 18). Another way to look at the increase in knowledge scores is along a letter grade scale. Before the workshop, the average grade of participants was an F. Following the workshop this average grade rose to a B. This is a tremendous increase in overall percent correct answers. This shift clearly demonstrates knowledge gained during the workshop and confirms again the workshop's success.

Questions regarding the general ecology of prairie chickens showed the greatest percent change $(50 \%)$ in participant knowledge between pre- to post- workshop scores (Table 18). This was followed closely by questions regarding the management of prairie chickens (48\%). This does not come as a large surprise as this workshop was based on prairie chickens and it was assumed that teachers did not previously hold a tremendous amount of knowledge on the topic. After showing an increase in the basic understanding of prairie chicken ecology and management, participants demonstrated they were armed 
with the knowledge and skills necessary to teach about prairie chickens in their classrooms.

Questions regarding environmental education showed the smallest percent change (24\%) in participant knowledge between pre- to post- workshop scores (Table 18). This can be explained by the fact that all participants had taken a college course in environmental education prior to the workshop, and $76 \%$ of the participants had taken an environmental education course from the workshop instructor. When planning the workshop, it was believed necessary to not only arm the teachers with knowledge about prairie chickens, but to give them the skills necessary to teach about what they learned during the workshop in their classrooms. The environmental education session not only covered the goal of EE and its history in Wisconsin, but also shared relevant resources to introduce teachers to different ideas and ways to incorporate the knowledge into their class. Unfortunately this statistic only shows that teachers in the areas surrounding UWStevens Point, a world-renowned center for EE research and instruction, are well versed in environmental education. It is possible that teachers in other localities do not have a strong EE background and therefore the $\mathrm{EE}$ instruction session is considered to be a valuable portion of the workshop.

\section{Overall Workshop Evaluation}

A post-evaluation was used to measure participants' opinion of the workshop, and to gather additional comments that could improve future workshops. Questions were asked regarding seven topics: BOW workshop content, workshop session content, 
workshop resources, one credit assignment, workshop structure, teacher specific workshop track, and session effectiveness.

\section{BOW Workshop Content}

Regarding the BOW workshop content, $100 \%$ of the participants agreed with the statements made in seven out of nine questions (Table 25). In the remaining two questions $94 \%$ of the participants agreed with the statements regarding the workshop content. The remaining $6 \%$ were neutral. Overall, these were extremely encouraging results indicating the workshop success in several ways. Specifically, participants' agreement with three statements should be highlighted. Two statements in this section addressed the lack of background information as an often-cited barrier to infusing EE into classroom. All of the participants agreed that the workshop provided them with factual information and that the workshop helped them to understand that information. A third statement regarding the usefulness of the resources was made. All of the participants agreed that the workshop presented them with resources they will be able to use in the future. Giving teachers helpful, useful and relevant resources throughout the workshop was an attempt to break the "lack of resources barrier" often cited as a reason for not infusing EE into their classrooms. Complete agreement on those three statements indicates that this workshop was able to help break down the resources barrier to infusing EE.

BOW is founded on the principle of hands-on education. While $65 \%$ of this BOW workshop's participants agreed they felt they gained hands-on skills associated with prairie chicken ecology/conservation, the percentage of participants in agreement 
can be increased. Before the workshop instructors were asked specifically to form lesson plans that included hands-on activities. While some sessions lend themselves more easily to these types of activities, for example using radio telemetry equipment in the prairie chicken ecology session, hands-on activities might not be as easily incorporated into others. In order to counteract this, future workshop planners should find ways to incorporate these types of activities beforehand. Overwhelmingly, agreement with statements regarding the BOW workshop content indicated that the BOW program is an effective learning environment for teachers.

\section{Workshop Session Content}

When asked if specific sessions helped participants expand their knowledge about the intended session topic, most participants agreed that it had. In four out of nine questions, some participants disagreed with these statements. They were regarding the following sessions: Buena Vista Marsh tour, prairie chicken ecology, environmental education, and curriculum development (Table 26). It is not surprising that some disagreed that the environmental education session helped them to expand their understanding of environmental education, as it was earlier noted that all participants indicated they had taken a college course in environmental education. However, it was surprising that some participants disagreed with the statement regarding the prairie chicken ecology session, as that session had the highest percent increase of correct answers from the pre- to post-workshop evaluation.

The curriculum development session had the highest percentage (29\%) of participants disagreeing with the statement that the session "helped me to understand how 
to develop curriculum using the knowledge gained in this workshop." After evaluating written comments and addressing what aspects of the workshop could be improved (Table 32), the majority of responses focused on the one credit class assignment. Unfortunately, it is believed that participants' frustrations with the one-credit assignment manifested while the participants rated the curriculum development session content. Further, the statement should be reworded to emphasize that participants are not asked to rate the instructor or assignment, but rather, if the session content expanded their knowledge. While participants rated this session as not very useful, it is felt teachers who leave the workshop with that background knowledge, materials, and recently created curriculum will most readily incorporate this newly gained information into their classroom. With some slight adjustments, it is believed that this session should be kept, and could play a valuable role in similar workshops.

\section{$\underline{\text { Resource Binder }}$}

The resource binder was very well received as all participants (100\%) indicated that the resource binder is a helpful resource and that it will influence their future teaching (Table 27). Additional comments in the form of emails and thank you notes were sent to the BOW program after the workshop, indicating that the resources were useful. "The resources you've provided are unbelievable (quantity and quality)", "Be assured that within the next two weeks I will be able to utilize the video, CD-ROM video and audio clips and the background of the marsh and prairie chicken immediately in my classroom. That is unbelievable!", and "I really appreciate the seeds. I will use them with my seed set to compare and contrast, to illustrate prairie habitat." These resources 
were designed to help overcome the lack of suitable materials available barrier, described by teachers. Based on the feedback from workshop participants the binder is deemed successful in breaking barriers to incorporating EE into classrooms.

\section{One Credit Assignment}

As previously mentioned, the one credit assignment caused some controversy amongst workshop participants. Participants made comments regarding the assignment when asked what parts of the workshop could be improved (Table 32). The assignment was mailed out to teachers in January, three months prior to the workshop, in order to give teachers sufficient knowledge of what would be expected in order to receive the one graduate university credit. Receiving the one credit was completely optional and the tuition was paid for by a 2002 Wisconsin Environmental Education Board grant.

Many of the participants indicated that they felt the one credit assignment was too much work and the due date did not give them enough time for completion. These complaints were originally aired during the workshop and minor concessions were made in order to encourage teachers to actually complete the assignment, and ultimately develop curriculum that would be incorporated into Wisconsin classrooms. The concessions included an extended due date and an alternative assignment. The revised assignment choices were sent to all participants allowing them to choose which to complete. Two participants choose not to receive the one credit prior to the workshop. One participant chose to complete the original assignment and eight chose to complete the alternative assignment. Five participants completed the assignment by the original deadline and the remaining four completed the assignments by the extended deadline. 
In trying to determine the basis for complaints surrounding the one credit assignment, assignments from similar programs such as the K-12 Energy Education Program (KEEP) were reviewed. The assignment requirements were similar to the requirements of the BOW workshop in that participants of their workshops were required to complete a lesson plan using the newly gained information. However, the assignment for the BOW workshop was slightly more detailed, requiring participants to indicate which Wisconsin Model Academic Standards are addressed in their lesson plan, as well as requiring a field trip option and addressing alternative forms of assessment. Of the assignments received to date, the overall results are deemed extremely successful, with 8 plans receiving an $\mathrm{A}$, and 1 plan receiving a $\mathrm{B}$.

It is felt that the revised lesson plan is similar to requirements from similar programs in the EE field and should be used in the future. It is not known if participants would have been willing to attend a workshop that does not offer a credit option, or if participants would pay for the one university credit themselves. It is assumed that participants would still attend this workshop without the one credit option, as two participants did so at this workshop. However, it is suggested that the one university credit option be kept available for those who wish to take advantage of the opportunity.

\section{Workshop Structure}

The seven questions regarding the workshop structure indicate a successful structure. All participants (100\%) agreed that the workshop was well organized and the BOW staff members were helpful and courteous (Table 29). One participant felt that there did not seem to be sufficient interaction between participants. The program had 
built in social hours, evening programs, as well as down time during sessions in order to provide time for participants to socialize. It is unlikely that more time could be scheduled in which to encourage further interaction between participants, due to the overall length of the workshop. One participant disagreed that the sessions were appropriate in length, and wrote in "too short." While this is seen as a positive sign, indicating that they would have liked to spend more time learning about the various session topics, again, longer sessions would be unfeasible due to overall workshop length. In general, responses to these seven questions indicate that the BOW workshop structure was successful with sessions flowing in a logical manner, easy registration process and sufficient interaction between students and instructors.

\section{Teacher Specific Workshop Track}

The Becoming an Outdoors-Woman program was extremely interested to see if teachers felt that a BOW workshop was a successful learning environment. The results to four questions confirmed that the BOW program is indeed successful for teacher specific workshops (Table 30). All participants (100\%) felt the format is effective and would be interested in other teacher specific workshop tracks. Teachers were asked to explain why they would be interested in other tracks and some indicated that, "Specific topic workshops are beneficial", and that it was a "Fun, informative, hands-on, active, relaxing atmosphere." And finally that, "Local case studies give students something to identify with / add relevance to teaching." With this type of positive feedback, it is strongly suggested that BOW can break down some barriers to infusing quality EE into Wisconsin classrooms by offering teacher specific workshop tracks as an effective way to give 
teachers the knowledge, skills and resources needed to infuse this new information into their classrooms.

A final question asked if this workshop would influence participant's future teaching. There was a $100 \%$ agreement from all participants to this statement, indicating that the knowledge gained during the workshops would be carried over into their teachings. The response to this statement is another indication of the success of the teacher specific BOW workshops as well as the success of the workshop overall.

\section{$\underline{\text { Session Ranking }}$}

The ranking of workshop sessions in terms of overall effectiveness (most helpful or useful) to the teacher participants allowed us to rank the sessions. Three similar questions were used that asked participants to rank the sessions in terms of overall effectiveness. First, teachers were asked to rank sessions in terms of their understanding of prairie chicken knowledge or prairie chicken/conservation (Figure 1). Second, participants were asked to rank sessions in terms of the sessions' value to participants as educators (Figure 2). The third question asked participants to rank sessions in terms of each sessions' value to participants personally (Figure 3). All three questions resulted in similar rankings. Most notably, viewing of the prairie chickens was ranked as the most effective session in all three categories to participants, in terms of knowledge, as an educator and personally. One explanation for this comes from conversations with participants during the workshop. Many claimed that everything they learned about prairie chickens throughout the workshop was only enhanced by the opportunity to personally view them. By viewing the prairie chickens on their booming grounds, 
participants were able to witness, first hand, what they were learning about. Not only were they able to see the birds and view their mating behavior, but also they were able to view the habitat that is actively managed for the birds.

The prairie habitat was the session ranked second, in all three categories, as most effective to the participants. Based on written comments on what participants liked most about the workshop (Table 31), and from discussions with participants, several factors played into this ranking. First, the instructor for this section has a very energetic and charismatic teaching style. Many participants remarked that they liked Dr. Bob Rosenfield because he not only gave them useful information about prairie habitat but he got them thinking about their own land ethic and teaching styles. Others remarked that he did a good job of tying the subject of prairie chickens into their habitat. They were no longer only learning about one bird species but were taking a step back to trace the history of the habitat on which prairie chickens are dependant. It is recommended that this session be included in future workshops and even that Dr. Rosenfield instruct the session again if possible.

Sessions that ranked the lowest, in terms of overall effectiveness to participants, were the environmental education and curriculum development sessions. As discussed earlier, it is believed that the environmental education session was ranked lower in terms of effectiveness because each participant had taken an environmental education college course prior to attending the workshop. It is not believed that this is an indication of the session performance itself, merely an indication that there was not a tremendous amount of new knowledge gained during that session. The curriculum development session ranked last in terms of overall effectiveness, to participants knowledge, to participants as 
an educator, and to participants personally. As discussed, it is believed that the lower ranking may have resulted from participants' discontent toward the one credit assignment. It would be interesting to see if these rankings would be different if there were less displeasure with the assignment.

\section{$\underline{\text { Additional Comments }}$}

Six open ended questions regarding the workshop were designed to provide more insight into the participants overall thoughts about the workshop. In general, all comments were very positive and indicated that participants liked the organization and opportunity to view prairie chickens (Table 31). Additional comments from participants were very positive and describe how they will use the information gained during the workshop in both their personal and professional lives. Finally, overall comments about the workshop were extremely supportive. The only negative comments throughout the open ended questions were related to the credit assignment. Again, these comments were all made before the assignment's second option was provided and the due date was extended. These responses might be different if they were asked about the changes made to the assignment. Overall, comments made on the evaluations, as well as numerous verbal comments made by the teachers, were extremely positive. One participant indicated that, "In a heartbeat I would strongly consider attending a workshop that you have organized," again indicating success for the BOW program. 


\section{Prairie Chicken Resource Binder}

The prairie chicken resource binder was created in attempt to gather relevant materials about prairie chickens into one central location. This was created in order to provide participants an easily accessed, useful tool for incorporating information about prairie chickens into their classroom. The resource binder was extremely well received by participants. Additional requests for a resource binder have been received from teachers who did not attend the workshop. All materials used in the binder have been converted into a computer format to ease duplication. The format allows room for changes and additions as seen fit by future users. In addition, sections of the resource binder were placed on a prairie chicken website maintained by the Becoming an Outdoors-Woman program.

\section{$\underline{\text { Printed Materials }}$}

Copyrighted printed materials can be used freely specifically for one time educational use. This must be taken into consideration if any changes or additions are to be made to the binder. Typically, permission is granted by the author for use in an educational situation such as this; however it must be considered. While offering the materials on a CD ROM instead of a printed version would be less expensive, it is suggested to continue using the print version as it allowed participants the ability to carry the resources with them from one session to the next and access information easily without the use of a computer. 
$\underline{\text { Video }}$

Some considerations for future use and creation of the resource binder and materials are copyright laws. Copyright permission was specifically given allowing us to use both video clips. However, this permission was given on the condition that only a certain number of videos are made. If more videos should be required, copyright permission must be requested again.

\section{$\underline{\text { CD ROM }}$}

Other considerations to be made would include changes in computer software that will be used to access the CD ROM in the future. A variety of free software was included on the CD ROM in order to allow computer users with different operating systems the ability to access the pictures, video clips and data. Updated versions of this software would need to be included if the CD ROM is reproduced. Finally, pictures taken by professionals are copyrighted and if any are to be used, permission must be sought. Therefore, all photos and video clips were taken and edited by the researcher.

\section{$\underline{\text { Prairie Seed Packets }}$}

The prairie seed packets were somewhat labor intensive to create as it involved physical collection of seeds. It was, however, deemed well worth the effort as participants indicated a great appreciation for the effort and final result. In addition to the seed packets, extra seeds were taken to the workshop for distribution to participants. Those who chose to were able to take bags full of various seeds for use in their classrooms. Many indicated a desire to grow the seeds either in their classrooms or on 
school grounds. Native plants can also be obtained from various vendors (e.g. Prairie Nursery, Westfield, Wisconsin, (800) 476-9453).

\section{BOOMING GROUND VIEWER DEMOGRAPHICS}

As a result of the booming ground viewer demographics survey, the $\mathrm{BOW}$ program and the Wisconsin DNR can now begin to understand who is participating in the booming ground opportunity. This in turn provides critical support to the prairie chicken management program. The return rate on the booming ground viewer demographics surveys was very high both in 2002 (62\%) and 2003 (94\%). Many viewers were excited about being part of the study and numerous appreciation letters made by the viewers were received after their viewing experience. One viewer expressed her appreciation, "Hi Mindy...just a little note to tell you we really enjoyed the 'chickening' experience.... I'll never forget the booming and the sense of being a privileged spectator in an ancient ritual. Thanks for arranging that for us." Similar sentiments were expressed by other viewers indicating the overall success of the booming ground viewing program.

\section{Descriptive Demographics}

In order to better plan for and to recruit future booming ground viewers, descriptive demographics were gathered for 2002 and 2003 viewers. In 2002, 65\% of the viewers were age 40 or above (Table 37). There was a shift in 2003 to younger viewers, as only $39 \%$ of the viewers were age 40 and above. One explanation for this shift was the increase of students to the booming grounds. The researcher actively sought out students as participants following the 2002 viewing season. Many of the students who 
did participant in 2003 were college students. A continued trend toward younger viewers, particularly grade school students, may indicate success of BOW's prairie chicken workshop for teachers.

In 2002 and 2003, most viewers came from communities of 5,000 to 24,999 (22\% in $2002,29 \%$ in 2003$)$ or from a city of 25,000 to 99,999 ( $25 \%$ in $2002,22 \%$ in 2003 ) (Table 38). This shows that viewers are coming from towns and small cities and gives a good indication of places to find new target audiences of potential viewers.

\section{Education and Occupation}

The viewers in both years were overall a highly educated group, with over half of the participants having received either an undergraduate college degree or a graduate or professional school degree (Table 39). In 2002, 76\% of the viewers had received either college degree. While this number fell to $56 \%$ in 2003 , it is still considered very high. It is likely that many viewers learned of the viewing opportunity while attending the University of Wisconsin - Stevens Point, or perhaps they have studied outdoor or nature related classes at other universities.

There was an interesting shift in occupations of viewers from 2002 to 2003 (Table 40). In 2002, the highest percentage of viewers was retired (21\%). The second highest percentage of viewers was students (14\%). In 2003, the number of retired viewers dropped to $6 \%$, while the number of students increased dramatically to $44 \%$. Again, this would reflect the shift in age characteristics seen in the two years. In addition, this shift may reflect active recruiting of students by the researcher after the 2002 viewing season. Recruitment techniques included a press release to local schools and universities, as well 
as speaking opportunities at the University of Wisconsin - Stevens Point classes. It is interesting to note that the majority of students seen in 2003 were college students. While the occupation "student" may include grade school to graduate school, the majority of student groups reserving blinds were undergraduate student groups. This point is further reinforced in Table 39 as $27 \%$ of participants currently held their GED or high school diploma. It is hoped that the number of students participating in the viewing program continues to grow. Students have the most to gain, in many ways, from the viewing program.

\section{$\underline{\text { Travel and Accommodations }}$}

In both 2002 and 2003, the highest percentage of viewers traveled 50 miles or less to view the prairie chickens ( $37 \%$ in $2002,35 \%$ in 2003 ) (Table 41 ). In addition, $75 \%$ of the viewers traveled 150 miles or less in both years. Distance traveled, combined with city size, can serve as good descriptors of areas to actively advertise the viewing opportunity in future years.

The average distance traveled indicates that the majority of viewers were from Wisconsin, which was the case in both years (88\%) (Table 41). It is interesting to note however, that over the two-year period, viewers to the booming grounds came from 10 additional states, with one viewer coming from Canada.

The majority of viewers $(60 \%$ in $2002,77 \%$ in 2003$)$ did not stay in a local area hotel the night before viewing (Table 42). It is assumed that because the majority of viewers live within 150 miles of the booming grounds, they drove directly from their 
house that morning. Several individuals indicated that they stayed either with family or friends the evening before.

Almost all of viewers (91\% in $2002,96 \%$ in 2003$)$ indicated that prairie chicken viewing was the main focus of their trip. This indicates that the viewers were coming specifically to see the booming ground displays rather than as part of a larger trip.

\section{Outdoor Related Experiences}

All 2002 and 2003 viewers indicated that they participated in at least one outdoor related recreation activity over the past year with most participants indicating more than one activity. There was a fairly even distribution of responses across the different activity choices (Table 43).

In addition to outdoor activities, viewers showed interest in environmental and conservation activities. More than half of the viewers (55\% in 2002, 52\% in 2003) were involved in conservation clubs or groups (Table 44). The Nature Conservancy, Sierra Club, and Audubon Society, had the highest percentage member participation among viewers in both years. These organizations, or local chapters of these organizations, may be a good place to advertise the viewing opportunity.

\section{Viewer Recruitment and Prairie Chicken Viewing Experience}

The majority of viewers indicated that they heard of the prairie chicken viewing from either a friend or other (Table 45). Viewers were asked to indicate through what other source they had heard about the program. In 2002, the most common answer was the Wisconsin Trails Magazine. In 2003, the most common answer was professor or 
teacher. Many other written comments indicated that viewers had attended the University of Wisconsin - Stevens Point and had heard of the opportunity through the university. Others indicated having known the Hamerstroms when they were conducting their research on the prairie chickens and some had even participated in the viewing opportunity with the Hamerstroms. Finally, some mentioned that they had read some of the books written by Frances Hamerstrom and wanted the opportunity to view the chickens.

The majority of viewers ( $71 \%$ in $2002,64 \%$ in 2003 ) indicated they have not viewed prairie chickens on the Buena Vista Marsh before (Table 45). It is interesting to note that many viewers were returning for at least their second viewing with $29 \%$ in 2002 and 36\% in 2003 indicating that they had previously viewed the prairie chickens. Many viewers had viewed the prairie chickens multiple times, from the earliest viewing in 1951 to the most recent repeat viewing in 2001. One viewer returned for another viewing opportunity after having participated 11 times before. While a high percentage of new viewers indicates a growing population of prairie chicken viewers, it is interesting to see a dedicated group of return viewers.

\section{Information Packet}

The effectiveness of the information packet sent to viewers prior to their visit was evaluated by asking viewers several questions. In $2002,87 \%$ of the viewers agreed that the information packet helped them learn about prairie chickens (Table 48). This number rose to $93 \%$ in 2003 . Viewers from both $2002(61 \%)$ and 2003 (75\%) found the most useful part of the information packet was the background information on prairie chickens 
(Table 46). This was followed closely (57\% in $2002,44 \%$ in 2003) by the map and directions. Viewers were asked which part or parts of the information packet they found to be the least useful. The answer with the highest percentage was none (54\% in 2002 , $51 \%$ in 3002) (Table 47). It was hoped that these questions would help to remove any unnecessary parts of the information packet that is sent out to all viewers prior to their viewing experience. However, results indicate that no part of the information packet seemed to be found as not useful. Therefore, rather than removing parts of the information packet to save on mailing costs, all parts of the information packet were recreated into Microsoft documents so that they may be emailed to some viewers. This will not only help cut down on mailing costs, but is also a faster way to get viewers the necessary information and was found to be particularly useful for those viewers who signed up to view too near the viewing date for the information packet, if traditionally mailed, to reach them.

\section{Learning Experiences}

In order to determine the information packet's effectiveness, viewers were asked to what degree viewers felt the information packet they received adequately prepared them for their visit. Eighty-nine percent agreed in 2002 and 96\% agreed in 2003 indicated the information adequately prepared them for their visit (Table 48). Viewers from 2002 suggested that mileages be added to the map included in the information packet. This was done before the 2003 season and seemed to be helpful, as there were few comments regarding the map. 
Based on the results to questions regarding the information packet, it was determined that the packet itself seems adequate for preparing the viewers for this visit, as well as giving them helpful information from which to learn about prairie chickens overall. It is recommended that the same packet be used to prepare future viewers.

In order to determine the usefulness of booming ground visits as an education tool, we asked viewers if they felt their visit to the booming grounds helped them to learn about prairie chickens (Table 49). In 2002, 92\% of the viewers agreed with this statement. This number increased to $98 \%$ in 2003 . This strongly supports the idea that viewers are learning about prairie chickens from their visit to the booming ground. This statistic also supports BOW's theory that a visit to the booming grounds would be a highly effective tool in teaching high school students a variety of subjects.

We wanted to know how viewers felt regarding their overall experience viewing the prairie chickens. When asked if their experience was satisfying, $92 \%$ of the viewers in 2002 agreed, while this number increased to $96 \%$ in 2003 (Table 49). These both represent extremely high satisfaction rates with the program and indicate a very successful viewing program.

\section{$\underline{\text { Returning Visits }}$}

As another way to gain an understanding of overall satisfaction rate with the viewing experience, viewers were asked if they would return for another visit. In 2002, $83 \%$ of the viewers indicated that they would (Table 50 ). This percentage rose to $92 \%$ in 2003. These numbers strongly support overall satisfaction with the program, as the majority of viewers in both years would return for another visit. 
Finally, viewers were asked if they would encourage others to participate in this opportunity. In 2002, $94 \%$ of the viewers indicated that they would encourage others to participate (Table 50). This number rose to $99 \%$ in 2003 . These high percentages of viewers that would encourage others to experience the viewing opportunity, because they truly believe that others should also experience this opportunity, are perhaps the best indication of a successful program. 


\section{IMPLICATIONS AND FUTURE DIRECTIONS}

\section{BOW PRAIRIE CHICKEN WORKSHOP}

Participating teachers were asked to rate the effectiveness of the workshop by indicating the degree to which they agree or disagree with statements about the workshop. Overall, the workshop was a tremendous success and this is reflected in the workshop evaluations. In addition, there were numerous favorable verbal comments made by participants, which were not included in this report. The participants were able to obtain additional knowledge regarding prairie chickens, as well as skills to teach this newly gained knowledge in their own classrooms.

\section{Workshop Highlights}

- All participants (100\%) believed they had benefited both personally and professionally from the workshop and felt that their expectations for the program were met.

- Following the workshop, $100 \%$ of the participants indicated that they felt confident in teaching about prairie chickens.

- Most (94\%) participants indicated that they intended to infuse the information gained, during the workshop, into their curriculum.

- Following the workshop, participants averaged $83 \%$ correct on knowledge questions regarding prairie chickens. This was a $35 \%$ increase from before the workshop.

- All participants $(100 \%)$ agreed that the workshop presented them with resources they will be able to use in the future, and that they were comfortable using those resources. 
- All participants (100\%) agreed that the workshop seemed well organized, that the workshop sessions flowed logically and that the BOW staff members were helpful and courteous.

- Al participants (100\%) indicated the BOW workshop format is effective for 'teacher specific' workshop tracks and 100\% indicated that they would be interested in other BOW teacher specific workshop racks.

- Finally, $100 \%$ of the participants indicated that this workshop would influence their future teaching.

The overall success of this workshop is expected to lead to implementation of similar BOW workshops, not only in Wisconsin, but also in other states as well, as results will be shared with other BOW coordinators across the country. The feedback received from this workshop will help to formulate future teacher specific workshops.

Results of this workshop will be shared with the Wisconsin DNR, which has a vested interest in prairie chickens in Wisconsin. Currently, a draft of the Greater Prairie Chicken plan is being constructed by researchers and personnel involved with the prairie chicken population in Wisconsin. One of the nine objectives in the draft is to increase awareness of the need for grassland conservation. It is believed that by continuing to offer this workshop, the Wisconsin DNR can successfully help accomplish this objective.

Finally, this workshop has demonstrated an expanded audience for the Becoming an Outdoors-Woman program. The BOW program recognized the common thread of lack of educational opportunities between women not participating in outdoor activities and teachers not providing EE in their classrooms. The prairie chicken workshop showed that the BOW workshop format can offer teachers a valuable educational opportunity. By including teachers in the BOW audience, we can offer teachers a valuable in-service 
educational opportunity, and can better help to break down some of the barriers to teaching EE that have been previously identified by teachers. By expanding the scope of the program to include teachers, we are increasing the population that can potentially benefit from the BOW experience.

\section{Further Study}

Continued study of workshop participants would answer several lingering questions regarding this study. First, it would be interesting to see how many of the $94 \%$ of teachers who indicated intent to infuse, actually did infuse the information gained during the workshop into their classrooms. This would require a questionnaire be sent to each participant and might ask how much time was spent teaching about prairie chickens, which topics they were instructing when teaching about prairie chickens and if they felt they had enough information in order to successfully teach about prairie chickens.

Another topic of further study is that of willingness to pay for the BOW workshop. This workshop was funded by a 2002 Wisconsin Environmental Education Board grant and thus the registration for the participants was free. The overall workshop evaluation did not include any questions regarding willingness to pay for the workshop. This information could help in planning for future workshops.

One final concern is the number of teachers who registered for the workshop and did not attend. Not only did it cause problems in planning in terms of numbers of supplies, meals and travel arrangements to be made, it also left possible openings unfilled during the workshop. The BOW program has experienced similar nonattendance situations with its scholarship program. When offered full scholarships, women were more likely to not attend without canceling than if they had some personal financial 
investment in the workshop (Personal communication, Diane Lueck, July 2003).

Therefore, some degree of financial commitment would help to ensure attendance at the workshop.

\section{Prairie Chicken ResourCe Binder}

The resulting resource binder was well received by workshop participants. BOW has received calls from teachers who did not attend the workshop, interested in obtaining the resources as well.

\section{$\underline{\text { Resource Binder Highlights }}$}

- All participants $(100 \%)$ felt the resource binder is a helpful resource to them.

- All participants (100\%) indicated that the resource binder would influence their future teaching.

\section{Follow Up}

It is recommended that the resource binder be made available to Wisconsin DNR employees involved with prairie chicken management. Particularly, the resources may be useful in addressing the prairie chicken management objective of increasing awareness of the need for grassland conservation. It is also recommended that BOW offer these resources, at cost, to teachers who might not be able to attend a workshop. While the resource binder cannot replace the knowledge and skills gained in a workshop, it can stand alone as an effective supplemental teaching aid. Copies of this binder should be distributed to locations where it may be easily accessed by teachers, such as the Wisconsin Center for Environmental Education, located in the Learning Resources 
Center of the University of Wisconsin - Stevens Point. Finally, similar BOW workshop tracks designed specifically for teachers should also create track specific resource binders as they proved to be an effective tool that will influence participants' future teaching.

\section{BOOMING GROUND VIEWER DEMOGRAPHICS}

The demographic survey had very high return rates $(62 \%$ in $2002,94 \%$ in 2003$)$ providing insight into the demographics of the booming ground viewers.

\section{Viewer Demographic Highlights}

- The mean age of 2002 viewers was 45 with a range of 9 to 79 years of age. The mean age of 2003 viewers was 36 with a range of 8 to 75 years of age.

- More than half of the viewers ( $76 \%$ in $2002,56 \%$ in 2003) had earned an advanced degree having completed either an undergraduate degree, graduate degree, or professional school.

- Viewers from 11 different states, and Canada participated in the viewing opportunity between 2002 and 2003.

- More than half of the viewers (55\% in $2002,52 \%$ in 2003 ) were members of environmental or conservation based clubs or organized groups.

- Many viewers had previously viewed prairie chickens on the Buena Vista Marsh with $29 \%$ of the 2002 viewers and $36 \%$ of the 2003 having participated in the viewing opportunity in the past.

- The vast majority of 2002 viewers (82\%) and 2003 viewers (92\%) would return for another visit.

- Finally, almost all viewers ( $94 \%$ in $2002,99 \%$ in 2003 ) would encourage others to participate in this viewing opportunity. 


\section{Further Study}

It would be helpful to continue to trace the viewer demographics in future years. Many changes were seen in the demographics of viewers between the two years, and a long-term data set would better help analyze any trends across years. It is recommended that the organization involved with viewer reservations (currently BOW) continue to build this data set, as it can be very helpful for recruiting new viewers and for determining the best outlets for advertising the viewing opportunities.

This data can also help the Wisconsin DNR in greater prairie chicken management. As written in the draft management plan, one strategy for increasing awareness of the need for grassland conservation includes maintaining the greater prairie chicken viewing blinds. By continuing this survey, data collected can benefit decisions made regarding the operation and function of those blinds.

\section{$\underline{\text { Summary }}$}

This study was meant to use the strengths of the Becoming an Outdoors-Woman program to benefit the management of the greater prairie chicken in Wisconsin. The project has increased the level of knowledge of, confidence in teaching about, and intent to infuse into the classroom, greater prairie chicken information for Wisconsin teachers. Further, this project has proven that the Becoming an Outdoors-Woman program is an effective format for teacher education. By collecting high quality popular and scientific writings, images, hands on instructional aids, and video clips, and by putting these materials in an easy to implement format, this project has also made prairie chicken instruction easier to infuse into Wisconsin classrooms. And through a survey of the 
viewers taking part in the unique booming ground viewing opportunity, the Becoming an Outdoors-Woman program and the Wisconsin Department of Natural Resources now have information critical in maintaining the booming ground viewing program as an educational opportunity. By increasing teachers' knowledge, consolidating instructional resources, and gaining more detailed understanding of booming ground viewers, the Becoming an Outdoors-Woman Program may be able to greatly benefit the management of the greater prairie chicken. 


\section{LiTERATURE CiTED}

Anderson, R. K. (1969). Prairie chicken responses to changing booming-ground cover type and height. Journal of Wildlife Management. 33(3), 636-643.

Anderson, R. K. \& Toepfer, J. E. (1999). History, status, and management of the greater prairie chicken in Wisconsin. Pages 39-58 in Svedarsky, W. D., R. D. Hier, and N. J. Silvy, editors. The greater prairie chicken: a national look. Agricultural Experiment Station, Miscellaneous Publication 99-1999, University of Minnesota, St. Paul, Minnesota.

Armantrout, N. B., compiler. (1998). Glossary of aquatic habitat inventory terminology. American Fisheries Society. Bethesda, Maryland.

Becoming an Outdoors-Woman. (2002). The becoming an outdoors-woman program: Growth, research and future directions. [Brochure] University of WisconsinStevens Point.

Berger, D. D., Hamerstrom, F., \& Hamerstrom, F. N. Jr. (1963). The effect of raptors on prairie chickens on booming grounds. Journal of Wildlife Management. 27(4), 778-791.

Beyer, M., Dagit, R., \& Rinker, H. B. (1988). “The impact of field experience on students." In Excellence in environmental education: Gaining momentum for the challenges ahead. 1987 conference proceedings. Selected papers from the $16^{\text {th }}$ annual conference of NAAEE. L. Mann, E. McCrea \& A. Medina, Eds. Troy, Ohio. Pp.182-186.

Brown, M., Ermer, S., Hoffman, S., \& Heimlich, J. E. (2002). Wildlife-based environmental education in a natural setting. NAAEE online Resources Library. http://www.ag.ohio-state.edu/ eetap/pdf/info114.pdf. Accessed May 18, 2003.

Christisen, D. M. (1985). The greater prairie chicken and Missouri's land-use patterns. Missouri Department of Conservation Terrestrial Series Number 15. 
Cobb, T. B. (1988). "The living environment: Resource base for science teachers." In Excellence in environmental education: Gaining momentum for the challenges ahead. 1987 conference proceedings. Selected papers from the $16^{\text {th }}$ annual conference of NAAEE. L. Mann, E. McCrea \& A. Medina, Eds. Troy, Ohio. Pp.232-236.

Cooper, T.L., Wilke, R., \& Champeau, R. (1989). Four years into the Wisconsin environmental education mandate. In M. Gross, R. Wilke, \& J. Passineau (Eds.), Proceedings from the Joint Conference of NAAEE and CEA: Working together to educate about the environment (pp. 57-62). Troy, OH: North American Association for Environmental Education/Conservation Education Association.

Dillman, D. A. (1978). Mail and telephone surveys. John Wiley \& Sons.

Doby, J.T. Editor. (1967). An introduction to social research. Appleton-Centry-Crofts. New York, New York.

Ensign, J. D. (1999). Becoming an outdoors-woman: Factors that enhance or inhibit the participation of women in fish and wildlife-based recreation. Masters Thesis, University of Wisconsin-Stevens Point. Stevens Point, Wisconsin.

Environmental Education and Training Partnership. (2002). Fundamentals of Environmental Education On-line Course. http://uwsp.edu/natres/rwilke/eetap/Evaluation/Evaluatin.htm edited by S. Wilcox.

Evans, K. E. \& Gilbert, D. L. (1969). A method for evaluating greater prairie chickens habitat in Colorado. Journal of Wildlife Management. 33(3), 643-649.

Fortner, R. W. \& Corney, J. R. (2002). Great Lakes educational needs assessment: Teachers' priorities for topics, materials, and training. Journal of Great Lakes Research. 28(1), 3-14.

Golner, D. P. (1997). Analysis of habitat selection by female greater prairie chickens in central Wisconsin. Masters Thesis, University of Wisconsin-Stevens Point. Stevens Point, Wisconsin.

Goodlad, J. (1984). Chapter 4 in A place called school: Prospects for the future. McGraw-Hill. New York, New York. 
Goodman, L. F. (2003). Assessing the educational needs of women who own nonindustrial private forestland in Wisconsin. Masters Thesis, University of Wisconsin-Stevens Point. Stevens Point, Wisconsin.

Grange, W. B. (1948). Wisconsin grouse problems. Wisconsin Conservation Department, Madison, Wisconsin.

Gransee, M. J. (2002). Becoming an outdoors-woman: Barriers and strategies for participation of women with physical disabilities in outdoor recreation. Masters Thesis, University of Wisconsin-Stevens Point. Stevens Point, Wisconsin.

Gransee, M., Lueck, D., \& Thomas, C. (2002). Proceedings of breaking down barriers III: No limits. University of Wisconsin Stevens Point.

Ham, S. H. \& Sewing, D. R. (1987). Barriers to environmental education. Journal of Environmental Education. 19(2), 17-24.

Hamerstrom, F. (1994). My Double Life. University of Wisconsin Press. Madison, Wisconsin.

Hamerstrom, F. N., Jr. (1939). A study of Wisconsin prairie chicken and sharp-tailed grouse. The Wilson Bulletin. 51(2), 105-121.

Hamerstrom, F. N., Jr. \& Hamerstrom, F. (1973). The prairie chicken in Wisconsin. Wisconsin Department of Natural Resources Technical Bulletin 64.

Hamerstrom, F. N., Jr., Mattson, O. H., \& Hamerstrom, F. (1957). A guide to prairie chicken management. Wisconsin Conservation Department Technical Bulletin 15.

Hamerstrom, F., Berger, D. D., \& Hamerstrom, F. N., JR. (1965). The effect of mammals on prairie chickens on booming grounds. Journal of Wildlife Management. 29(3): 536-542.

Hines, J., Hungerford, H., \& Tomera, A. (1987). Analysis and synthesis of research on responsible environmental behavior: A meta-analysis. Journal of Environmental Education. 18(2), 1-8.

Huck, A. R. \& Decker, E. (1987). Environmental Respect. Curriculum Activity Guide. Second Edition. Safari Club International Conservation Fund. Tucson, Arizona. Hungerford, H., Peyton, B., \& Wilke, R. (1980). Goals for curriculum development in environmental education. Journal of Environmental Education. 11(3), 42-47. 
Jones, R. E. (1963). Identification and analysis of lesser and greater prairie chicken habitat. Journal of Wildlife Management. 27(4), 757-778.

Keenlance, P. W. (1998). Reproductive ecology of greater prairie chickens in central Wisconsin. Masters Thesis, University of Wisconsin-Stevens Point. Stevens Point, Wisconsin.

Keir, J. R. (1999). Wisconsin prairie chicken management: an agency perspective. Pages 59-62 in Svedarsky, W. D., R. D. Hier, and N. J. Silvy, editors. The greater prairie chicken: a national look. Agricultural Experiment Station, Miscellaneous Publication 99-1999, University of Minnesota, St. Paul, Minnesota.

Kirsch, L. M. (1974). Habitat management considerations for prairie chickens. Wildlife Society Bulletin. 2(3), 124-129.

Lane, J. F. (1993). An assessment of Wisconsin teachers' perceived competencies in, attitudes toward, and amount of class time devoted to teaching about the environment. Masters Thesis, University of Wisconsin-Stevens Point. Stevens Point, Wisconsin.

Lane, J., Wilke, R., Champeau, R., \& Sivek, D. (1994). Environmental education in Wisconsin: A teacher survey. Journal of Environmental Education, 25(4), 9-17. . (1995) Strengths and weaknesses of teacher environmental education preparation in Wisconsin. Journal of Environmental Education. 24(1), 36-45.

Lueck, D. H. (1995). Becoming an outdoors-woman: Effect on activities and attitudes. Masters Thesis, University of Wisconsin-Stevens Point. Stevens Point, Wisconsin.

Lueck, D. H. \& Thomas, C. L. (1997). Effect of the becoming an outdoors-woman program on attitudes and activities. Women in Natural Resources. 19(1), 4-8. . (2000). What color is your tradition? In Mansell, W. Dan (ed). Proceedings of the 2000 Premier's symposium on North America's hunting heritage. 165-170. Ottawa: Wildlife Forever.

Leopold, A. (1931). Report on a game survey of the north central states. Sporting Arms and Ammunition Manufacturer's Institute, Madison, Wisconsin.

Monroe, M. C. \& Cappaert, D. Managing editors. (1994). Integrating environmental education into the school curriculum. School of Natural Resources and Environment. University of Michigan. Ann Arbor, Michigan. 
Niemuth, N. D. (2000). Land use and vegetation associated with greater prairie-chicken leks in an agricultural landscape. Journal of Wildlife Management. 64(1), 278286.

Peri, Phyllis. (1996). The development of an instrument to assess environmental literacy of eleventh grade students in Wisconsin. Masters Thesis, University of Wisconsin-Stevens Point. Stevens Point, Wisconsin.

Project WILD. (2000). Project WILD: K-12 Curriculum \& Activity Guide. Council for Environmental Education.

Prose, B. L. (1987). Management techniques for the greater prairie-chicken. U.S. Fish and Wildlife Service. U.S. Government and Printing Office.

Ramsey, J. M., Hungerford, H. R., \& Volk, T.L. (1992). Environmental education in the K-12 curriculum: Finding a niche. Journal of Environmental Education. 23(2), $35-45$

Roberson, R. L. (1992). Development and validation of a survey instrument to measure the effect of the American Wilderness Leadership School's teacher workshop in wildlife ecology and conservation. Masters Thesis, Stephen F. Austin State University. Nacogdoches, Texas.

Ruskey, A. \& Wilke, R. (1994). Promoting environmental education: An action handbook for strengthening environmental education in your state and community. University of Wisconsin-Stevens Point Foundation Press Inc. Stevens Point, Wisconsin.

Schnell, M. J. (2000). Becoming an outdoors-woman: Barriers and strategies to minority women's participation in natural resource-based recreation. Masters Thesis, University of Wisconsin-Stevens Point. Stevens Point, Wisconsin.

Schorger, A. W. (1943). The prairie chicken and sharp-tailed grouse in early Wisconsin. Wisconsin Academy of Sciences, Arts, and Letters. 35, 1-59.

Schroeder, M. A. \& Robb, L. A. (1993). Greater prairie chicken. In The Birds of North America, No. 36. (A. Poole, P. Stettenheim, and F. Gill, editors). Philadelphia: The Academy of Natural Sciences; Washington, DC and the American Ornithologists' Union. 
Svedarsky, D. \& Van Amburg, G. (1996). Integrated management of the greater prairie chicken and livestock on the Sheyenne National Grassland. North Dakota Game and Fish Department, Bismarck, North Dakota.

Thomas, C. L. (1990). Strategies that others have used. Proceedings of Breaking down the barriers to participation of women in angling and hunting. 25-27. College of Natural Resources, University of Wisconsin-Stevens Point.

. (1994). Wilhelmine LaBudde. Wisconsin Natural Resources. 18(1), 17-23.

Thomas, C. L. \& Lueck, D. H. (1996). Training and retaining women in traditional fish and wildlife-based recreation. Transactions North American Wildlife and Natural Resources Conference. 61, 374-378.

Thomas, C. L. \& Peterson, T. A. (1990). Proceedings of breaking down the barriers to participation of women in angling and hunting. College of Natural Resources, University of Wisconsin-Stevens Point.

. (1993a). "Becoming an outdoors-woman." Women in Natural Resources.

15(3), 16-21.

. (1993b). Becoming an Outdoors-Woman: Concept and Marketing.

Transactions of the $58^{\text {th }}$ North American Wildlife and Resource Management Conference. 185-192.

Thomas, C. L., Ensign, J., \& Lueck, D. (1999). Becoming an outdoors-woman: Factors that enhance or inhibit the participation of women in fish and wildlife-based recreation. Transactions North American Wildlife and Natural Resources Conference 64, 507-521.

Toepfer, J. E. (1988). The ecology of the greater prairie chicken as related to reintroductions. Ph.D. Thesis. Montana State University. Bozeman, Montana.

United Nations Educational, Scientific and Cultural Organization (UNESCO). (1978, January). The Tbilisi Declaration. Connect: UNESCO-UNEP Environmental Education Newsletter, 3.

Van Koevering, T. W. \& Sell, N. J. (1983). An analysis of the effectiveness of energy education workshops for teachers. Science Education. 67(2), 151-158.

Weisberg, H. F., Krosnick, J. A., \& Bowen, B. D. (1989). An introduction to survey research and data analysis. Scott, Foresman \& Co. Glenview, Illinois. 
Westphal, J. M. \& Halverson, W. F. (1984). Assessing the long-term effects of an environmental education program: a pragmatic approach. Journal of Envrionmental Education. 17(2), 26-30.

Wilke, R. J. (1985). Mandating preservice environmental education teacher training: the Wisconsin experience. Journal of Environmental Education. 17(1), 1-8. . Editor. (1993). Environmental education teacher resource handbook: A practical guide for $K-12$ environmental education. Kraus International Publications. Arlington, Virginia.

Windows on the Wild. (1994). Results of a national biodiversity educations survey. World Wildlife Fund.

Wisconsin Center for Environmental Education. (1997). Environmental education in Wisconsin: Are we walking the talk? A profile of environmental education in Wisconsin K-12 schools based on statewide surveys and assessments of students, teachers, curriculum coordinators, and principals. Stevens Point, Wisconsin. Wisconsin Department of Natural Resources. (1995). This wide horizon, a habitat preserved: greater prairie chicken, a Wisconsin wildlife success story. Society of Tympanuchus Cupido Pinnatus, Ltd., and Wisconsin Department of Natural Resources. 13pp.

Yeatter, R. E. (1963). Population responses of prairie chickens to land-use changes in Illinois. Journal of Wildlife Management. 27(4), 739-756. 


\section{APPENDiX A}

«FIRST_NAME» «LAST_NAME»

November 1, 2002 «ADDRESS»

«CITY», «STATE»«Zip»

Dear «FIRST_NAME»,

Thank you for registering for the Prairie Chicken Conservation and Courtship Workshop track at the Wisconsin Lions Camp, April 25-27, 2003. We have a great program lined up and are excited that you will be joining us!

Enclosed in this confirmation packet please find a list of suggested clothing, map and syllabus to help you prepare for your weekend. Registration will be in the Memorial Building from 4:30 p.m. to 5:30 p.m. on Friday, April 25, 2003. Please arrive in ample time to register, which will insure we remain on schedule for the rest of the day.

You should come prepared for a variety of weather conditions. Most classes will be outdoors and hands-on. We will move indoors only if the weather becomes hazardous. Wisconsin Lions Camp has modern cabin-style housing, with several people per cabin. No linens are provided. You are responsible to provide all linens (including towels, wash cloths, and sheets or a sleeping bag) and personal items for yourself. Please also note that you will be viewing the prairie chickens on the Buena Vista Marsh early on Saturday, April 26 and should bring plenty of warm clothes for that excursion.

This pilot workshop, funded by a 2002 Wisconsin Environmental Education Board grant, is part of a Becoming an Outdoors-Woman (BOW) graduate research project. In order to determine the effectiveness of our teacher workshop, we will require each of you to complete both a pre- and post-workshop survey. The results of this survey will not only benefit our current research, but will also help BOW develop and implement future teacher-specific workshops. You will receive the pre-workshop survey by mail, before the workshop, and I thank you in advance for your cooperation in completing those.

If you have any questions regarding the directions to the camp, or the workshop in general, please feel free to contact me at (715) 346-3259 or e-mail mbrow327@uwsp.edu. See you in April!

Sincerely,

Mindy Brown, Wisconsin Graduate Assistant Becoming an Outdoors-Woman program

Encl. 


\section{APPENDIX B}

«First_Name» «Last_Name»

«Address»

«City», «State» «Zip»

Dear «First_Name»,

Thank you for sharing your skills with us by teaching in the Prairie Chicken: Conservation and Courtship track at the Becoming an Outdoors Woman (BOW) Workshop, April 25-27, 2003. We are very excited that you will be joining us. I have enclosed in this confirmation packet a map to the Lions Camp, a copy of the class syllabus and assignment, and a brief outline of what will be covered in all of the sessions in order to give you an overview of the weekend. I have also enclosed an Instructor Needs form that will allow us to make sure that we have your area set up with everything you will need to effectively teach your section.

You will be instructing on Friday, April $25^{\text {th }}$ from 7:00-9:00 p.m. We will pay you an honorarium of . I will submit the payment form to our accounting office, and it will be processed immediately following the workshop. In addition, BOW will cover your meals at the Lion's Camp.

BOW is founded on the principle of learning new things in a fun, safe, and outdoor environment. Therefore, please try to think of fun ways to fill the class with interesting hands-on experiences. For example, rather than strictly lecture, try to bring as many visual aids and materials to share as you think may help with your instruction. We also encourage you to spend as much time outdoors as the subject matter allows.

In addition to class preparation, we are asking that you prepare a few handouts that can be included into a resource binder for the participants. Items for the resource binder can include outlines of your session, fact sheets, stories, etc. Essentially we are looking for anything that will allow these 9-12 grade teachers to more effectively teach their own students what they have learned in your class. If you need anything duplicated, please email or mail a hard copy of the documents to me and I will photocopy those materials. If at all possible, please have items for the resource binder to me as soon as possible before the workshop so that I can incorporate them directly into the binder.

This pilot workshop, funded by a 2002 Wisconsin Environmental Education Board grant, is part of my graduate research project. The results of this workshop will help BOW develop and implement future teacher-specific workshops. I cannot thank you enough for all of your help and participation, not only with the workshop but also with my graduate project.

If you have any questions regarding your classes, or the workshop in general, please feel free to contact me at (715) 346-3259 or e-mail mbrow327@uwsp.edu. See you in April!

Sincerely,

Mindy Brown, Wisconsin Graduate Assistant Becoming an Outdoors-Woman program

Encl.

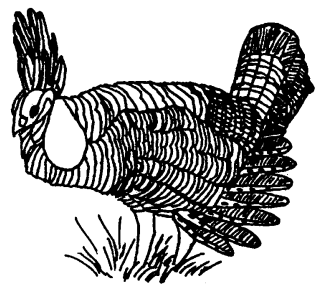




\section{APPENDIX C}

\section{Individual Session Objectives}

After participation in all sessions of the Becoming an Outdoors-Woman Prairie Chicken:

Conservation and Courtship workshop, participating teachers will be able to:

Historical Perspectives (Session 1)

1. Identify at least five states, excluding Wisconsin, that have prairie chicken populations.

2. Identify two prairie chicken management practices used by other states.

3. Describe the change in prairie chicken abundance from the 1800 's to present.

4. Identify two other areas in Wisconsin that have a prairie chicken population.

5. Describe the history of land acquisition in the Buena Vista Marsh.

6. Indicate the main agricultural product whose production greatly benefited the prairie chicken population in the early 1900's.

7. Identify three individuals and or organizations involved with preserving the land now know as the Buena Vista Grasslands.

8. Define "ecological patterning" as first described by the Hamerstroms (1973). 
Prairie Chicken Viewing (Session 2)

9. Record counts of prairie chickens on booming grounds.

10. Participate in booming ground viewing session.

11. Observe, first-hand, prairie chicken booming on the Buena Vista Marsh.

Tour of the Buena Vista Marsh (Session 3)

12. Identify two management practices currently used on the Buena Vista Marsh to maintain the prairie chicken habitat.

13. Indicate the relative timing of various management practices on the Buena Vista Marsh.

14. Observe, first-hand, various management practices on the Buena Vista Marsh.

Prairie Chicken Ecology (Session 4)

15. Identify food types important during different stages of the prairie chicken lifecycle.

16. Identify shelter requirements important during different stages of the prairie chicken lifecycle.

17. Define "lek".

18. Describe the sequence of prairie chicken reproduction.

19. Demonstrate familiarity with use of radio telemetry equipment. 


\section{Prairie Habitat (Session 5)}

20. Describe the general trend in total prairie habitat acreage across the United States.

21. Describe the general trend in total prairie habitat acreage in Wisconsin.

22. Identify three plant species as being prairie plants.

23. Identify three animal species that typically associated with healthy prairie habitat.

\section{Environmental Education (Session 6)}

24. Identify two individuals important in the history of environmental education in Wisconsin.

25. Identify the office responsible for environmental education in Wisconsin.

26. Identify the goal and subgoals of environmental education.

27. Describe techniques used to infuse environmental education into the classroom.

\section{Curriculum Development (Session 7)}

28. Create a lesson plan for infusing prairie chicken based environmental education into the classroom.

29. Demonstrate familiarity with Wisconsin's Model Academic Standards. 


\section{APPENDIX D \\ Workshop Schedule}

Friday, April 25

4:30-5:30 p.m. Registration

$\begin{array}{ll}\text { 5:30-6:30 } & \text { Dinner } \\ \text { 6:30-7:00 } & \text { Welcome } \\ \text { 7:00-9:00 } & \text { Historical Perspectives (Session 1) }\end{array}$

Saturday, April 26

3:30 a.m.

Prairie Chicken Viewing (Session 2)

8:00-8:15

Breakfast (Bag)

$8: 30-9: 30$

Buena Vista Marsh (Session 3)

9:30-10:15

Hamerstrom House tour

10:30-12:00

Break

12:00-1:00

Lunch

1:00-2:45

Group 1 - Prairie Chicken Ecology (Session 4)

Group 2 - Prairie Habitat (Session 5)

2:45-4:30

Group 1 - Prairie Habitat (Session 5)

Group 2 - Prairie Chicken Ecology (Session 4)

4:30-5:30

Social Hour

5:30-6:30

Dinner

7:00-8:00

Evening Program

8:00-9:00

BOW Raffle \& Silent Auction

\section{Sundav, April 27}

7:00-8:00 a.m.

Breakfast

8:00-9:45

Group 1 - Environmental Education (Session 6)

Group 2 - Curriculum Development (Session 7)

9:45-11:30

Group 1 - Curriculum Development (Session 7)

Group 2 - Environmental Education (Session 6)

12:00-1:00

Lunch

1:00-1:30

Farewell \& Depart 


\section{APPENDIX E}

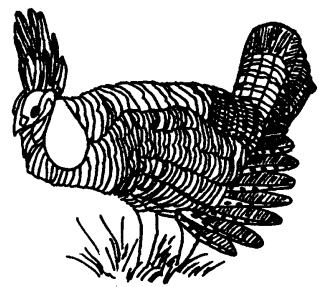

April 14, 2003

«FIRST_NAME» «LAST_NAME»

«ADDRESS»

«CITY», «STATE»«Zip»

Dear «FIRST_NAME»,

Thank you again for registering for the Prairie Chicken Conservation and Courtship Workshop track at the Wisconsin Lions Camp, April 25-27, 2003. We are looking forward to a fun-filled weekend.

Enclosed please find the pre-workshop survey. This survey was designed to assess the demographics of our participants, your expectations and beliefs of the workshop, and finally your knowledge of prairie chicken information. The information that you provide on this survey will remain confidential. These surveys are part of a Becoming an Outdoors-Woman (BOW) graduate research project. The combination of a pre- and postworkshop survey will be the basis of my graduate research and thesis. Therefore, your participation is greatly appreciated, because your responses will not only be used for my research, but will also provide valuable feedback to help improve our program in future years to come.

I hope that by mailing this survey beforehand, I have provided you time to complete the survey at your convenience. I ask that you please bring the survey with you to the workshop registration. As an added bonus, when you return this survey we will add your name to a special drawing to win some exciting prairie chicken resources.

If you have any questions regarding this survey, or the workshop in general, please feel free to contact me at (715) 346-3259 or e-mail mbrow327@uwsp.edu. See you on the $25^{\text {th }}$ !

Sincerely,

Mindy Brown, Wisconsin Graduate Assistant

Becoming an Outdoors-Woman program

Encl. 


\section{Becoming an Outdoors-Woman (BOW) Prairie Chicken Teacher Workshop}

\section{Pre-Workshop Evaluation}

We would like you to help us evaluate and improve the BOW teacher workshop by filling out the following questionnaire. Please indicate the most appropriate answer for each question, and return the completed form. All responses will be absolutely confidential.

\section{$\underline{\text { Part I }}$}

1. Sex:__ Female __ Male

2. What is your age?

3. How did you find out about the BOW program?
a. Exhibit at the WI Association for Environmental Education (WAEE)
b. Exhibit at the WI Education Association Council (WEAC)
c. BOW mailing list
d. Internet
e. Friend
f. Other Please specify,

4. What size city did you spend most of your life in?
a. Rural
b. Community with fewer than 5,000 people
c. Community with 5,000 to 24,999 people
d. City of 25,000 to 99,999 people
e. Major city of over 100,000 people
f. _— Suburb of major city

5. What is your education level?
a.
GED or high school diploma
b. Some college
c. Bachelor's degree
d. Master's degree
e. __ Doctoral degree or equivalent

6. Have you taken any college courses in the following subject areas?

Yes No

Wildlife Management

$\square=$ Habitat Management Conservation of Natural Resources Environmental Education 
7. Which of the following best describes the subjects you normally teach?
a. Biological / Environmental Science
b. — Earth Science (Geography, Geology, Physics, Chemistry)
c. Social Science (Language, Art, Music, History, Government)
d. All Subjects
e. Other, please specify

8. Please circle the grade level(s) you currently teach.

$\begin{array}{lllllllllllll}\mathrm{K} & 1 & 2 & 3 & 4 & 5 & 6 & 7 & 8 & 9 & 10 & 11 & 12\end{array}$

9. In what school district are you currently teaching?

10. Do you cover natural resource management or conservation in your classes?
a. Yes
b. No

11. Please mark each of the following types of outdoor recreation in which you have participated in the past year.
a. _ Bird watching
f. _ Canoeing
b. Camping
g. Gardening
c. Fishing
h. Photography
d. _ Hunting
i. Boating
e. Hiking or Backpacking
j. — Other,

12. Do you subscribe to any outdoor or conservation magazines?
a. Yes
b. No

If Yes, Please list one magazine you feel you get the most out of

13. Are you presently a member of any environmental or conservation based clubs or organized groups?
a. Yes
b. No

If yes, please list the clubs or organizations you are most active in

14. Do you regularly watch natural resource oriented television programs?
a.
b. Yes No

If yes, please indicate one program you watch the most

15. Have you ever viewed prairie chickens on the Buena Vista Marsh before?
a.
b. Yes

If yes, what year or years? 


\section{Part II}

In this portion of the survey, we would like to know what expectation, beliefs and opinions you have toward a variety of subjects. Please indicate the degree to which you agree or disagree with the following statements.

$(1=$ Strongly Disagree, 2 = Disagree, $3=$ Neutral, $4=$ Agree, $5=$ Strongly Agree $)$

Strongly Strongly

Disagree Disagree Neutral Agree Agree

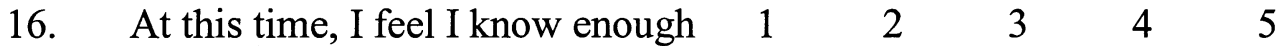
about what will happen at BOW.

17. I believe the BOW program will $\quad \begin{array}{lllllll}1 & 2 & 3 & 4 & 5\end{array}$ benefit me personally.

18. I believe the BOW program will $\begin{array}{lllllll}1 & 2 & 3 & 4 & 5\end{array}$ benefit my work.

19. I feel confident in my ability to $\begin{array}{llllllll}1 & 2 & 3 & 4 & 5\end{array}$ teach environmental/conservation education.

20. I feel confident in my ability to $\begin{array}{lllllll}1 & 2 & 3 & 4 & 5\end{array}$ teach about prairie chickens.

21. I have high expectations for the $\begin{array}{lllllll}1 & 2 & 3 & 4 & 5\end{array}$ BOW program.

22. I intend to infuse the information $\begin{array}{lllllll}1 & 2 & 3 & 4 & 5\end{array}$ gained in this workshop into my curriculum.

23. Please rate the following topics and activities included in the BOW program according to their value to you as a participant.

$(1$ = Not Valuable, $2=$ Slightly Valuable, $3=$ Moderately Valuable, $4=$ Very Valuable, $5=$ Extremely Important)

\begin{tabular}{ccccc}
$\begin{array}{r}\text { Not } \\
\text { Valuable }\end{array}$ & $\begin{array}{c}\text { Slightly } \\
\text { Valuable }\end{array}$ & $\begin{array}{c}\text { Moderately } \\
\text { Valuable }\end{array}$ & $\begin{array}{c}\text { Very } \\
\text { Valuable }\end{array}$ & $\begin{array}{c}\text { Extremely } \\
\text { Valuable }\end{array}$ \\
\hline
\end{tabular}

Historical issues of prairie chickens Valuable Valuable

History of the Buena Vista Marsh

$\begin{array}{llllll}1 & 2 & 3 & 4 & 5\end{array}$

Individuals involved with prairie chickens

1

2

3

4

5

Prairie chicken management

1

Prairie chicken ecology

1

2

3

45




\begin{tabular}{ccccc}
$\begin{array}{c}\text { Not } \\
\text { Valuable }\end{array}$ & $\begin{array}{c}\text { Slightly } \\
\text { Valuable }\end{array}$ & $\begin{array}{c}\text { Moderately } \\
\text { Valuable }\end{array}$ & $\begin{array}{c}\text { Very } \\
\text { Valuable }\end{array}$ & $\begin{array}{c}\text { Extremely } \\
\text { Valuable }\end{array}$ \\
\hline
\end{tabular}

Prairie habitat trends

Natural resource management

Environmental education in Wisconsin

Current environmental issues

(associated with prairie chickens)

Buena Vista Marsh tour

Meeting with natural resource managers

Socializing with colleagues

$\begin{array}{lllll}1 & 2 & 3 & 4 & 5 \\ 1 & 2 & 3 & 4 & 5 \\ 1 & 2 & 3 & 4 & 5 \\ 1 & 2 & 3 & 4 & 5 \\ 1 & 2 & 3 & 4 & 5 \\ 1 & 2 & 3 & 4 & 5 \\ 1 & 2 & 3 & 4 & 5\end{array}$

Please indicate the degree to which you agree or disagree with the following statements regarding natural resource management.

Strongly
Disagree Disagree Neutral Agree $\begin{gathered}\text { Strongly } \\ \text { Agree }\end{gathered}$

24. Humans must manage natural Disagree Disagree Neutral Agree Agree resources in order to ensure the $\begin{array}{lllll}1 & 2 & 3 & 4 & 5\end{array}$ future existence of those resources.

25. Management of wildlife is not needed.

26. Extinction of wildlife is an unavoidable result of human involvement with nature.

27. Humans have the capability to successfully manage natural resources.

28. I think most of the concern about environmental problems has been exaggerated.

29. There are already enough effective laws to protect the environment.

30. I want to help solve environmental 1 2 problems.

31. There is not much that I can do that 1 will help solve environmental problems.

2

3

4

5 


\section{Part III}

This portion of the survey asks questions intended to discover what you now about various topics related to prairie chicken ecology and conservation. Please choose the best answer for each of the following statements. Please do not use any outside sources when answering these questions.

32. There are ___ species of grouse native to Wisconsin.
a. 3
b. 4
c.
d. don't know

33. What is the scientific name for the greater prairie chicken?
a.
b. Bonasa umbellus Tympanuchus phasianellus
c. Tympanuchus cupido
d. don't know

34. The status of the greater prairie chicken population in Wisconsin is
a. endangered
b. threatened
c. extinct
d. don't know

35. Other states that have a greater prairie chicken population include:
a. Minnesota, North Dakota, Colorado
b. Ohio, Connecticut, Delaware
c. Washington, Montana, Texas
d. don't know

36. In 2002, the population of male prairie chickens on the Buena Vista Marsh, was estimated to be around
a. 220
b. 540
c. 1,100
d. don't know

37. Significant counts of male prairie chickens in Wisconsin were reported in
a. Leola Grasslands
b. Meadow Valley Wildlife Area
c. Paul Olson Area
d. both a and c
e. don't know 
38. Prairie chicken population management practices used in states other than Wisconsin include all but which one:
a. hunting
b. zoo specimens
c. _ grazing
d. $\longrightarrow$ translocations
e. don't know

39. Habitat management practices used in Wisconsin include all but which one:
a. predator control
b. prescribed burning
c. crop rotation
d. translocations
e. don't know

40. Through time, the range and number of greater prairie chickens in has
a. remained fairly stable throughout time.
b. _ increased following westward settlement then dwindled.
c. _ increased and continues to increase with management.
d. don't know

41. A decline in prairie chicken abundance in Wisconsin was first evident as early as
a. 1850
b. 1900
c. 1910
d. 1950
e. don't know

42. Historic levels of prairie chickens declined dramatically due largely to
a. habitat loss from agricultural development.
b. parasitic diseases.
c. use of insecticides on farms.
d. global warming.
e. don't know

43. Prairie chicken research began in Wisconsin in 1928, under the direction of
a. L__ Lyle Nauman.
b. _ Alfred O. Gross.
c. Frederick and Frances Hamerstrom.
d. Willis Sullivan.
e. don't know 
44. "Ecological patterning", as described by the Hamerstroms is
a. the natural practice of landscape management that patterns one area after another.
b. a method to apply pesticides and herbicides at minimal doses in spot treatments.
c. a scattered distribution of relatively small land parcels, rather than one large, homogeneous parcel.
d. don't know

45. Today, what is the organization in charge of prairie chicken management in WI?
a. Dane County Conservation League
b. Wisconsin Society of Ornithology
c. Fish and Wildlife Service
d. W Wisconsin Department of Natural Resources (WDNR)
e. _ don't know

46. Today, the major threats to prairie chicken conservation in Wisconsin include all but one:
a.
loss of genetic diversity
b. habitat loss / fragmentation
c. unconnected subpopulations
d. uncontrolled fire
e. don't know

47. In Wisconsin, researchers learn more about prairie chickens behavior and habitat use by all following methods except:
a.
b. annual census and blind observation
b. captive breeding
c. monitoring radio marked birds
d. _ study populations in other states
e. don't know

48. Juvenile prairie chickens are heavily dependent on for food, and make up a substantial part of the diet in the adult stage.
a. insects, cultivated grains
b. — plants, meat
c. — berries, corn
d. don't know

49. Prairie chicken production is dependent on of grass cover type(s) to meet the needs of the birds.
a. one kind
b. two kinds
c. a combination
d. none, they are not dependent on grass cover
e. don't know 
50. Historically, prairie chickens were supported by tallgrass or true prairie grassland. Today, they are able to adapt to various types of grasslands both native and introduced.
a. true
b. false
c. don't know

51. Short grass cover is used for
a. booming.
b. roosting.
c.
d. nesting and brood rearing.
d. don't know

52. are identified as the most significant habitat type to prairie chicken success.
a. booming grounds
b. roosting cover
c. nesting and brood rearing cover
d. don't know

53. "Lek" is defined as
a. the berries that many animals are dependent upon as a food source.
b. an area where animals carry on display and courtship behavior.
c. a small prairie rodent.
d. don't know

54. Booming ground counts can be used as an index to population abundance and can be useful in showing trends over a span of years.
a. true
b. false
c. don't know

55. Cocks (male prairie chickens) do not show strong fidelity to booming grounds year after year.
a. true
b. false
c. don't know

56. Hens (female prairie chickens) do not show strong fidelity to booming grounds year after year.
a. true
b. false
c. don't know 
57. Prairie chickens tend to have brood(s) per year with an average of eggs per clutch
a. $1,2-3$
b. 2, 2-3
c. $1,10-15$
d. $2,10-15$
e. don't know

58. A sign that copulation is successful can be seen by
a. a cock that ceases to boom for the remainder of the morning.
b. a hen who "rouses", or shakes her feathers violently, and leaves the booming grounds within ten minutes.
c. a cock and hen pair that leave the booming ground together.
d. don't know

59. Wilhelmine LaBudde wrote Wisconsin's first environmental education (EE) initiative in
a. 1935
b. 1955
c. 1975
d. 1995
e. don't know

60. Held in Tbilisi, Georgia of the USSR, 1977 marked
a. the celebration of environmental education reform in the United States.
b. the acceptance of environmental education in the school systems.
c. the first intergovernmental conference on environmental education.
d. don't know

61. The goal of environmental education is to

a.

b.

c.

d.

a. produce environmentally responsible citizens who can work for a balance between quality of life and quality of the environment.

b. create active citizens with increased participation in outdoor activities who show a genuine concern for the environment.

c. practice education in an outdoors setting in order to show first hand the hazards that humans can inflict on the surrounding environment. don't know

62. Wisconsin employed an model requiring a systematic incorporation of EE into existing curriculum plans.

a.

b. implementation

c. infusion

d. induction don't know 
63. Beside environmental ethic, the other EE subgoal that focuses on grades 9-12 is

a. perceptual awareness.

b. - knowledge.

c. citizen action experience.

d. don't know

64. The office responsible for environmental education in Wisconsin is the
a. Wisconsin Department of Natural Resources.
b. Wisconsin Department of Public Instruction.
c. Wisconsin Association for Environmental Education.
d. don't know 


\section{APPENDIX F \\ Becoming an Outdoors-Woman (BOW) Prairie Chicken Teacher Workshop}

Post-Workshop Evaluation

Part I

Please indicate the degree to which you agree or disagree with the following statements. $(1=$ Strongly Disagree, $2=$ Disagree, $3=$ Neutral, $4=$ Agree, $5=$ Strongly Agree $)$

Strongly

Strongly

Disagree Disagree Neutral Agree

Agree

1. I feel I knew enough about BOW prior to attending the program.

2. I believe I received some persona benefit from the BOW program.

$\begin{array}{llllllll}3 . & \text { I believe the BOW program will } & 1 & 2 & 3 & 4 & 5\end{array}$ benefit my work.

4. I feel confident in my ability to

$\begin{array}{lllll}1 & 2 & 3 & 4 & 5\end{array}$
teach environmental/conservation education.

5. I feel confident in my ability to teach about prairie chickens.

6. The BOW program met my expectations.

7. I intend to infuse the information gained in this workshop into my curriculum.

$\begin{array}{lllll}1 & 2 & 3 & 4 & 5\end{array}$

al

1
1
1

2

3

4

5

5


Prairie habitat trends

$\begin{array}{lllll}1 & 2 & 3 & 4 & 5\end{array}$

Natural resource management

$\begin{array}{lllll}1 & 2 & 3 & 4 & 5\end{array}$

Environmental education in Wisconsin

$1 \quad 2 \quad 3$

$4 \quad 5$

Current environmental issues

$\begin{array}{lllll}1 & 2 & 3 & 4 & 5\end{array}$

(associated with prairie chickens)

Buena Vista Marsh Tour

$\begin{array}{lllll}1 & 2 & 3 & 4 & 5\end{array}$

Meeting with natural resource managers

$\begin{array}{lllll}1 & 2 & 3 & 4 & 5 \\ 1 & 2 & 3 & 4 & 5\end{array}$

Socializing with colleagues

Please indicate the degree to which you agree or disagree with the following statements regarding natural resource management.

Strongly Strongly

Disagree Disagree Neutral Agree Agree

9. Humans must manage natural

$\begin{array}{lllll}1 & 2 & 3 & 4 & 5\end{array}$

resources in order to ensure the future existence of those resources.

10. Management of wildlife is not needed.

11. Extinction of wildlife is an unavoidable result of human involvement with nature.

12. Humans have the capability to successfully manage natural resources.

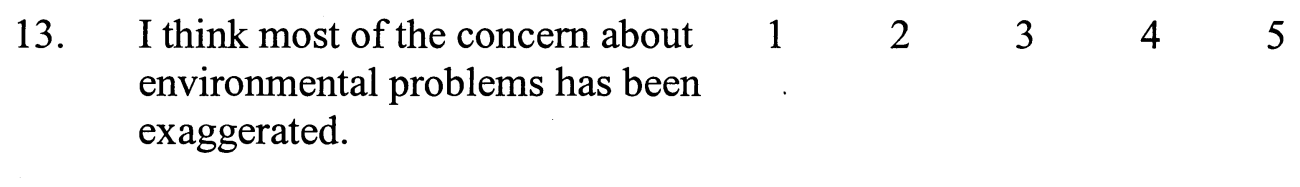

14. There are already enough effective $\begin{array}{lllllll}1 & 2 & 3 & 4 & 5\end{array}$ laws to the environment.

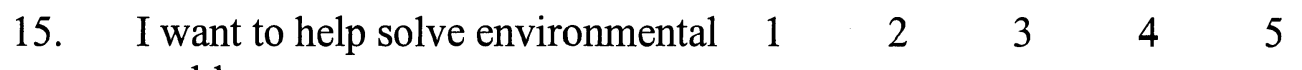
problems.

16. There is not much that I can do that $\begin{array}{lllllll}1 & 2 & 3 & 4 & 5\end{array}$ will help solve environmental problems. 


\section{Part III}

This portion of the survey asks questions intended to discover what you now about various topics related to prairie chicken ecology and conservation. Please choose the best answer for each of the following statements. Please do not use any outside sources when answering these questions.

17. There are ___ species of grouse native to Wisconsin.
e. 3
f. 4
g. 5
h. don't know

18. What is the scientific name for the greater prairie chicken?
e.
f. Tympanuchus phasianellus
f. B__ Bonasa umbellus
g. Tympanuchus cupido
h. don't know

19. The status of the greater prairie chicken population in Wisconsin is
e. endangered
f. threatened
g. extinct
h. don't know

20. Other states that have a greater prairie chicken population include:

e.

f. Minnesota, North Dakota, Colorado

g. Washington, Montana, Texas

h. _ don't know

21. In 2002, the population of male prairie chickens on the Buena Vista Marsh, was estimated to be around
e. 220
f. $\quad 540$
g. 1,100
h. don't know

22. Significant counts of male prairie chickens in Wisconsin were reported in
f. Leola Grasslands
g. __ Meadow Valley Wildlife Area
h. Paul Olson Area
i. both a and c
j. — don't know 
23. Prairie chicken population management practices used in states other than Wisconsin include all but which one:
f. hunting
g. zoo specimens
h. grazing
i. translocations
j. don't know

24. Habitat management practices used in Wisconsin include all but which one:
f. predator control
g. _ prescribed burning
h. crop rotation
i. translocations
j. don't know

25. Through time, the range and number of greater prairie chickens in has

a. remained fairly stable throughout time.

b. - increased following westward settlement then dwindled.

c. increased and continues to increase with management.

d. don't know

26. A decline in prairie chicken abundance in Wisconsin was first evident as early as
f. 1850
g. 1900
h. $\quad 1910$
i. 1950
j. _ don't know

27. Historic levels of prairie chickens declined dramatically due largely to

f. habitat loss from agricultural development.

g. parasitic diseases.

h. use of insecticides on farms.

i. global warming.

j. _ don't know

28. Prairie chicken research began in Wisconsin in 1928, under the direction of
f. Lyle Nauman.
g. _ Alfred O. Gross.
h. Frederick and Frances Hamerstrom.
i. Willis Sullivan.
j. _ don't know 
29. "Ecological patterning", as described by the Hamerstroms is
d. the natural practice of landscape management that patterns one area after another.
e. a method to apply pesticides and herbicides at minimal doses in spot treatments.
f. a scattered distribution of relatively small land parcels, rather than one large, homogeneous parcel.
d. don't know

30. Today, what is the organization in charge of prairie chicken management in WI?
f. Dane County Conservation League
g. Wisconsin Society of Ornithology
h. Fish and Wildlife Service
i. _ Wisconsin Department of Natural Resources (WDNR)
j. — don't know

31. Today, the major threats to prairie chicken conservation in Wisconsin include all but one:
f. loss of genetic diversity
g. habitat loss / fragmentation
h. unconnected subpopulations
i. . uncontrolled fire
j. don't know

32. In Wisconsin, researchers learn more about prairie chickens behavior and habitat use by all following methods except:
f. annual census and blind observation
g. captive breeding
h. __ monitoring radio marked birds
i. study populations in other states
j. _ don't know

33. Juvenile prairie chickens are heavily dependent on for food, and make up a substantial part of the diet in the adult stage.
e.
f. $\longrightarrow$ plants, meat
g. berries, corn
h. don't know

34. Prairie chicken production is dependent on of grass cover type(s) to meet the needs of the birds.
f. one kind
g. two kinds
h. a combination
i. none, they are not dependent on grass cover
j. don't know 
35. Historically, prairie chickens were supported by tallgrass or true prairie grassland. Today, they are able to adapt to various types of grasslands both native and introduced.

d.

e. true

f. don't know

36. Short grass cover is used for
a.
e. roosting.
f. nesting and brood rearing.
g. don't know

37. are identified as the most significant habitat type to prairie chicken success.
e. __ booming grounds
f. roosting cover
g. nesting and brood rearing cover
h. don't know

38. "Lek" is defined as
e. the berries that many animals are dependent upon as a food source.
f. an area where animals carry on display and courtship behavior.
g. a small prairie rodent.
h. don't know

39. Booming ground counts can be used as an index to population abundance and can be useful in showing trends over a span of years.

d. true

e. false

f. don't know

40. Cocks (male prairie chickens) do not show strong fidelity to booming grounds year after year.

d. true

e. false

f. don't know

41. Hens (female prairie chickens) do not show strong fidelity to booming grounds year after year.

d. true

e. false

f. don't know 
42. Prairie chickens tend to have brood(s) per year with an average of eggs per clutch
f. $1,2-3$
g. $2,2-3$
h. $1,10-15$
i. $2,10-15$
j. don't know

43. A sign that copulation is successful can be seen by

e. a cock that ceases to boom for the remainder of the morning:

f. a hen who "rouses", or shakes her feathers violently, and leaves the booming grounds within ten minutes.

g. a cock and hen pair that leave the booming ground together.

h. don't know

44. Wilhelmine LaBudde wrote Wisconsin's first environmental education (EE) initiative in
f. 1935
g. 1955
h. 1975
i. 1995
j. don't know

45. Held in Tbilisi, Georgia of the USSR, 1977 marked

e. the celebration of environmental education reform in the United States.

f. the acceptance of environmental education in the school systems.

g. the first intergovernmental conference on environmental education.

h. don't know

46. The goal of environmental education is to

a. produce environmentally responsible citizens who can work for a balance between quality of life and quality of the environment.

b. create active citizens with increased participation in outdoor activities who show a genuine concern for the environment.

c. practice education in an outdoors setting in order to show first hand the hazards that humans can inflict on the surrounding environment.

d. don't know

47. Wisconsin employed an model requiring a systematic incorporation of EE into existing curriculum plans.

e. implementation

f. infusion

g. induction

h. don't know 
48. Beside environmental ethic, the other EE subgoal that focuses on grades 9-12 is e. __ perceptual awareness.

f. — knowledge.

g. — citizen action experience.

h. don't know

49. The office responsible for environmental education in Wisconsin is the e. __ Wisconsin Department of Natural Resources.

f. W Wisconsin Department of Public Instruction.

g. Wisconsin Association for Environmental Education.

h. don't know 


\section{APPENDIX G \\ Becoming an Outdoors-Woman (BOW) Prairie Chicken Teacher Workshop \\ Overall Workshop Evaluation}

We would like you to help us evaluate and improve the BOW teacher workshop by filling out the following questionnaire. The information that you provide on this questionnaire will be kept confidential. Thank you for your participation in this workshop and for offering us this valuable feedback.

$$
\text { ( } 1 \text { = Strongly Disagree, } 2 \text { = Disagree, } 3 \text { = Neutral, } 4 \text { = Agree, } 5=\text { Strongly Agree })
$$

\section{WORKSHOP CONTENT}

Strongly

Disagree Disagree Neutral Agree

Strongly

1. The workshop provided me with factual information.

2. The workshop helped me understand the information.

$\begin{array}{lllll}1 & 2 & 3 & 4 & 5\end{array}$

3. The workshop challenged me intellectually. 1
4. The workshop was applicable to my current $\begin{array}{llllll}1 & 2 & 3 & 4 & 5\end{array}$ or future career.

5. This workshop presented me with resources 1
I will be able to use in the future.

$\begin{array}{llllllll}\text { 6. I am comfortable using the resources } & 1 & 2 & 3 & 4 & 5\end{array}$ presented to me during the workshop.

$\begin{array}{llllllll}\text { 7. I feel I gained hands-on skills associated } & 1 & 2 & 3 & 4 & 5\end{array}$ with prairie chicken ecology/conservation.

$\begin{array}{llllllll}\text { 8. I became familiar with general prairie } & 1 & 2 & 3 & 4 & 5\end{array}$

9. I consider myself more knowledgeable $\quad \begin{array}{lllllll}1 & 2 & 3 & 4 & 5\end{array}$ about prairie chicken ecology/conservation after taking this course.

10. The "Historical Perspective" session helped $\begin{array}{llllll}1 & 2 & 3 & 4 & 5\end{array}$ me expand my knowledge about the past and present prairie chicken population in Wisconsin. 
11. The "Historical Perspective" session helped 1 me expand my knowledge of the Buena Vista Marsh.

12. The "Historical Perspective" session helped 1 me expand my knowledge of pioneering conservationists involved with prairie chickens.

13. The 'Prairie Chicken Viewing' session helped me expand my understanding of prairie chicken courtship and behavior.

14. The 'Buena Vista Marsh Tour' sessio helped me expand my knowledge of management practices on the Marsh.

15. The 'Prairie Chicken Ecology' session helped me to expand my understanding of prairie chicken ecology.

16. The 'Prairie Habitat' session helped me to expand my understanding of prairie habitat. helped me to expand my understanding of environmental education.

18. The 'Curriculum Development' session helped me to understand how to develop curriculum using the knowledge gained in this workshop.

19. The resource binder is a helpful resource 1 2

345
to me.

20. The resource binder will influence my future teaching.

21. This workshop will influence my future teaching.

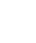

.


22. The workshop was well organized.

$\begin{array}{lllll}1 & 2 & 3 & 4 & 5\end{array}$

23. The workshop sessions seemed to flow 1 logically.

24. There seemed to be sufficient interaction between participants.

25. There seemed to be sufficient interaction between students and the instructor.

26. The sessions were appropriate in length. $\begin{array}{lllllll}1 & 2 & 3 & 4 & 5\end{array}$ If you disagree, were they (please indicate) too short too long

27. The registration process was easy to 12 understand.

28. The BOW staff members were helpful and courteous.

29. The assignment seems appropriate.

30. The assignment will be useful to me as an educator.

31. The BOW workshop format is effective for 'teacher specific' workshop tracks.

32. I would be interested in other BOW teacher specific workshops tracks.

Why or Why not? (Please briefly explain)

33. I would consider attending other BOW workshops that focused on another species.

Please rank the following in order of interest:

$\begin{array}{ll}\text { Plant } & \text { Mammal } \\ \text { Fish } & \text { Reptile } \\ \text { Bird } & \text { Amphibian }\end{array}$

12

3

4 5 


\section{OVERALL}

34. Please rank the following sessions in terms of overall effectiveness (most helpful/useful) to your understanding about prairie chicken ecology/conservation. The instructors have been included for clarification; however, please rank the content of the session, not the instructor's abilities.

(1=most effective, $7=$ least effective)

$\begin{array}{ll}\text { Historical Perspective } & \text { (Jim Keir, Lyle Nauman, Kelly Bleich) } \\ \text { Prairie Chicken Viewing } & \\ \text { Tour of the Buena Vista Marsh } & \text { (Gary Wolf) } \\ \text { Prairie Chicken Ecology } & \text { (Dave Halfmann) } \\ \text { Prairie Habitat } & \text { (Bob Rosenfield) } \\ \text { Environmental Education } & \text { (Dan Sivek) } \\ \text { Curriculum Development } & \text { (Dorothy Ginnett) }\end{array}$

35. Please rank the following sessions in terms of overall value (most helpful/useful) to you as an educator.

(1=most effective, $7=$ least effective)

Historical Perspective

Prairie Chicken Viewing

Tour of the Buena Vista Marsh

Prairie Chicken Ecology

Prairie Habitat

Environmental Education

Curriculum Development

36. Please rank the following sessions in terms of overall value (most helpful/useful) to you personally.

(1-most effective, $7=$ least effective)

Historical Perspective

Prairie Chicken Viewing

Tour of the Buena Vista Marsh

Prairie Chicken Ecology

Prairie Habitat

Environmental Education

Curriculum Development 
37. What did you like most about this workshop?

38. What aspects of the workshop could be improved?

39. Would you recommend this workshop to a colleague or friend? Why or Why Not?

40. How will you apply information gained during this workshop into your personal or professional life?

41. If you intend to infuse the information gained in this workshop, please describe how you will do so.

42. Additional comments about the workshop: 


\section{Prairie Chicken Viewer Survey}

YOUR ANSWERS TO THESE QUESTIONS WILL HELP US DRAW A COMPOSITE PICTURE OF PRAIRIE CHICKEN VIEWERS.

1. Gender: $\square$ Male $\square$ Female

2. Age:

3. Education: Please describe your formal education. Check the highest level completed.

$\square$ GED or high school diploma

$\square$ Undergraduate college degree

Currently attending (grade)
Apprenticeship, trade school or similar

$\square$ Graduate or Professional school

$\square$ Other

4. What is your current occupation (please be specific)?

5. Please indicate where you live (City) and (State)

6. Which of the following best describes the area where you live (Check one):

$\square$ Rural

Community with under 5,000 people

$\square$ Community with 5,000 to 24,999 people

City of 25,000 to 99,999 people

$\square$ Major city of over 100,000 people

$\square$ Suburb of major city

7. What is the distance traveled from your house, to view the prairie chicken booming?

Total Distance (miles)

8. The night before viewing the prairie chickens did you stay in a local area hotel?

$\square$ Yes $\quad \square$ No If no, what were your accommodations?

9. Is this prairie chicken viewing session part of a larger trip?
$\square$ Yes
$\square$ No If yes, how many days is your trip?

10. Was prairie chicken viewing the main focus of your trip?
Yes
$\square$ No

11. What other outdoor activities do you participate in? Please circle all that apply.

\begin{tabular}{lllll} 
Hunting & Fishing & Bird Watching & Canoeing & Camping \\
Photography & Hiking & Boating & Other & \\
\hline
\end{tabular}

12. Have you ever viewed prairie chickens on the Buena Vista Marsh before?

$\square$ Yes $\quad \square$ No
If yes, what year or years?

13. Are you presently a member of any environmental or conservation based clubs or organized groups?

$\square$ Yes $\square$ No
If yes, please list here

14. How did you hear about the prairie chickens viewing? Please check all that apply.
Internet
Magazine
Newspaper
$\square$ Friend
Other
Please indicate source

حOVER 
15. The information packet I received adequately prepared me for my visit.
1
2
Disagree
3
Strongly disagree
Neutral
4
Somewhat agree
5
Strongly agree

16. Please indicate which part(s) of the information packet you found most useful. Please check all that apply.

$\square$ Color Brochure $\square$ List of Accommodations \& What to Bring $\square$ Census Methods $\square$ Magazine story
Map/Directions
$\square$ Background information on prairie chickens
$\square$ Sample Census
$\square$ None

17. Please indicate which part(s) of the information packet you found least useful. Please check all that apply.

$\square$ Color Brochure $\square$ List of Accommodations \& What to Bring $\quad \square$ Census Methods $\quad \square$ Magazine story
$\square$ Map/Directions $\quad \square$ Background information on prairie chickens $\square$ Sample Census $\quad \square$ None

18. What information would have better prepared you for this visit ?

19. The information packet helped me learn about prairie chickens.
1
2
3
4
5

Strongly disagree Disagree Neutral Somewhat agree Strongly agree

20. What things did you learn?

21. My visit to the booming grounds helped me learn about prairie chickens.
1
2
3
Neutral
4
5
Somewhat agree
Strongly agree

Strongly disagree Disagree

22. What things did you learn?

23. My experience viewing the prairie chickens was satisfying.

$$
\begin{array}{lll}
1 & 2 & 3
\end{array}
$$

\begin{tabular}{ccccc}
1 & 2 & 3 & 4 & 5 \\
Strongly disagree & Disagree & Neutral & Somewhat agree & Strongly agree \\
Provide any relevant details & & & \\
\hline
\end{tabular}

24. Would you return for another visit?
$\square$ Yes
$\square$ No
Why or Why not?

25. Would you encourage others to participate in this opportunity?
Yes
$\square$ No
Why or Why not?

26. Comments: Please share any suggestions that could make this program better.

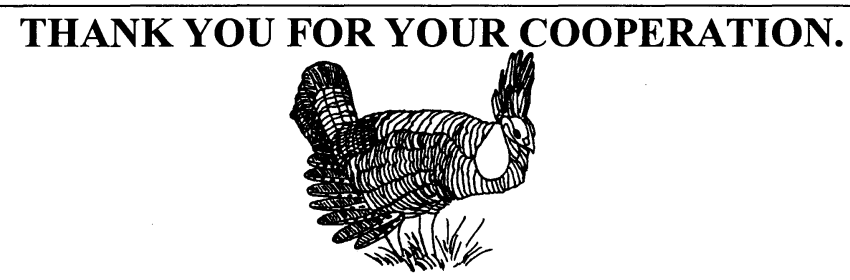




\section{APPENDIX I \\ Additional comments from the Overall Workshop Evaluation}

Question 32. Participants' responses when asked why they would or would not be interested in other BOW teacher specific workshop tracks

\section{Response}

- Especially science research based applied programs.

- Fun, informative, hands-on, active, relaxing atmosphere.

- Specific topic workshops are beneficial.

- Definitely has been rewarding and welcome other topics.

- Local case studies give students something to identify with / add relevance to teaching.

- Great focus on topic area in depth.

- It was very inspiring and the location was great. Staff exceptional.

- Time to interact, discuss, hands-on experience. 


\section{APPENDIX J \\ The Greater Prairie Chicken: Conservation and Courtship Resource Binder Contents}

The following materials are included as contents to this binder:

\section{Printed Materials}

This section is divided into Prairie Chicken Ecology, Prairie Habitat, The Hamerstroms, Environmental Education, and Sample Activities. Each section includes relevant literature, newspaper articles, book chapters, maps, and other materials.

\section{Video}

The VHS video contains two 30-minute videos. The first segment, entitled "Wisconsin Prairie Chicken: A Cause for Preservation" was produced by the Wisconsin Department of Natural Resources in 1988. This film depicts greater prairie chicken ecology, habitat and the conservation efforts to save this unique species. This film also contains interviews with many individuals who dedicated their lives to helping the prairie chickens, including Frances and Frederick Hamerstrom.

The American Museum of Natural History Library produced the second 30minute clip, entitled "Sunrise Serenade" in 1950. This film contains footage of greater prairie chickens booming, as well as the booming activities of two other grouse species. Finally, there is a unique footage of a traditional Native American prairie chicken dance.

\section{Rom}

The compact disk contains audio files, video files, still photos, and census data of greater prairie chickens. Census data is located in a Microsoft Excel spreadsheet, still photos are JPEG files, audio files are Mp3 files, and video files are MPEG files. Both audio and video files can be accessed using Microsoft Media Player. Several versions of Microsoft Media Player have been included on the CD Rom and can be downloaded to your computer by simply opening the file in the folder of the desired version (Macintosh or MS Windows).

\section{Prairie Seed Packets}

Seed samples were collected in Central Wisconsin and included the following species:

Big blue-stem (Andropogon gerardii)

Little blue-stem (Schizachyrium scoparium)

Blazing-star (Liatris aspera)

Yellow coneflower (Ratibida pinnata)

Lead plant (Amorpha canescens)

Whorled milkweed (Asclepias verticillata) 


\section{APPENDIX K \\ PRAIRIE ChICKEN ECOLOGY \\ TABLE OF CONTENTS}

The items in this section can be found in the following order:

1. Prairie Chicken Resources

- A list of website resources covering prairie chicken and wildlife sources.

2. Prairie Chickens in Wisconsin

- A brief checklist of important Wisconsin prairie chicken facts.

3. Greater Prairie Chicken

- Wisconsin Department of Natural Resources fact sheet.

4. History, Status, and Management of the Greater Prairie Chicken in Wisconsin

- A cumulative publication effort that takes an in depth look at the history, status and management practices in Wisconsin.

5. Wisconsin Prairie Chicken Management: An Agency Perspective

- Background information and current habitat management practices in WI.

6. Tympanuchus cupido Greater Prairie Chicken

- Life history of the greater prairie chicken from The Birds of North America.

7. A Management Plan for Greater Prairie Chicken in Wisconsin

- 1995 plan addressing resource base, goal, objectives, problems and strategies and research direction.

8. Central Wisconsin Prairie Chicken Census

- 2002 final report of booming ground counts in Wisconsin.

9. Booming Ground Census Methods

- Explanation of census methods on the booming grounds accompanied by a completed sample census and a blank census.

10. Prairie Chicken Dance of Life

- A 1996 Milwaukee Journal Sentinel article describing the use of radio telemetry on Wisconsin's prairie chickens. 


\section{Relevant citations for items in this section:}

3. Wisconsin Department of Natural Resources. 2003. Greater Prairie Chicken. Available: http://www.dnr.state.wi.us/org/land/er/factsheets/birds/Prchick.htm

4. Anderson, R. K. AND J. E. Toepfer. 1999. History, status, and management of the greater prairie chicken in Wisconsin. Pages 39-58 in Svedarsky, W. D., R. D. Hier, and N. J. Silvy, editors. The greater prairie chicken: a national look. Agricultural Experiment Station, Miscellaneous Publication 99-1999, University of Minnesota, St. Paul, Minnesota, USA.

5. Keir, J. R. 1999. Wisconsin prairie chicken management: an agency perspective. Pages 59-62 in Svedarsky, W. D., R. D. Hier, and N. J. Silvy, editors. The greater prairie chicken: a national look. Agricultural Experiment Station, Miscellaneous Publication 99-1999, University of Minnesota, St. Paul, Minnesota, USA.

6. Schroeder, M. A., and L. A. Robb. 1993. Greater prairie-chicken (Tympanuchus cupido). The birds of North America, number 36. The American Ornithologists' Union, Washington, D. C., USA, and The Academy of Natural Sciences, Philadelphia, Pennsylvania, USA.

7. Society of Tympanuchus Cupido Pinnatus. 1995. A Management Plan for Greater Prairie Chicken in Wisconsin. Society of Tympanuchus Cupido Pinnatus, Ltd. 20pp.

8. Keir, James R. 2002. Central Wisconsin Prairie Chicken Census 2002 Final Report. Wisconsin Department of Natural Resources. 9pp. 


\section{PRAIRIE CHICKEN RESOURCES}

Central Wisconsin Greater Prairie Chicken

http://www.uwsp.edu/wildlife/programs/Pchicken/Home.htm

Cornell Laboratory of Ornithology $\sim$ Greater Prairie Chicken

http://birds.cornell.edu/bow/grpchi/Index.htm

EEK! Wisconsin Department of Natural Resources

http://www.dnr.state.wi.us/org/caer/ce/eek/critter/bird/prairiechicken.htm

Fossil Rim Wildlife Recovery Attwater's Prairie Chicken Recovery

http://www.fossilrim.com/research/attwater.php

Management of the Greater Prairie Chicken on the Sheyenne National Grassland http://www.npwrc.usgs.gov/resource/othrdata/sheyenne/sheyenne.htm

Missouri Greater Prairie Chicken

http://www.conservation.state.mo.us/nathis/birds/chickens/

Sutton Avian Research Center - Ecology of the Greater Prairie Chicken http://www.suttoncenter.org/chickens.html

U.S. Fish \& Wildlife $\sim$ Attwater Prairie Chicken National Wildlife Refuge http://southwest.fws.gov/refuges/texas/attwater/index.html

USGS Greater Prairie Chicken

http://www.mbr-pwrc.usgs.gov/id/framlst/i3050id.html

Wisconsin Department of Natural Resources Greater Prairie Chicken http://www.dnr.state.wi.us/org/land/er/factsheets/birds/Prchick.htm 


\section{Wildlife Resources}

National Park Service Wildlife Management Activity Guide

http://www.nps.gov/piro/wl_lesns.htm

National Wildlife Federation

http://www.nwf.org/education/

Northern Prairie Wildlife Research Center

http://www.npwrc.usgs.gov/

\section{Project Wild}

http://www.projectwild.org/

Ranger Rick's Kid Zone

http://www.nwf.org/kids/

U.S. Fish \& Wildlife Service

http://endangered.fws.gov/education/index.html

Windows on the Wild

http://www.worldwildlife.org/windows/ 


\section{APPENDIX L \\ Buena Vista Marsh \& Prairie Habitat}

TABLE OF CONTENTS

The items in this section can be found in the following order:

1. Prairie Resources

- List of website resources covering prairie and grassland habitat.

2. Map of the Buena Vista Marsh

- Plat map of the Buena Vista Marsh booming ground locations.

4. Managing Habitat for Grassland Birds A Guide for Wisconsin

- Introduction to guidebook derived from the Wisconsin grassland bird study conducted from 1985-1997.

5. Overview of Grassland and Grassland Birds Management Issues

- Definition of grassland bird habitat and grassland bird communities from the Managing Habitat for Grassland Birds guide.

5. Central Plains

- Grassland bird species of management concern in the Central Plains from the Managing Habitat for Grassland Birds guide.

6. Conservation Reserve Program

- Fact sheet for the CRP program from the U.S. Department of Agriculture.

7. Conservation Reserve Enhancement Program

- Fact sheet for the CREP program from the U.S. Department of Agriculture.

8. \$1 Million Offer for Chicken Land

- 1988 Stevens Point Journal article describing DNR purchase of prairie chicken habitat.

9. Towns Stand Opposed to DNR Chicken Land Purchase

- Stevens Point Journal article, date unknown, describing some controversy to proposed purchase of prairie chicken habitat. 
Relevant citations for items in this section:

2. Map compiled by Mindy Brown using 2000 Portage County Plat Maps.

3-5. Sample, D. W. and M. J. Mossman. 1997. Managing Habitat for Grassland Birds A Guide for Wisconsin. Bureau of Integrated Science Services, Wisconsin Department of Natural Resources, Madison, WI.

6. United States Department of Agriculture. 2002. Conservation Reserve Program Fact Sheet.

Available: http://www.fsa.usda.gov/pas/publications/facts/html/crp02.htm

7. United States Department of Agriculture. 2001. Conservation Reserve Program Wisconsin Enhancement Program Fact Sheet.

Available: http://www.fsa.usda.gov/pas/publications/facts/html/crepwi01.htm 


\section{PRAIRIE Habitat RESOURCES}

Atlas of the Wisconsin Prairie and Savanna Flora

http://www.botany.wisc.edu/wisflora/PSAtlas.html

Bell Museum On the Prairie

http://www.bellmuseum.org/distancelearning/prairie/index.html

Blue Planet Biomes North American Prairie

http://www.blueplanetbiomes.org/prairie.htm

Conservation Reserve Program

http://www.fsa.usda.gov/dafp/cepd/crp.htm

Managing Habitat for Grassland Birds A Guide for Wisconsin http://www.npwrc.usgs.gov/resource/2002/wiscbird/wiscbird.htm

Neal Smith National Wildlife Refuge $\sim$ Friends of the Prairie Learning Center http://www.tallgrass.org/

Northern Prairie Wildlife Research Center

http://www.npwrc.usgs.gov/index.htm

Tallgrass Prairie Plants and Wildlife in Wisconsin

http://www.theprairieenthusiasts.org/flora/table.htm

Tallgrass Prairie National Preserve

http://www.nps.gov/tapr/home.htm

Wisconsin Department of Natural Resources EEK!

http://www.dnr.state.wi.us/org/caer/ce/eek/nature/habitat/prairiel.htm 


\section{APPENDIX M \\ THE HAMERSTROMS \\ TABLE OF CONTENTS}

The items in this section can be found in the following order:

1. Hamerstrom Resources

- A list of resources involving Frances and Frederick Hamerstrom.

2. A Tribute to the Hamerstroms

- A tribute article to the Hamerstroms from The Greater Prairie Chicken: A National Look.

6. Simply Remarkable: Frances Hamerstrom

- An essay about Frances Hamerstrom that originally appeared in the Women of Vision book (1999) and later in The Hamerstrom Stories (2002).

4. The Hamerstroms - Two People for the Birds

- A 1972 article in the University of Wisconsin-Stevens Point Pointer that includes pictures of the Hamerstroms and some of their pet birds of prey.

5. A Feathery Legacy - Lifetime of Wildlife Work Brings Honors to Hamerstroms

- A 1996 article from the Stevens Point Journal describing the Hamerstroms work.

6. Hamerstrom Was Conservation Pioneer

- A 1998 article from the Stevens Point Journal after the death of Frances Hamerstrom at the age of 91 .

7. Home of Famed Biologist Focus of Preservation Effort

- A 2001 article from the Milwaukee Journal Sentinel describes efforts to preserve the Hamerstroms house in Plainfield, WI. 


\section{Relevant citations for items in this section:}

2. Anderson, R. K. AND D. E. Gawlik. 1999. A tribute to the Hamerstroms. Pages 1-8 in Svedarsky, W. D., R. D. Hier, and N. J. Silvy, editors. The greater prairie chicken: a national look. Agricultural Experiment Station, Miscellaneous Publication 99-1999, University of Minnesota, St. Paul, Minnesota, USA.

3. Thomas, C.L. 1999. Frances Hamerstrom 1909-1998. Pages 113-118 in Croft, M. K, J. Jurgella, S. Koehl, and B. Maher, editors. Women of vision: reflections on notable women of Portage County. Epitaph Press, Stevens Point, Wisconsin, USA. 


\section{HAMERSTROM RESOURCES}

\section{Books by Frances Hamerstrom:}

Hamerstrom, Frances, and Deann De La Ronde. An Eagle to the Sky. Guilford, CT: The Lyons Press, 1970.

, and Robert Katona. Walk When the Moon Is Full. Darlinghurst, NWS Austrailia: Crossing Press, 1975

Adventure of the Stone Man. Darlinghurst, NWS Austrailia: Crossing Press, 1977.

Strictly for the Chickens. Ames, IA: Iowa State University Press, 1980.

, and Jack Orr. Birding with a Purpose: Of Raptors, Gabboons, and Other Creatures. Ames, IA: Iowa State University Press, 1984.

--------, and Roger Tory Peterson. Eagles, Hawks, Falcons and Owls of America: A Coloring Album. Lanham, MD: Roberts Rinehart Publishers, 1984.

---------, and Frederick Hamerstrom, and Jonathan Wilde. Harrier, Hawk of the Marshes: The Hawk That is Ruled by a Mouse. Washington, Smithsonian Institute Press, 1986.

Is She Coming Too?: Memoirs of a Lady Hunter. Ames, IA: Iowa State University Press, 1989.

, and Elva H. Paulson. Wild Food Cookbook. Woodruff, WI: Amherst Press, 1989.

and Elva Hamerstrom Paulson. My Double Life; Memoirs of a Naturalist.

Madison, The University of Wisconsin Press, 1994. 


\section{Stories about the Hamerstroms:}

Elva Hamerstrom Paulson. Hamerstrom Stores. Roseburg OR. 2002

Helen Corneli. Mice in the Freezer, Owls on the Porch: The Lives of Naturalists

Frederick and Frances Hamerstrom. Madison: The University of Wisconsin Press, 2002.

\section{Selected Publications by the Hamerstroms:}

Hamerstrom, F. N., JR. 1939. A study of Wisconsin prairie chicken and sharp-tailed grouse. The Wilson Bulletin. 51(2): 105-121.

Hamerstrom, F. N., Jr., and F. Hamerstrom. 1949. Daily and seasonal movements of Wisconsin prairie chickens. Auk 66:313-337.

Hamerstrom, F. 1950. Range habits and food requirements of prairie chicken. Wisconsin Conservation Bulletin. 15(11):9-11.

Hamerstrom, F. N., Jr., and F. Hamerstrom. 1955. Population density and behavior in Wisconsin prairie chickens (Tympanuchus cupido pinnatus). Proceedings of the International Ornithological Congress 11:459-466.

Hamerstrom, F. N., Jr., O. E. Mattson, and F. Hamerstrom. 1957. A guide to prairie chicken management. Wisconsin Conservation Department Bulletin 15. 128pp.

Hamerstrom, F. N and F. Hamerstrom. 1973. The prairie chicken in Wisconsin: highlights of a 22-year study of counts, behavior, movements, turnover and habitat. Wisconsin Department of Natural Resources Technical Bulletin no. 64. $52 \mathrm{pp}$ 


\section{APPENDIX N \\ ENVIRONMENTAL EDUCATION}

TABle OF CONTENTS

The items in this section can be found in the following order:

1. Environmental Education Resources

- A list of website resources covering environmental education sources.

2. The Myths of Environmental Education - Revisited

- A paper that addresses the myths surrounding environmental education and compares myths of EE from 1975 to 2000.

7. Goals for Curriculum Development in Environmental Education

- A paper that addresses the goals for curriculum development using the Tbilisi Declaration as a basis for the structure of EE.

4. The Tbilisi Declaration

- A paper describing the Intergovernmental Conference on Environmental Education, considered one of the most important documents in EE.

5. Wildlife-based Environmental Education in a Natural Setting

- 2002 EETAP sheet addressing EE based on wildlife, wildlife in a natural setting, and first-hand experiences with wildlife. 


\section{Relevant citations for items in this section:}

2. Hungerford, H.R. "The myths of environmental education - Revisited " In Essential Readings in Environmental Education, edited by $\mathrm{H}$. Hungerford et al. Champaign, IL: Stipes Publishing Company, 1998.

3. Hungerford, H.R., R. B. Peyton, and R. J. Wilke. "Goals for curriculum development in environmental education " In Essential Readings in Environmental Education, edited by H. Hungerford et al. Champaign, IL: Stipes Publishing Company, 1998.

4. "The Tbilisi Declaration " In Essential Readings in Environmental Education, edited by H. Hungerford et al. Champaign, IL: Stipes Publishing Company, 1998.

5. Brown, M., S. Ermer, S. Hoffman, and D. Sivek. 2002. Wildlife-based environmental education in a natural setting. Environmental Education \& Training Partnership Resource Library.

Available: http://www.ag.ohio-state.edu/ eetap/pdf/info114.pdf 


\section{ENVIRONMENTAL EDUCATION RESOURCES}

\section{Ask Eric}

http://ericir.syr.edu/

\section{EE Link}

http://eelink.net/

Environmental Education and Training Partnership

http://www.eetap.org

EETAP Resource Library Information Sheets

http://www.ag.ohio-state.edu/ eetap/infosheets.htm

Environmental Literacy Council

http://www.enviroliteracy.org

Environmental Education Materials: Guidelines for Excellence Workbook http://www.naaee.org/ npeee/Workbook/

National Council for Science and the Environment

http://cnie.org

National Environmental Education Advancement Project

http://www.uwsp.edu/cnr/neeap

National Environmental Education and Training Foundation

http://www.neetf.org

North American Association for Environmental Education

http://www.naaee.org

State Education and Environment Roundtable

http://www.seer.org

United States Environmental Protection Agency Office of Environmental Education http://www.epa.gov/enviroed

U.S. EPA Environmental Education Center http://www.epa.gov/teachers/ 


\section{APPENDIX O}

\section{SAMPLE ACTIVITIES}

\section{TABLE OF CONTENTS}

The items in this section can be found in the following order:

1. Sample Activities

- A list of website resources containing sample activities.

2. From Bison to Bread: The American Prairie

- A Project Wild lesson plan in which students describe the needs of prairie plants and animals and how they can be preserved.

8. Wildlife 140 - Buena Vista Field Trip

- A sample field trip to the Buena Vista Marsh that covers the history of the marsh, habitat and prairie chicken knowledge.

4. Prairie Chicken Radio Telemetry

- A lesson plan that covers the use of radio telemetry and maps to discover the locations of prairie chickens.

5. What is ECOgraphy?

- An AskERIC lesson plan that uses graphic media devices to record fieldbased data. 


\section{Sample Activities \& Lesson Plan Resources}

\section{Discovery School Lesson Plans}

http://school.discovery.com/lessonplans/subjects/k-12.html

Education Works - Lesson Planning Center

http://www.education-world.com/a_lessons/index.shtml

EDSITEment Lesson Plans

http://edsitement.neh.gov/lesson_index.asp

Environmental Education Materials for K-12

www.dfwinfo.com/envir/swap/parents/links.html

GEM - The Gateway to Educational Materials

http://www.thegateway.org/

Ideas

http://www.ideas.wisconsin.edu/

K-12@UW-Madison

http://www.k12.wisc.edu

PBS TeacherSource

http://www.pbs.org/teachersource/

Teachers.Net Lesson Plan Exchange

http://teachers.net/lessons/

Teachnet.com Lesson Plans

http://www.teachnet.com/lesson/index.html

USDA Forest Service Conservation Education Curriculum

http://na.fs.fed.us/spfo/ce/content/for teachers/index.cfm 


\section{APPENDIX P}

Complete list of cities in Wisconsin that viewers are from.

\begin{tabular}{lccc|}
\hline & $\underline{2002}$ & $\underline{\mathbf{2 0 0 3}}$ \\
& City & Frequency & Frequency \\
\hline Almond & 2 & - \\
Amherst & 1 & - \\
Appleton & - & 5 \\
Aroca & 1 & - \\
Arpin & - & 1 \\
Baraboo & 2 & - \\
Bear Creek & 1 & - \\
Beloit & - & 2 \\
Black River Falls & 1 & - \\
Blue River & 1 & - \\
Bonduel & - & 1 \\
Cottage Grove & 2 & - \\
Custer & 2 & 1 \\
Dodgeville & - & 5 \\
Eagle River & 2 & - \\
Edgerton & 1 & 1 \\
Evansville & 2 & 2 \\
Fall Creek & 2 & - \\
Fredonia & 1 & - \\
Grand Rapids & - & 2 \\
Green Bay & - & 2 \\
Greenfield & - & 1 \\
Hartland & - & - \\
Hayward & 1 & 1 \\
Hillsboro & 1 & - \\
Hudson & - & - \\
Iola & - & - \\
Jackson & - & - \\
Junction City & - & - \\
Kenosha & - & - \\
LaCrosse & - & - \\
Lake Geneva & - & - \\
Ledgewiew & - & - \\
Madison & - & - \\
Manitowoc & - & - \\
Marinette & - & - \\
Marshfield & - & - \\
Mayville & - & - \\
\hline & -1 & - \\
\hline
\end{tabular}


Complete list of cities in Wisconsin that viewers are from (Continued).

\begin{tabular}{|c|c|c|}
\hline & $\underline{2002}$ & $\underline{2003}$ \\
\hline City & Frequency & Frequency \\
\hline McFarland & 1 & - \\
\hline Medford & 2 & - \\
\hline Menasha & - & 2 \\
\hline Menomonie & 1 & - \\
\hline Mequon & 1 & - \\
\hline Merrill & 3 & - \\
\hline Middleton & 1 & - \\
\hline Milladore & 1 & - \\
\hline Milwaukee & 13 & 5 \\
\hline Mosinee & 1 & - \\
\hline Mount Horeb & - & 1 \\
\hline Mukwonago & 1 & 3 \\
\hline Muscoda & 10 & - \\
\hline Neenah & - & 1 \\
\hline Nekoosa & 3 & 2 \\
\hline New Berlin & 1 & - \\
\hline New Richmond & - & 1 \\
\hline New London & 1 & - \\
\hline Oostburg & 1 & - \\
\hline Oregon & 1 & 1 \\
\hline Oshkosh & 5 & 5 \\
\hline Paddock Lake & 1 & - \\
\hline Pine River & 1 & - \\
\hline Plover & 11 & 9 \\
\hline Portage & 1 & - \\
\hline Port Edwards & - & 1 \\
\hline Poynette & 2 & - \\
\hline Racine & 2 & 1 \\
\hline Rhinelander & 4 & - \\
\hline Saukville & 1 & - \\
\hline Scandanavia & - & 1 \\
\hline Seymour & - & 1 \\
\hline Shawano & 1 & - \\
\hline Shorewood & 1 & - \\
\hline Spring Green & - & 1 \\
\hline Stevens Point & 41 & 16 \\
\hline Two Rivers & 2 & - \\
\hline Viroqua & - & 1 \\
\hline Wales & - & 1 \\
\hline Watertown & - & 2 \\
\hline Wannakee & 1 & - \\
\hline
\end{tabular}


Complete list of cities in Wisconsin that viewers are from (Continued).

\begin{tabular}{lccc|}
\hline & City & $\underline{\mathbf{2 0 0 2}}$ & $\underline{\mathbf{2 0 0 3}}$ \\
& Frequency & Frequency \\
\hline Waupaca & - & 1 \\
Wausau & 5 & 2 \\
Wauwatosa & 1 & 4 \\
West Bend & 4 & - \\
Whitefish Bay & 1 & - \\
Wisconsin Rapids & 2 & 9 \\
\hline
\end{tabular}




\section{APPENDiX Q}

Complete list of environmental or conservation based clubs.

\begin{tabular}{|c|c|c|c|c|}
\hline \multirow[b]{2}{*}{ Characteristic } & \multicolumn{2}{|c|}{$\underline{2002}$} & \multicolumn{2}{|c|}{$\underline{2003}$} \\
\hline & $\begin{array}{c}\text { \# of } \\
\text { Responses } \\
\end{array}$ & Percent & $\begin{array}{c}\text { \# of } \\
\text { Responses }\end{array}$ & Percent \\
\hline Aldo Leopold Foundation & - & - & 1 & 0.89 \\
\hline American Birders Association & 2 & $2.67 \%$ & - & - \\
\hline American Chestnut Foundation & 1 & $1.33 \%$ & - & - \\
\hline American Fisheries Society & - & - & 2 & 1.79 \\
\hline American Rivers & 2 & $2.67 \%$ & 1 & 0.89 \\
\hline American Water Resources Association & - & - & 1 & 0.89 \\
\hline Audubon Society & 18 & $24.00 \%$ & 20 & 17.86 \\
\hline Birding Clubs & 2 & $2.67 \%$ & 8 & 7.14 \\
\hline Cousteau Society & 1 & $1.33 \%$ & - & - \\
\hline Delta Waterfowl & - & - & 1 & 0.89 \\
\hline Ducks Unlimited & 3 & $4.00 \%$ & 6 & 5.36 \\
\hline Ecological Society of Foresters & - & - & 1 & 0.89 \\
\hline Environmental Defense Fund & 3 & $4.00 \%$ & - & - \\
\hline Friends of Crex Meadows & 1 & $1.33 \%$ & & \\
\hline Future Farmers of America & - & - & & \\
\hline Green Peace & 1 & $1.33 \%$ & & \\
\hline Ice Age Park & 1 & $1.33 \%$ & & \\
\hline International Crane Foundation & 4 & $5.33 \%$ & & \\
\hline Iowa County Prairie Restoration & 2 & $2.67 \%$ & & \\
\hline Izaak Walton League & 1 & $1.33 \%$ & & \\
\hline Land Trust & 1 & $1.33 \%$ & & \\
\hline Madison Arboretum & 1 & $1.33 \%$ & & \\
\hline $\begin{array}{l}\text { National Association of Nature } \\
\text { Photographers }\end{array}$ & 1 & $1.33 \%$ & & \\
\hline National Association of Interpreters & 3 & $4.00 \%$ & & \\
\hline National Parks Conservation Association & 1 & $1.33 \%$ & & \\
\hline National Wildlife Federation & 8 & $10.67 \%$ & & \\
\hline Nature Centers & 4 & $5.33 \%$ & & \\
\hline North American Butterfly Association & 1 & $1.33 \%$ & & \\
\hline Northern Nut Growers Association & 1 & $1.33 \%$ & & \\
\hline Pheasants Forever & 2 & $2.67 \%$ & & \\
\hline Prairie Enthusiasts & 2 & $2.67 \%$ & & \\
\hline Ranger Rick & 1 & $1.33 \%$ & & \\
\hline River Alliance of Wisconsin & 1 & $1.33 \%$ & & \\
\hline River Revitalization & 1 & $1.33 \%$ & & \\
\hline Rock Creek Conservationists & 1 & $1.33 \%$ & & \\
\hline Sierra Club & 16 & $21.33 \%$ & & \\
\hline Soil and Water Conservation Society & 1 & $1.33 \%$ & & \\
\hline
\end{tabular}


Complete list of environmental or conservation based clubs (Continued).

\begin{tabular}{lcr|rr}
\hline \multicolumn{1}{c|}{ Characteristic } & $\begin{array}{c}\text { \# of } \\
\text { Responses }\end{array}$ & Percent & $\begin{array}{c}\text { \# of } \\
\text { Responses }\end{array}$ & Percent \\
\hline The Nature Conservancy & 23 & $30.67 \%$ & \\
The Wilderness Society & 1 & $1.33 \%$ & \\
Trail Foundation & 1 & $1.33 \%$ & \\
Trout Unlimited & 3 & $4.00 \%$ & \\
Whitetails Unlimited & 1 & $1.33 \%$ & \\
Wild Ones & 2 & $2.67 \%$ & \\
Willow River OWLS & 2 & $2.67 \%$ & \\
Wisconsin Association for & 3 & $4.00 \%$ & \\
Environmental Education & & & \\
Wisconsin Society for Ornithology & 5 & $6.67 \%$ & \\
Wisconsin Wildlife Federation & 2 & $2.67 \%$ & \\
Yosemite Association & 1 & $1.33 \%$ & \\
& & & \\
\hline
\end{tabular}




\section{APPENDIX R}

\section{Additional comments from the Prairie Chicken Viewer Survey}

Question 18. What Information would have better prepared you for this visit?

\section{Response}

2002

- Size of blind.

- Picture and dimensions of blind, soft seat cushions.

- I felt well prepared.

- Nothing, good prep.

- Long underwear.

- Info on blind size and seating.

- Charting territories.

- Very well organized.

- Very organized.

- Very well organized.

- Detailed description of blind ports for photography.

- Mileage from 39 to kiosk.

- Size of viewing holes.

- Cushion for bench.

- Map with mileage indicated.

- Map with mileage indicated.

- Firewood in blind.

- Bring a cushion.

- Seat cushion.

- Nothing .

- None.

- Likely viewing distances to birds.

- Walking distances.

- None.

- Nothing.

- Read more about birds before attending.

- None, experience of past trips (rain etc.) helped most.

- The information given was more than adequate.

- Can't think of much, you did a good job.

- The packet prepared me well - you did a fine job with it. 


\section{Response}

- Blanket for colder weather.

- If the weather could be predicted accurately two months in advance

- Dimensions of blind and height of viewing ports.

- We should have brought one more pair of binoculars.

- None.

- None - except perhaps a map.

- Everything was great.

- None.

- The degrees, weather.

- Warm packs for hands and feet.

- I forgot how cold it gets.

- Size of blind.

- None.

- None.

- None.

- Small size of the blind and distance from car - I didn't know we'd be walking so far.

- Not much since I've been here before and I sort of knew what to expect.

- Well done.

- Knowing a little more what the blind is like.

- Maybe a description of the blind.

- None.

- None.

- Warning to bring flashlight and writing utensil.

- Possibly a video of what it is like, instead of reading everything.

- None - great.

- Not sure.

- None, perfectly prepared.

- Weather info.

- We had wondered if we were going to be sitting on the ground or not. I brought plastic.

- More info on blind itself. Eg, where we would be sitting.

- Information on what the blind is like. Didn't know if we would be sitting on ground.

- Your info was perfect.

- You did a fine job.

- A practice map.

- None.

- Information was good. 
Question 18 (Continued) What Information would have better prepared you for this visit?

Response

- More flashlights, seat cushions.

- Assignment to a specific site so we could go directly there. And, of course, a detailed map to that site.

- All just OK.

- All OK.

- Other things (animals) we might see, what does copulation look like?

- Mileage indicators on directions.

- Better info on how to draw territories and determine them - what time should you draw it?

- History.

- Info very good.

- Very complete and well run program.

- It was all useful.

- Nothing.

- Nothing!!!

- I felt adequately prepared. Maybe a description of the blinds.

- It's all good.

- Complete and well-run program.

- We were adequately prepared.

- It was great! 


\section{Response}

2002

- Historical info, hunting season (last), population of males.

- Background info about Buena Vista.

- Previously knew nothing, all info provided was interesting.

- Calls, behaviors, markings.

- Rituals, habits

- Was already familiar.

- Natural history and habits.

- Booming and booming grounds.

- More on habits of prairie chickens.

- Lots! Would like some past year's stats and figures.

- Good review.

- What chickens do, habitat, history.

- What their behavior might be.

- Mostly their behavior.

- I did not know that the females would be the only ones bothered by us and the males didn't mind at all.

- Male mating dance at dawn, endangered species protection.

- How frightened the chickens were of humans.

- Determining sex, habits of birds.

- What to expect, what to look for.

- History and mating habits.

- History and habits of prairie chickens.

- My kids learned how to distinguish the birds.

- Learned about the birds.

- Learned about birds

- They return to the same booming grounds every year, population of birds.

- Recovery program, habitat, behavior.

- History in Wisconsin.

- I knew virtually nothing before.

- Behavior, habitat, history.

- Refreshed knowledge in general.

- What the cocks look like and how they interact with other males.

- Had already read articles on them.

- Reviewed what previously knew.

- General info.

- History of birds.

- Behavior.

- What they were, why it is possible to watch them. 
- Identification, behaviors.

- Biology.

- History in Wisconsin.

- They're little birds.

- Nothing.

- They're funny looking.

- History, range.

- Behavior to watch for.

- I knew nothing before I read this, so it was all new to me.

- Nature is great.

- Identification, mating habits.

- Biological info, habits.

- History, habitat.

- The meaning of various displays and mock combat.

- Everything I learned was new, I knew nothing previous.

- History, population of years.

- How to view them.

- Bird behaviors, bird vocalizations.

- Before this I knew very little about prairie chickens.

- Ecology and Buena Vista history.

- Most of what I heard.

- How strongly these birds protect their territory.

- They are extremely territorial.

- History, description of bird and activity.

- History of the prairie chicken.

- Orange air sacs, if you scare them, they'll fly away.

- I had limited knowledge so all info was helpful.

- Behavior, characteristics.

- History, population, habitat.

- Reinforced what I already knew.

- That they had big orange horns.

- Breeding and bird habits.

- What to look for in the behavior of the birds.

- Everything I now know.

- Habits.

- Habits. 


\section{Response}

- Lots of competition between males, not to leave if hens are around.

- History of its preservation.

- How territorial the birds are and all the vocals.

- Territory.

- Behavior, vocalization, context of population decline, reason for counting them.

- My friend received the entire package and I just referred to the map.

- Differences between male and female. They stay in their own area.

- Natural history, management being done.

- Males vs. females, characteristics, some history, why this is important.

- Male vs. female, most managed area.

- Good review.

- General mating habits.

- Behavior.

- Things about chickens!

- Sex differentiation.

- Sex identification, history.

- About sexing the chickens.

- Looks, mating rituals.

- Not as good as seeing it.

- Their appearance.

- About the rituals they go through.

- What they were and looked like.

- The difference between male and females, what they look like.

- Extensive mating rituals.

- Blinds too small.

- That they set up territories and only top male breeds.

- Territory.

- History, differences in sexes.

- The differences in male and female.

- Differences in males and females.

- How to distinguish $\mathrm{M} / \mathrm{F}$, lots about their habits.

- That they were living everywhere.

- What they look like.

- Behaviors.

- About leks.

- I learned about their mating systems.

- Behavior sounds.

- Differences between male and female, displays, behavior.

- Identification. 


\section{Response}

- Reproductive ecology.

- A lot! Their mating methods in general.

- General information.

- Have known from prior knowledge.

- Difference between male and female.

- ID, sexes, behavior, history.

- Not to disturb hens because they might not come back.

- Territory info, unaware of strong presence in WI.

- Already knew everything.

- Proper protocol for viewing.

- Their physical description and habits.

- Characteristics of prairie chickens.

- The orange are male. And other general facts.

- Population history and behavior.

- What they look like.

- Mating behavior.

- Life history, how to view, mating dance techniques. 


\section{Response}

2002

- The call of the displaying males.

- Displays, interactions, rituals, mating behaviors.

- Rituals, habits.

- Behavior, habits, how to identify.

- Identification, behavior.

- Habitat, mating, interaction of chickens.

- Mating habits.

- Very strange \& most interesting bird (cocks of course).

- First time seen p.c's drive mallards from the lek!

- Habits, rituals, etc.

- How great their "booming".

- Sneaky males.

- They showed a well-defined group behavior.

- I never knew what they sounded like.

- I did not know that the females would be the only ones bothered by us and the males didn't mind at all.

- Habits of birds, what it is like to live in a refrigerator carton.

- They are amazing, beautiful, musical and worth preserving.

- Actual physical activity.

- Habits and actions of prairie chickens.

- The importance of preserving the marsh.

- About their natural habitat.

- About how they mate.

- Mating habits of males v. females.

- The hens are nowhere to be seen in shitty weather.

- Behavior, info pack was main source of info.

- Territorial behavior.

- The sounds were wonderful.

- Nothing like direct experience.

- Behavior, vocalizations.

- Behavior.

- To actually see p.c's and their behavior.

- I enjoyed the booming.

- What they do.

- The sounds, behaviors and habits.

- The sounds.

- What they sound like.

- Reconnect with nature. 

grounds?

\section{Response}

- The awe of seeing them doesn't dwindle with age.

- How the cocks set up territories.

- Up close and personal.

- Mating behavior.

- Lots!

- A sense of their patterns.

- Patterns of males, reassuring persistence of males.

- Habits.

- Species reproduction strategy.

- Mating ritual, vocal sounds.

- They look funny.

- The mating habits.

- Mating habits.

- ID.

- Seeing, hearing.

- Count is difficult to be accurate.

- Noises they make, mating behavior.

- Numbers, behavior, habit.

- There is nothing like seeing it live, even if you've read about it and know what to look for.

- Proprietary nature of prairie chickens.

- Females can be aggressive too.

- Behavior of males $\mathrm{v}$. males and females $\mathrm{v}$ females.

- Natural history.

- Courting ritual.

- Courting ritual.

- Behavior patterns.

- Behavior, identification.

- Lek boundaries are quite easy to determine.

- Mating rituals.

- Somewhat of their behavior.

- Their calls, teritories, mating displays.

- They make more noise than I thought.

- It was just fascinating to watch the birds.

- Prairie chicken appearance and habits. 


\section{Response}

- Booming, different behavior between mail / female.

- I didn't know much about, so I learned a lot.

- Sounds and characteristics differing male / female mating behavior.

- Their courting, booming.

- Behaviors, physical characteristics, sounds.

- Their breeding ritual.

- Courtship, behavior, history.

- Behavior, mating pattern.

- Size doesn't matter - smaller male was dominant.

- Sounds, courtship rituals, what a meadowlark looks like.

- Habitat, behavior, characteristics.

- They are spooked by marsh hawks and short-eared owls.

- I learned the behavior in college, an emotional gratifying experience to view to be able to share with students.

- Observed behavior.

- Sounds, behavior.

- Mating habits.

- Female very unwilling to make a decision (spent an hour on lek and strutted through territory many times).

- The bird's behavior, hen's selection of a mate.

- The female rules at mating time.

- It was just inspiring and I learned about management.

- How amazing they are! Female behavior different from male.

- Real life experience does not compare to literature.

- Habitat, breeding, threatened status.

- The order of sounds, starting with their feet.

- They try to attract mates by booming.

- How noisy the booming actually is!

- Behavior, characteristics.

- Mating habits.

- Reinforced what I already knew.

- They attracted chicks in a weird way.

- How they fly in and establish territories, sounds and actions.

- There's no substitute for viewing things live.

- Coloration.

- Behavioral ecology.

- Chicken behavior, habitat info.

- Mating ritual, how to ID birds.

- Display. 


\section{Response}

- Elaborateness of displaying.

- Reaction to predators, unusual call.

- More about their behavior.

- Where they winter and how, do they roost or sleep on ground. When do hens start coming in, how long into spring does this ritual last?

- Territory displays, behaviors, plumage coloration.

- About males and their booming displays.

- That definitive territories are held during lekking.

- Rough-legged hawks spook the prairie chickens - short-eared owls do not.

- Male lekking behavior.

- Display patterns, hawk sensitivity.

- Territory defense.

- They flush at harriers but not short-eared owls (at least that is how it seemed).

- Territory habits - sounds, looks, too few gals.

- Got a better close up view of behavior.

- How they interact, see something wild in a natural setting!

- Birds of prey in vicinity spook the chickens easily.

- Behavior, booming behavior.

- When raptors appear - birds flush, when no hen's males mostly quiet.

- Territories.

- Lek protocol.

- Behavior.

- Hierarchy/territory and territorial display, their bird call.

- Looks, mating rituals, sounds, dancing that they do.

- Visually said it all.

- Mating behaviors.

- How hard it is to have enough females to mate.

- They are very early risers, make weird noises, and attack each other.

- How they act.

- Visual - loud.

- Blinds too small

- How they fight for territories.

- They were just so amazing.

- All about mating dance.

- The prairie chickens are afraid of hawks.

- That when they walk they "bob" like pigeons.

- Good to see stuff learned in \#20 in action.

- About territory.

- How they dance. 
- It's still early.

- How they compete for mates.

- Males are dominant.

- Alpha male, how males dance, they have individual territories.

- Lots - real live prairie chicken action.

- Beauty, sounds, behavior.

- Territorial behavior, drumming and displays.

- Air sac and dance.

- Breeding behavior, territories, and vocalizations.

- Reproductive ecology.

- Sounds, behavior.

- You sure can tell when the females are around.

- Confirm what I read.

- The males are persistent and the females are awful flirts.

- Territorial behaviors.

- Behaviors, sounds, variability.

- Competition for territory.

- Dance ritual, defending territory, sights and sounds!

- Already knew everything.

- How mate, behavior with each other.

- About their behavior.

- Everything about them.

- Mating rituals.

- What male birds do to gain hens attention.

- Their "dance" and mating.

- Territory, response to potential danger.

- Prairie chickens are interesting.

- Mating behavior.

- Reproduction techniques, history in WI. 
Question 23. Provide any relevant details of your experience viewing the prairie chickens.

Response

2002

- Experience helped me to strongly appreciate these marvelous birds and the awe of nature overall.

- A fantastic learning experience.

- Couldn't believe how fast the 2 hours went.

- Always great to witness bird behavior and to be involved with their conservation.

- It is important for children to develop an environmental ethics (I brought my kids).

- Perfect weather - high quality blind.

- Good photos (video).

- Beautiful morning but no females.

- Well organized, Mindy very responsive to questions.

- Would like to see some hens and copulation.

- A lot of fun!

- Very close to birds.

- Very close to wildlife.

- Nothing.

- Last year I didn't get to se any females so this was a great new experience.

- First time, didn't think I would see so many birds.

- Awesome.

- It was great.

- Great show.

- Distinct characteristics of the interaction among males and females making the mating choice.

2003

- They weren't as active as in the past.

- The hens were out.

- Very interesting to watch!!

- Was my first experience.

- 10 yr daughters first time, Wow's.

- Want to do this again.

- It was sweet, but no hens.

- I have seen these birds on TV but viewing them in person was impressive.

- Very interesting, pretty much as expected.

- I loved it - want to do it again.

- Many birds to view, lots of activity. 


\section{Response}

- Interesting to see.

- Weather could have been better.

- It was lively and action packed - no copulations though.

- I didn't like the temp.

- Displays were great, good activity.

- Great morning with plenty of booming. No females though.

- Not very many females.

- No breeding.

- Blind in good position, room compared with the Hamerstrom blinds! Perfect weather - absolutely clear and still.

- An amazing lesson in animal behavior (mating ritual and territoriality).

- Great way to spend morning and although I didn't take any photos, that was reason for the trip.

- No females observed.

- I have a favorite, I named him Tubby.

- Interesting, provides better understanding.

- Very cold!

- Watching the territory boundaries and what they do.

- Cold!

- It was interesting.

- Great experience.

- -19 degrees F. explains this.

- It was too cold.

- They were just so amazing.

- Very cold but the whole thing was spectacular. One male kept booming on top of blind.

- It was great, we almost got frozen in.

- Very interesting to see courtship.

- I wish the females had come, but too freezing!

- A lot of birds were present.

- Very exciting.

- Several times landed on our blind and drummed!! Amazing to watch especially when female arrives! Things sure quiet down when the sun is high and the females are gone.

- Neat to see them. To see what rolls each bird had.

- I had to go to the bathroom.

- The chickens were entertaining.

- It was very cold...brrr...

- A wonderful natural experience. Great way to start a day. 


\section{Response}

2002

- I had a great time.

- It was a great and rare experience.

- Great!

- To take a friend.

- Rites of spring.

- Been there, done that.

- I will remember this visit.

- It was fascinating to observe.

- Undecided.

- Enjoyed it but we did get a good look.

- It was a unique experience.

- To bring others.

- To bring friends.

- More photography.

- Live in Michigan.

- Photo op.

- Once is enough.

- Interested in different wildlife viewing opportunities.

- Not sure.

- Maybe.

- Beautiful courtship.

- Very enjoyable.

- Best way to enjoy a limited resource.

- Not sure, time availability.

- Maybe.

- It was cool.

- Once is enough.

- Possible to show someone else.

- I 'd love to bring visiting friends or family.

- To show someone else that has never done this.

- Great experience.

- Still a beautiful experience.

- It's neat to see.

- Fun.

- Time concerns.

- With others. 


\section{Response}

- Bring students and others.

- Bring others.

- It's a real hoot!

- I never imagined the beauty of these birds.

- Probably wait a few years.

- It's amazing.

- Have seen / done it.

- Take more pictures.

- Too freezing.

- It's fun.

- Not every year.

- It is really cool.

- Fun.

- They're cool.

- Loved it!

- Great photo opportunities.

- Great photos.

- It was really cool.

- So great!

- It is a nice spring tradition.

- Very Interesting.

- Because I like it!!

- To try and get photos and enjoy the birds.

- I would be interested in doing long-term research.

- Was a good experience.

- Seen it once, that's enough.

- Good learning experience.

- To see many differences came through over the days.

- Seen once, go to another place.

- Too cold.

- In summer.

- In the summer.

- But only if it is warmer.

- It was awesome.

- Interesting.

- It was fun.

- Cool.

- Too early.

- Not an early riser.

- See habitat in summer.

- Because prairie chickens are the coolest dam bird ever!!!! 


\section{Response}

- Fun.

- To see the females.

- Its fun to watch.

- Valuable experience for a naturalist.

- Once is enough.

- Really enjoy observing these birds close up.

- Why not?

- Neat.

- Very enjoyable.

- If got bathrooms.

- Great fun and wildlife.

- Too far from home.

- If an opportunity presented itself.

- It'd be neat to share this experience with others. 
Question 25. Would you encourage others to participate in this opportunity, why or why not?

Response

2002

- It allows you to see up close some of the beauty of the species and why we need to protect the environment.

- Great!

- A good experience for birders.

- A unique experience with nature.

- Fascinating experience.

- What experience could be better!

- A very interesting and learning experience.

- Must see at least once.

- It is a unique chance to see wonderful birds.

- A lifetime opportunity.

- Fun and interesting.

- Educational, show value of undeveloped land and habitat.

- Interesting.

- Very well done, Informative.

- It was fascinating.

- To be aware of unique birds.

- More people need to connect with such an incredible natural wonder.

- Great learning experience.

- Peaceful and fun.

- An interesting educational experience.

- This is something you can't just see by chance alone.

- Spread knowledge and awareness of value of conservation.

2003

- I want my daughter to witness prairie chickens while she can.

- Seeing and doing is understanding.

- Uncommon opportunity to view 1 st hand.

- Definitely, if they would enjoy it as much as I did.

- Very good way to immerse people into nature, if receptive to "primeval" experiences a person can really value the "wilderness" aspect of this activity!

- To give them a better understanding as to how important it is to have wild and protected areas.

- It was inspiring.

- To better understand prairie chicken issue.

- It is a fantastic learning experience. 
Question 25 (Continued) Would you encourage others to participate in this opportunity, why or why not?

Response

- It is a very unique experience.

- It was fun.

- It's fun.

- The birds are very funny and beautiful.

- It was great fun.

- It is really cool.

- Fun.

- Unique experience.

- Unique chance.

- Education them on preservation.

- Very enjoyable.

- Very enjoyable.

- Excellent wildlife viewing opportunity.

- No one should miss this.

- Because it was fun.

- Something about booming sound that's indescribably. People never hear it.

- Opportunity to learn more about these animals.

- Good to see at least once.

- Good learning experience.

- It is good to learn and see how hard it is to mate breeds of animals in the wild.

- A good learning experience.

- They will learn about them.

- Good chance to learn more.

- Something you can't experience anywhere else.

- Everyone should do it at least one time in their life.

- Good experience.

- It's unique.

- Unique opportunity.

- A little known amazing bird.

- Everyone should see a prairie chicken!

- Interesting.

- Everybody should see it.

- Neat to see.

- To learn to value the prairie chickens.

- They were cool to watch.

- Good learning experience.

- Great fun and wildlife.

- Very informative.

- Awesome experience. 
Question 26. Please share any suggestions that could make this program better.

Response

2002

- I don't know if it was because of the lack of females on the lek that morning, but the males seemed very aware of the blind windows. They squeaked when being opened. I also think that painting the top $1 / 4$ of the blind black would hide the fact that the windows would be opened. When they or it is open there is a black hole that is created. By painting them black it might be so noticeable that the black holes are changing when one opens them from one to another. I'll be back nest year for sure!

- Perhaps a little more emphasis on dressing appropriately for very cold weather for an extended period of time.

- The staff involved - especially Mindy were excellent - enthusiastic, helpful, very informative. Thank you for this fantastic experience.

- It was an amazing sight!

- It was a life bird experience.

- Very well organized, don't fix it! Keep it small groups.

- Excellent job Mindy Brown keep up the good work! Hope to see you and the crew next year.

- Excellent info packet! I liked the new blind with the larger port (and lower) for larger photo lenses. I again apologize for making Mindy get up so early and drive in the cold to direct only one observer to his blind. Thanks again Mindy.

- Perhaps more media coverage.

- Good work!

- This mailing might be considered an unnecessary part of the overhead.

- A little more information on determining territories. More information on the history of the chickens we're watching. More description of human impact on prairie chickens. The program was well done. You made it easy and enjoyable to participate.

- It was a very marvelous experience - the time (daybreak) was mystical - I hope to go again.

- More prairie chickens. Will be back next year. Send information.

- One large viewing port in center of blind up high - like lower one for photography. You have it covered well!

- Just want to say how much all your work is appreciated.

- Recommend bringing cushions, camera. Warn people of holes, especially when entering in the dark.

- Have a bigger blind.

- Cappuccino machine in blind! Great experience overall.

- The weather was awful.

- Keep trespassing dogs off the booming grounds. Adjust the blind direction.

- Thank you! Very nice. 


\section{Question 26 (Continued) Please share any suggestions that could make this program better.}

\section{Response}

- None- it was great!

- Very well done - informative.

- It was fascinating!

- Thanks so much!

- Mindy very helpful.

- Although I think our notes are/seem inadequate, this is a great experience.

- Great as is.

- Birds not as active today. No females. Two males facing each other, not much booming. Only one had any hormonal activity!

- After 35 years, it is good to see that the birds persist and that people remain interested here. This has been my 1st return. Keep it up.

- Thanks to Mindy for being so helpful.

- Free breakfast.

- An interesting educational experience.

- Thank you for this program.

- If someone had a bad back or knees, they'd have trouble with the walking and sitting. I picked up a tick on my way out - maybe a warning about that. I enjoyed it a lot. Thanks!

- Questions 15-20 do not apply very much to me because of my background.

- The only thing that would have made it better is to have one of the researchers in the blind with us.

- Would it be less intrusive if the blind was put on the edge of the grounds rather than in the middle? Nice blinds!

- Great blinds.

- Map and directions could be better.

- Provide blinds with larger viewing ports.

- Blinds more photography friendly.

- Thank you very much.

- This was an excellent opportunity to learn about the chickens. Thank you!

- This was fun. It's always great to be outdoors the prairie chickens were just an added benefit.

- Very cool!!

- Don't leave until the birds are gone. I don't agree we have to scare them.

- Mindy rocks!

- Excellent!!

- Great experience - need more of S. WI to find out about chickens. 


\section{Question 26 (Continued) Please share any suggestions that could make this program better.}

\section{Response}

- Less written work at end.

- Mindy, excellent job of organizing and being on time for our group.

- I felt maybe the blinds could have been a little larger. I felt cramped in the blind.

- This was an excellent opportunity. Thank you and the supporting partners for doing this good work. I hope the "drummers of love" are still thriving for my kids and grandkids years from now.

- Increase the blind size so a person could stand if need be. Due to an injury I had a very difficult time sitting as long as I had to. Please don't get me wrong - I did enjoy my visit!!!

- It was great, can't think of a thing.

- Good blinds.

- Bring in more chickens.

- There was some trading of territories as the hen moved around, then the males returned to their original territories.

- Great time.

- Seeing wild animals this close up is always great.

- Blinds could be roomier, but this is no big deal.

- Put a heater in the blind. Make the blind bigger.

- Nothing.

- Excellent experience.

- This was a fantastic show this year! We were right in the middle of the birds. One landed on the roof of the blind! The weather cooperated as well.

- More copulating.

- Better trail reflectors.

- I'll be emailing you with some of our many questions! Thanks!

- We had a swell time - thanks!

- Heated blinds.

- Heated blinds, cushioned seats.

- Thank you.

- Heated blinds! (Ha Ha)

- Heated blinds.

- It 's rewarding to see these creatures and realize there are people who have no knowledge they are even here! Thanks for the opportunity!

- Well done!

- When 2 blinds are placed side by side, vision is blocked on one side. Therefore, we probably did not have an accurate count most of the time.

- None.

- Great program - Gary was great - no better way to spend April morning. 


\section{Question 26 (Continued) Please share any suggestions that could make this program better.}

\section{Response}

- Thanks!

- Nothing (maybe make it warm).

- Heaters in the blinds, it was very cold!

- Provide warmer blinds!!!

- Maybe not sit both blinds next to each other.

- A little more room in the blind.

- It was cold!!

- Heated blinds.

- Some windows were stuck shut.

- Try to cut the saplings down so we don't trip on them walking to the blind in the dark.

- Bigger blinds.

- Chickens rock!!!

- Bigger (higher) more head room.

- This was so interesting - don't change anything.

- Good guide, help was nice!

- NW Heath badly in need of covering dangerous, sharp metal corners on roof of blind!

- 4 people in our party.

- A truly amazing experience, one that anyone can learn from. A unique opportunity to observe not only nature, but the effects that man has had, and what we can hopefully do using this knowledge.

- I think it would be very nice if you could get the prairie chickens to hold still longer and also you should start a bunny viewing program!!!

- Mindy was very helpful - tough job in the rain.

- I used my own blind - much better for photography.

- Thank you.

- This is the type of learning experience all students should receive.

- Great!

- Wonderful program - recently read article in WI Natural resources - need more avenues such as this to the word out about prairie chickens.

- Don't put blinds up tight against each other. Couldn't see out of one end. Poor choice. Make sure people understand instructions. Other group left just as a female came in the males were still active.

- 2 blinds adjacent suck. People left at 7 from other blind when a female had just flown into outskirts. Better paper that's waterproof.

- Make no blinds next to each other. Maybe make them bigger or wider. Have people stay in blind until 7:30 or later. 
Question 26 (Continued) Please share any suggestions that could make this program better.

\section{Response}

- Complements to Mindy.

- It was great! Thank you Mindy.

- Maybe work on the seating in the blinds. It's a very uncomfortable $2 \mathrm{hrs}$.

- This is a unique and valuable experience!

- Complements to Mindy.

- Great job - Amazing. 